\title{
EVALUACIÓN DE LA CALIDAD DE GELES PÉCTICOS DESHIDRATADOS DE MANZANA DURANTE EL ALMACENAMIENTO.
}

Tesis de Maestría

Ing. Química NATALIA ANDREA QUINTERO RUIZ

Presentada ante la Facultad de Ingeniería de la Universidad Nacional de La Plata como requisito para la obtención del grado académico de

MAGÍSTER EN TECNOLOGÍA E HIGIENE DE LOS ALIMENTOS

Dirigida por:

Dr. Sergio Adrián Giner

Jurado de Tesis:

Dra. Sandra Norma Guerrero

Dra. Ana María Luisa Rojas

Fecha de defensa oral y pública: 16 de Febrero de 2011

UNIVERSIDAD NACIONAL DE LA PLATA

FACULTAD DE INGENIERÍA 
Agradecimientos

Al director de esta tesis el Dr. Sergio Giner y los miembros del CIDCA por todo el apoyo, ayuda y comprensión durante el tiempo de desarrollo de este trabajo.

A pú papi, mi mami, Nany, el resto de mi familia y Andrés "el Gatto" que en la distancia siempre se hicieron presentes brindándome aliento y caríno, los quiero mucho.

A mis amigos nuevos y antiguos por todas las risas, abrazos, tonterías y buenos deseos que hicieron de estor años lejos de casa algo más sencitlo.

"En los tiempos oscuros, debes aprender a mirar las estrellas. Pero no todas están arriba. El Planeta Tierra flota y gira en el espacio y es necesario que sepas que mientras caminas por el duro suelo, miles y miles de estrellas, brillan bajo tus pies."

JAIRO ANÍBAL NIÑO 


\section{ÍNDICE}

Pág.

RESUMEN

INTRODUCCIÓN GENERAL Y OBJETIVOS

Introducción general 5

Objetivo general 7

Objetivos especificos

CAPÍTULO I: VERIFICACIÓN DEL FUNCIONAMIENTO DEL SECADERO Y DETERMINACIÓN DE LOS COEFICIENTES DE TRANSFERENCIA DE MASA Y CALOR

1.1 Introducción

1.2 Materiales y métodos 8

1.2.1 Túnel de secado 8

1.2.2 Ensayos de verificación 10

1.2.3 Determinación de los coeficientes de transferencia de masa y calor 11

1.3 Resultados

CAPÍTULO II: OPERACIONES PREPARATORIAS DE LA MATERIA PRIMA

2.1 Introducción 18

2.2 Materiales y métodos 20

2.2.1 Adecuación de la materia prima 20

2.2.2 Tratamiento térmico 21

2.2.2.1 Descripción 21

2.2.2.2 Test de inactivación de peroxidasa 21

2.2.2.3 Medición de temperatura de manzana 22

2.3 Resultados 23

2.3.1 Estimación teórica de inactivación de peroxidasa 23

2.3.2 Determinación experimental del tiempo de tratamiento térmico 
CAPÍTULO III: PREPARACIÓN DE GELES PÉCTICOS

3.1 Introducción 28

3.1.1 Aspectos relacionados con la formulación 28

3.1.2 Estudios de la curva experimental de secado y predicción teórica 30

3.2 Materiales y métodos 31

$\begin{array}{lll}3.2 .1 & \text { Equipos } & 31\end{array}$

3.2.2 Materiales 31

3.2.3 Metodología 31

3.2.3.1 Determinación del contenido de humedad en las muestras 31

3.2.3.2 Determinación de las cantidades de aditivo a utilizar 32

3.2.3.3 Preparación de la formulación $\quad 34$

3.3 Resultados $\quad 35$

3.3.1 Deshidratación de la muestra formación del producto 35

3.3.2 Curva de secado 36

$\begin{array}{lll}\text { 3.3.3 Envasado del producto } & 39\end{array}$

CAPÍTULO IV: EVOLUCIÓN DE PARÁMETROS FISICOQUÍMICOS Y POBLACIÓN MICROBIANA

$\begin{array}{lll}4.1 & \text { Introducción } & 42\end{array}$

$\begin{array}{lll}4.2 & \text { Materiales y métodos } & 46\end{array}$

4.2.1 Determinación del contenido de sólidos solubles 46

4.2.2 Determinación de $\mathrm{pH} \quad 46$

4.2.3 Determinación de actividad de agua 46

4.2.4 Determinación de mohos y levaduras 48

$\begin{array}{lll}4.3 & \text { Resultados } & 50\end{array}$

4.3.1 Humedad y sólidos solubles $\quad 50$

$\begin{array}{lll}4.3 .2 \mathrm{pH} & 51\end{array}$

$\begin{array}{lll}\text { 4.3.3 Actividad acuosa } & 51\end{array}$

4.3.4 Población microbiana $\quad 52$ 
CAPÍTULO V: VARIACIONES DE COLOR DURANTE EL

ALMACENAMIENTO

5.1 Introducción $\quad 54$

5.2 Determinación del color 56

5.2.1 Equipo 56

5.2.2 Metodología 56

$\begin{array}{lll}5.3 & \text { Resultados } & 58\end{array}$

CAPÍTULO VI: ACTIVIDAD ANTIOXIDANTE

$\begin{array}{lll}6.1 & \text { Introducción } & 62\end{array}$

$\begin{array}{lll}6.2 & \text { Materiales y métodos } & 63\end{array}$

6.2.1 Preparación de las muestras $\quad 63$

6.2.2 Ensayo de decoloración del radical $\mathrm{ABTS}^{*+} \quad 63$

$\begin{array}{lll}6.3 & \text { Resultados } & 65\end{array}$

CAPÍTULO VII: ANÁLISIS SENSORIAL

$\begin{array}{lll}7.1 & \text { Introducción } & 68\end{array}$

$\begin{array}{lll}7.2 & \text { Diseño de la prueba } & 69\end{array}$

$\begin{array}{lll}7.3 & \text { Resultados } & 71\end{array}$

CAPITULO VIII: ALMACENAMIENTO ACELERADO

$\begin{array}{lll}8.1 & \text { Introducción } & 74\end{array}$

$\begin{array}{lll}8.2 & \text { Consideraciones teóricas } & 75\end{array}$

$\begin{array}{lll}8.3 & \text { Metodología } & 76\end{array}$

8.4 Resultados $\quad 76$

8.4.1 Índice de pardeamiento (Browning Index, BI) 76

$\begin{array}{ll}\text { 8.4.2 Capacidad antioxidante } & 78\end{array}$

8.4.3 Extrapolación de resultados a temperaturas de almacenamiento menor a 79 las usadas para las determinaciones 
REFERENCIAS BIBLIOGRÁFICAS

ANEXO 1 NOMENCLATURA

ANEXO 2 PROGRAMAS MATLAB

ANEXO 3 CARACTERÍSTICAS DE LOS ADITIVOS

ANEXO 4 CARACTERÍSTICAS DEL MEDIO DE CULTIVO 


\section{RESUMEN}

Históricamente el secado de alimentos se ha utilizado para permitir su conservación. Sin embargo, las tendencias modernas ubican a este proceso como una etapa en la formación de numerosos productos innovadores, de mayor valor agregado, proporcionando conveniencia al consumidor, agregando diversidad a la dieta.

Uno de estos nuevos productos es el gel péctico deshidratado de manzana, también denominado como laminado de manzana o "piel de fruta", como lo indica el Códex Alimentarius de la FAO/OMS. Por ser éste un producto novedoso y que ha despertado interés en la industria, se planteó como objetivo principal de esta tesis determinar los posibles cambios en la calidad organoléptica y nutricional durante el almacenamiento del producto envasado con y sin aditivos.

En el Capitulo I se realizaron ensayos del túnel de secado con pesada in situ a efectos de corroborar su funcionamiento, y por tanto su adecuabilidad para los procesos de formación de los geles pécticos deshidratados. Los ensayos del equipo se realizaron a efectos de corroborar la uniformidad de los perfiles de temperatura y velocidad de aire. Esto se realizó en forma indirecta, comparando la velocidad de evaporación de agua en las tres bandejas del equipo, bajo las mismas condiciones operativas. Se comprobó que la velocidad de transferencia de materia era uniforme sin importar la posición de la bandeja dentro de las tres posiciones posibles en el bastidor que las sostiene, dentro de la cámara de secado. Asimismo, los datos permitieron la determinación de los coeficientes de transferencia de masa y calor, los cuales fueron bastante mayores a los de las correlaciones publicadas, pero comparables con los de valores determinados durante el secado de alimentos por autores previos.

En el Capitulo II se presenta el procesamiento previo de la materia prima principal de los geles pécticos: la manzana verde (Granny Smith). Se realizó un tratamiento térmico donde los cubos de manzana pelados se escaldaron el tiempo suficiente para lograr la inactivación enzimática, manteniéndose luego un tiempo adicional en la vaporera para generar un color dorado típico de los productos de manzana. Por otra parte, a efectos de desarrollar un método predictivo del tiempo de inactivación enzimática (mediante el 
uso de temperaturas preestablecidas de inactivación), se midió la historia térmica del centro de los cubos y los datos se interpretaron con un modelo matemático de conducción no estacionaria. A efectos de confirmar la validez del tiempo estimado mediante el modelo predictivo ( $\mathrm{t}>160 \mathrm{~s}$ ), los mismos se compararon con los resultantes del ensayo cualitativo de inactivación de peroxidasa, que tuvo resultado positivo (es decir, actividad enzimática) a $120 \mathrm{~s}$, y negativo a $180 \mathrm{~s}$.

No obstante, el tiempo total de tratamiento térmico excedió el necesario para lograr la inactivación enzimática: se necesitó un tiempo adicional a efectos de impartir un color dorado atractivo en los cubos. Se ensayaron, con este fin, tiempo totales de 5, 10 y 15 minutos. El valor seleccionado fue el de 10 minutos debido que un mayor tiempo no causó cambios ulteriores observables, ahorrándose así energía y evitando la posibilidad de una mayor pérdida de micronutrientes si el mismo se prolongara otros 5 minutos.

En el Capitulo III se explica como se realizaron los geles pécticos deshidratados de manzana o "laminados de manzana", mediante el secado con aire caliente en el túnel de secado a partir de una formulación a base de puré de manzana, solución de acido cltrico y sacarosa, pudiendo o no contener aditivos. La formación del gel se realiza mediante el mecanismo de gelificación azúcar - ácido - pectina de alto metoxilo. Se evaluaron dos conservantes, metabisulfito de potasio (MBK), un agente antipardeamiento, y sorbato de potasio (SK) por lo que se produjeron laminados con 4 formulaciones: una control, sin éstos aditivos $(A)$, y tres formulaciones adicionadas con 173,7 ppm de MBK (B), 134 ppm de SK (C) y la cuarta con una mezcla de 173,7 ppm de MBK y 134 ppm de SK (D).

Los laminados así formulados se envasaron herméticamente en pouches retortables con características adecuadas para la conservación de alimentos deshidratados. Los laminados de manzana se almacenaron en un cuarto a temperatura ambiente de $20^{\circ} \mathrm{C}$ y $60 \%$ de humedad relativa durante siete meses.

Con los datos experimentales de contenido de humedad en función del tiempo, del secado de las formulaciones, se graficaron las respectivas curvas de deshidratación, a las cuales se les aplicaron dos modelos difusivos, uno para la zona de altos y otro para la zona de bajos contenidos de humedad. Los modelos predijeron muy 
satisfactoriamente el comportamiento experimental, por lo que podrían utilizarse dentro de modelos de diseño de equipos de secado de estos productos.

El Capitulo IV muestra los ensayos realizados para determinar humedad del producto, contenido de sólidos solubles, $\mathrm{pH}$ y actividad acuosa $\mathrm{a}_{\mathrm{w}}$. Los parámetros no variaron en las distintas formulaciones por lo que la adición de aditivos no generó cambios. Los resultados satisficieron la humedad menor al $25 \%$ b.h recomendada por el Código Alimentario Argentino (CAA) para la comercialización de productos deshidratados. El producto mostró un contenido de sólidos solubles de 75 Brix, valor superior al necesario para lograr la gelificación péctica (55-65 Brix). A su vez, el pH tuvo un valor de 3,3 apropiado para la gelificación, y su actividad acuosa fue cercana a 0,7, valor que ya de por sí inhibe considerable el crecimiento microbiano. Si bien esta $a_{w}$ permitiría las reacciones de pardeamiento no enzimático, su valor resulta necesario para conferir flexibilidad al producto (condición imprescindible en un gel). No obstante, la reacción de Maillard se ve retardada por el bajo $\mathrm{pH}$.

En este capítulo se realizó una evaluación microbiológica en los geles, sobre los tipos de microorganismos que son capaces de desarrollarse en las condiciones mencionadas anteriormente: mohos y levaduras. Ninguna formulación tuvo un desarrollo considerable de microorganismos, pero la única en la cual no se observaron fue la que contenía MBK. En consecuencia en el resto de determinaciones de calidad solo se utilizaron la formulación control y la que contenía este aditivo.

En el Capitulo $V$ se evaluó la evolución del color de las muestras durante el almacenamiento utilizando un colorímetro triestímulo, que fue programado para proveer las medidas en el espacio de color CIELAB. Con los valores $L^{*}, a^{*}, b^{*}$ se calculó el índice de pardeamiento (Browning index, $\mathrm{BI}$ ), como parámetro representativo. Se ajustaron tres modelos cinéticos: orden cero, primer orden y logístico a los datos experimentales de BI en función del tiempo. El modelo logístico mostró el mejor ajuste, por su mayor versatilidad para ajustarse a curvas de distinta forma.

En el Capítulo VI, se explica el método de medición de la actividad antioxidante de los laminados envasados durante el almacenamiento. La técnica empleada fue el ensayo de 
decoloración del radical catión $\mathrm{ABTS}^{*+}$, determinado espectrofotométricamente. Los resultados se expresan como equivalentes de acido clorogénico por gramo de muestra seca. El radical se decolora en presencia de antioxidantes como los que posee la muestra, tendiendo a volver a su forma estable, incolora. Los resultados obtenidos muestran que la presencia de MBK disminuyó la pérdida del la actividad antioxidante (AA): ésta fue de sólo 15,9\% en la formulación que contenía el aditivo, mientras que en la formulación control, la AA experimentó un decrecimiento del $47 \%$.

En el Capitulo VII se muestran los resultados del panel sensorial que evaluó la aceptabilidad del producto. A los miembros del panel, se les suministraron 4 tipos de muestras, una recién elaborada y tres almacenadas durante cuatro, cinco y seis meses. Se les solicitó a los panelistas que en una escala hedónica evaluaran color, sabor, textura y aceptabilidad general. La escala se convirtió en puntajes numéricos para ser analizados. Los resultados fueron muy satisfactorios, siendo todos mayores al valor de aceptación. Esto mostró, adicionalmente, que la textura no cambió durante el almacenamiento, pero que el color y el sabor sí variaron desde el cuarto mes aunque mantuvieron calificaciones por encima de la aceptación hasta el final de los ensayos (mes seis). Por tanto el tiempo de almacenamiento, ya de por sí suficiente para la distribución del producto como deshidratado, podrí ser incluso mayor.

En el último capítulo de la tesis (Capítulo VIII), se realizó un almacenamiento acelerado para laminados preparados con la formulación B. Las muestras se mantuvieron a una temperatura de $30^{\circ} \mathrm{C}$ durante 35 dís, analizándose el cambio de color como índice de pardeamiento y la actividad antioxidante cada cinco dís.

Los resultados de ambos índices de calidad en función del tiempo se interpretaron con modelos cinéticos de primer orden, determinándose las constantes cinéticas a 20 y $30^{\circ} \mathrm{C}$. Con éstas, se determinaron los correspondientes factores representativos del efecto de la temperatura, $Q_{10}$ y a partir de éstos, las energís de activación. Con los datos de $Q_{10}$ calculados se realizó una extrapolación para una temperatura de $10^{\circ} \mathrm{C}$ : los datos estimados indicaron que a bajas temperaturas el parámetro de calidad determinante de la vida útil sería el cambio de color, mientras que a altas temperaturas lo sería la actividad antioxidante. 
INTRODUCCIÓN GENERAL Y OBJETIVOS 


\section{INTRODUCCIÓN GENERAL}

El proceso de secado o deshidratación es una técnica donde se remueve agua de cierto material, a partir de un intercambio de calor y masa de manera simultánea, y que implica la remoción de un líquido asociado a una matriz sólida, por parte de una gaseosa no saturada. Este proceso se puede realizar de diversas maneras dependiendo de la rapidez que se necesite y del material a secar: discontinuo o continuo, con transferencia de calor directa o indirecta, por circulación tangencial o transversal del medio gaseoso. Por ejemplo, la operación de secado directo (en contacto con gases calientes) por lotes y circulación tangencial se emplea para sólidos contenidos en bandejas, que no pierden sus características al tener contacto con aire o gases calientes. En el caso de materiales granulares, como las frutas u hortalizas peladas y cortadas o los granos de cereales u oleaginosas el sólido se arregla en lechos delgados sostenidos sobre bases perforadas, de forma que el aire $u$ otros gases puedan pasar a través, produciendo un secado rápido, que aprovecha mejor el área de transferencia.

El secado se considera un método tradicional de preservación que ha incrementado su vigencia en las últimas décadas y que como objetivo busca prolongar la vida útil de alimentos naturales, además de reducir su peso y su volumen lo que facilita su transporte y almacenamiento. El efecto preservador de esta técnica se da debido a que los microorganismos no pueden desarrollarse a bajas actividades de agua y es por eso que los alimentos secos se pueden almacenar por largos períodos de tiempo (Eskin y Robinson, 2001).

Actualmente, además de los productos clásicos como pastas secas, leche y chocolate en polvo, especias y frutas deshidratadas y en especial sopas y alimentos deshidratados instantáneos, se desarrollan productos novedosos, que se adaptan a los nuevos ritmos de vida, son agradables para el consumidor, aportan nutrientes valiosos, tienen poca o ninguna adición de aditivos y no es necesaria su refrigeración.

Entre esta gama de nuevos productos se encuentran los geles pécticos deshidratados de manzana denominados "laminados", "pieles de fruta" o en inglés "Fruit Leathers". 
Este producto, que se obtiene mediante la deshidratación de puré de frutas, utiliza la técnica no solo como factor de preservación del producto sino también para la formación y reestructuración de éste, generando una nueva matriz alimentaria que se puede presentar en forma de tiras o láminas flexibles para ser consumido como snack, golosina o postre. Este producto puede constituirse en una vía práctica de incorporación de sólidos de fruta, especialmente en poblaciones de niños y adolescentes renuentes a incorporar fruta fresca en la dieta. Por otra parte, siendo un producto de origen $100 \%$ vegetal, podría sustituir a las gelatinas saborizadas con frutas, en dietas de vegetarianos.

El mercado argentino no cuenta hoy con un producto de características similares en el mercado por lo que este desarrollo se considera novedoso.

Raab y Oehler (1976), publicaron lo que posiblemente haya sido la primera guía de preparación de "Fruit Leathers", sin describir los mecanismos subyacentes de formación del gel. Desde entonces la producción cientifica ha sido escasa y discontinua hasta el presente. Los primeros trabajos describieron los métodos de obtención del producto empleando distintas condiciones de secado, sin reparar en sus características finales; luego comenzaron a estudiarse las propiedades fisicoquímicas y atributos sensoriales que definen a los geles pécticos (Huang y Hsieh, 2005).

En investigaciones recientes se ha optimizado la formulación para reforzar los factores de gelificación azúcar - ácido - pectina de alto metoxilo, y se han realizado estudios detallados, teóricos y experimentales, del equilibrio sorcional, contracción volumétrica y cinética de secado de geles pécticos de manzana (Leiva Díaz y col., 2009).

No obstante no se han estudiado los cambios de calidad que se pueden dar en el producto durante el almacenamiento.

Teniendo en cuenta que este desarrollo ha despertado interés en la industria y que la evaluación del cambio de calidad durante el periodo de almacenamiento es esencial para aportar información útil en la cadena de distribución y venta minorista potencial de estos productos como "alimentos deshidratados", en este trabajo se evaluarán fenómenos que se producen en el "laminado" durante su conservación a temperatura ambiente $\left(20^{\circ} \mathrm{C}\right)$ por siete meses y temperatura de $30^{\circ} \mathrm{C}$ durante 35 días. En función de 
estos resultados se realizará una estimación extrapolatoria de los cambios que podrían ocurrir en un almacenamiento a $10^{\circ} \mathrm{C}$ (Labuza y Riboh, 1982), con el fin de ofrecer a los potenciales consumidores un producto inocuo, estable sin necesidad de ser refrigerado y que cumpla las normas exigidas porla legislación actual del Código Alimentario Argentino (CAA) tanto para frutas deshidratadas como para confituras.

\section{OBJETIVO GENERAL}

Comparar la variación de parámetros representativos de la calidad organoléptica y nutricional durante el almacenamiento a temperatura ambiente de geles pécticos deshidratados de manzana envasados, con y sin aditivos, a efectos de poder pronosticar la vida útil de estos productos.

\section{OBJETIVOS ESPECÍFICOS}

- Comparar los cambios en parámetros fisicoquímicos como humedad, $\mathrm{pH}$, actividad acuosa $\left(a_{w}\right)$ y contenido de sólidos solubles.

- Estudiar el desarrollo de pardeamiento no enzimático e interpretar sus variaciones mediante modelos matemáticos.

- Cuantificar la degradación de antioxidantes totales en el gel péctico deshidratado.

- Evaluar el efecto del uso de aditivos en la vida útil del producto. 


\section{CAPÍTULO I}

VERIFICACIÓN DEL FUNCIONAMIENTO DEL SECADERO Y DETERMINACIÓN DE LOS COEFICIENTES DE TRANSFERENCIA DE MASA Y CALOR. 


\subsection{INTRODUCCIÓN}

Para obtener las muestras necesarias para la evaluación de calidad, se utilizó un túnel de secado de bandejas con pesada in situ que había sido recientemente modificado, por lo que su adecuado funcionamiento no estaba probado. Se decidió, por tanto, realizar ensayos de evaporación con muestras de agua destilada para verificar la uniformidad del secado antes de utilizar el equipo para preparar los laminados. Al mismo tiempo, se aprovechó el estado estacionario promovido por la evaporación de agua para determinar los coeficientes de transferencia de materia y calor en el equipo

\section{MATERIALES Y MÉTODOS}

\subsubsection{Túnel de secado (Figura. 1.1)}

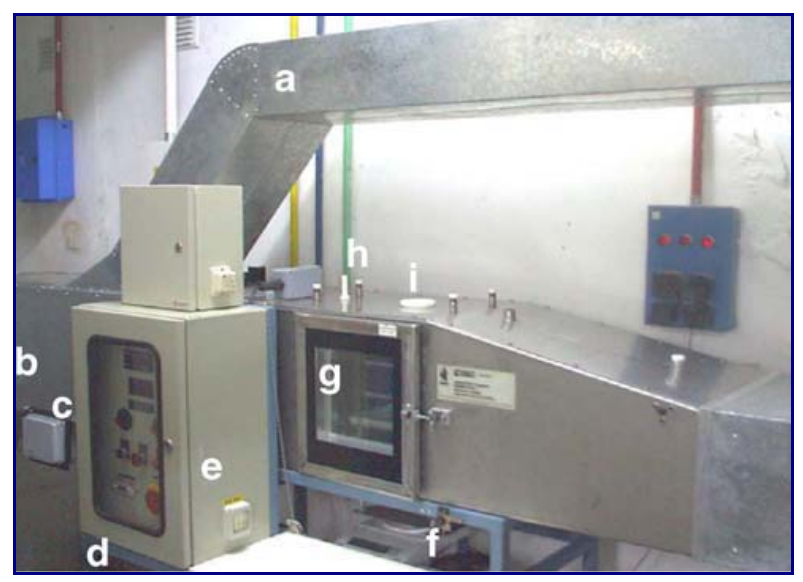

Figura 1.1. Túnel de secado

Tabla 1 1. Partes Constituyentes del equipo

\begin{tabular}{|c|l|}
\hline Código & \multicolumn{1}{|c|}{ Parte } \\
\hline a. & Conducto paralelo de derivación \\
\hline b. & Resistencias internas de calentamiento del aire \\
\hline c. & Deflector de derivación \\
\hline d. & Control automático de temperatura del aire \\
\hline e. & Controlador de velocidad de aire \\
\hline f. & Balanza digital de precisión \\
\hline g. & Cámara de secado aislada térmicamente \\
\hline h. & Sensores de temperatura del aire \\
\hline i. & Orificio para tomar medidas de temperatura sin contacto \\
\hline
\end{tabular}


Tabla 12 . Características generales del equipo

\begin{tabular}{|c|c|}
\hline \multicolumn{2}{|c|}{ Dim ensiones totales extemas } \\
\hline Longitud & $318 \mathrm{~cm}$ \\
\hline Altura & $200 \mathrm{~cm}$ \\
\hline Ancho & $74 \mathrm{~cm}$ \\
\hline Dim ensiones in temas de la cám ara de secado \\
\hline Longitud en el sentido del flujo & $35 \mathrm{~cm}$ \\
\hline Altura & $31 \mathrm{~cm}$ \\
\hline Ancho, perpendicular al flujo & $30 \mathrm{~cm}$ \\
\hline Rango de velocidad de aire & $1-3,5 \mathrm{~m} / \mathrm{s}$ \\
\hline Rango de temperatura del aire & Ambiente $+10^{\circ} \mathrm{C}-\mathrm{Ambiente}+70^{\circ} \mathrm{C}$ \\
\hline Capacidad bruta de la balanza & $3000 \mathrm{~g}$ \\
\hline Resolución de la balanza & $0,01 \mathrm{~g}$ \\
\hline
\end{tabular}

Se seleccionó un túnel de secado de bandejas de 0.2 × $0.2 \mathrm{~m}$ para la realización de los geles pécticos, en la Tabla 1.1 se listan los componentes principales y en la Tabla 1.2 se describen las características generales del equipo. En las Figuras 1.2 y 1.3 se puede observar con mas detalle el sistema de pesada in situ y el bastidor de la cámara de secado. El equipo permite controlar la temperatura y velocidad del aire de secado, la masa de la muestra durante el secado sin retirarlo del equipo, lo que evita perturbar el fenómeno en estudio y puede secar hasta tres muestras en un solo ensayo.

El equipo funciona impulsando aire ambiente con una velocidad definida por el regulador de velocidad hacia las resistencias eléctricas, las resistencias calientan el aire hasta la temperatura deseada, esta temperatura se regula mediante un medidor conectado a un sistema de control que permite que durante el tiempo de operación esta se mantenga estable. El aire caliente entra a la cámara de secado y pasa uniformemente por las bandejas que se colocan en el bastidor. Para tomar los datos de peso el flujo de aire se desvía de la cámara de secado mediante un sistema que dirige al aire por el ducto paralelo de derivación. Todo el aire que circula por el equipo sale por un ducto que se encuentra en la parte superior del equipo. 
Se probó el funcionamiento del equipo y se generó un manual de operaciones antes de utilizarlo para generar las muestras, debido a que éste se construyó y modificó en las instalaciones del laboratorio.

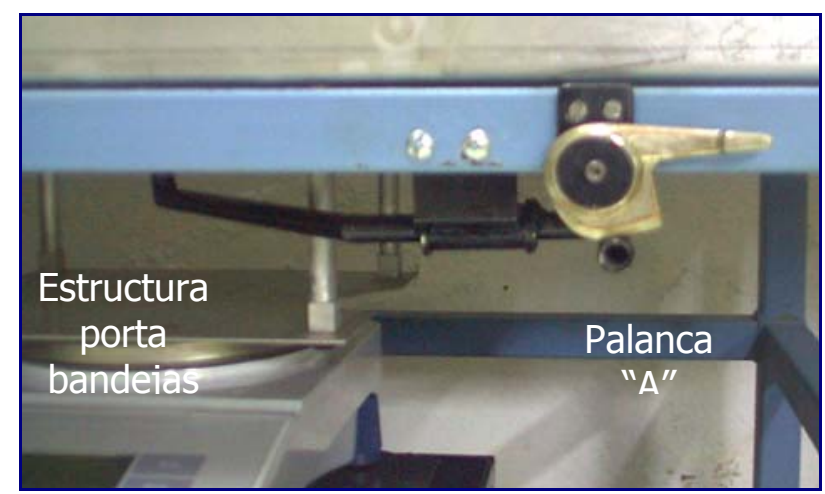

Figura 12 . Mecanismo para pesar muestras

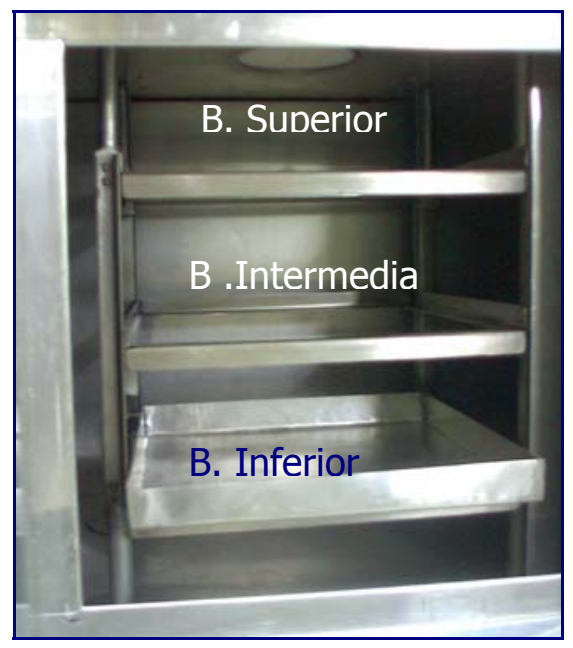

Figura 1 .3. Bastidor porta bandejas de la cámara de secado

\subsubsection{Ensayos de verificación}

Los ensayos se realizaron evaporando agua destilada ubicando una sola bandeja por vez. En el primer ensayo la bandeja se ubicó en el estante superior, en el segundo en el intermedio, y en el tercero en el inferior (Figura. 1.3). Se realizaron duplicados, llevando a cabo los tres ensayos nuevamente en las mismas condiciones. En cada ensayo, la bandeja en estudio se llenó con una cantidad de agua destilada suficiente para formar una capa de cinco milímetros de espesor, lo cual representa $200 \mathrm{~g}$.

Los ensayos se realizaron a temperatura constante de aire de $60^{\circ} \mathrm{C}$ y una velocidad de aire de $1,5 \mathrm{~m} / \mathrm{s}$, que es típica de la operación de los secaderos de 
bandejas. Estos datos se verificaron por medio de los termómetros de mercurio en vidrio instalados en el equipo y por medio de sensores de temperatura de circuito integrado.

Para realizar las pruebas se acondicionó el equipo previamente a la temperatura y velocidad de aire durante 40 minutos antes de introducir la bandeja cargada con agua. Se tomó el peso inicial de la bandeja, y luego a intervalos de 10 minutos para hallar la velocidad de secado.

1.2.3 Determinación de los coeficientes de transferencia de masa y calor.

Utilizando la ecuación de transferencia de masa interfacial para el sistema (Fiorentini y col., 2008) se puede hallar un coeficiente de transferencia de materia $\mathrm{k}_{\mathrm{p}}$.

$$
\dot{\mathrm{m}}_{\mathrm{wev}}=-\frac{\mathrm{dm}_{\mathrm{w}}}{\mathrm{dt}}=\mathrm{k}_{\mathrm{p}} \mathrm{A}\left(\mathrm{p}_{\mathrm{sbh}}-\mathrm{p}_{\mathrm{va}}\right)
$$

Integrando, se obtiene

$$
m_{w}(t)=m_{w o}-k_{p} A\left(p_{s b h}-p_{v a}\right) t
$$

La ecuación (1.2) se puede expresar en forma más conveniente, dividiendo por la masa inicial de agua, $\mathrm{m}_{\mathrm{wo}}$.

$$
m_{n}=\frac{m_{w}(t)}{m_{w o}}=1-\frac{k_{p} A\left(p_{s b h}-p_{v a}\right)}{m_{w o}} t
$$

A efectos de calcular $p_{\text {sbh }}$ y $p_{v a}$ se necesitan las relaciones psicrométricas usando las condiciones ambiente y de secado.

Esta ecuación se ajustará a los datos experimentales es a efectos de determinara el $k_{p}$ empleando el método de los cuadrados mínimos.

Durante la evaporación de agua pura, se produce una situación de desequilibrio estacionario (superado un transitorio inicial), donde el flujo de calor del aire hacia la superficie evaporativa guarda una correspondencia exacta con el requerimiento de calor 
latente de vaporización. Por tanto la masa de agua evaporada por unidad de tiempo puede expresarse tanto en función de la transferencia de calor interfacial como de la de materia.

$$
\dot{\mathrm{m}}_{\mathrm{wev}}=\frac{\mathrm{h}_{\mathrm{T}}\left(\mathrm{T}_{\mathrm{a}}-\mathrm{T}_{\mathrm{bh}}\right)}{\mathrm{L}_{\mathrm{wbh}}}=\mathrm{k}_{\mathrm{p}}\left(\mathrm{p}_{\mathrm{sbh}}-\mathrm{p}_{\mathrm{va}}\right)
$$

Reorganizando la ecuación anterior se tiene

$$
h_{T}=\frac{k_{p}\left(p_{s b h}-p_{v a}\right) L_{w b h}}{\left(T_{a}-T_{b h}\right)}
$$

Donde $L_{\text {wbh }}$ es el calor de vaporización del agua a la temperatura de bulbo húmedo del aire de secado, calculada con incluida en el trabajo de Gely y Giner (2000). La expersión se dedujo partir de la ecuación de Clapeyron y la ley de los gases.

$$
L_{w b h}=\frac{R T^{2}}{M_{v}} \frac{d L n p_{s b h}}{d T}
$$

El valor de $p_{\text {sbh }}$ se calculó utilizando la ecuación de presión de saturación de vapor de agua empleada anteriormente por Giner y Mascheroni (2001).

$$
p_{s b h}=\exp \left(A-\frac{B}{\left(T_{b h}+273,16\right)}-C * \ln \left(T_{b h}+273,16\right)\right)
$$

Con $A=54.119, B=6547.1$ y $C=4.230$

Por tanto

$$
L_{w b h}=M_{v}\left(B-C\left(T_{b h}+273,16\right)\right)
$$


En condiciones de flujo laminar (Re < 15000), Singh y Heldman (2009) y Geankoplis (1993), sugieren utilizar la siguiente correlación para el coeficiente de transferencia de calor interfacial

$$
\mathrm{Nu}=\frac{\mathrm{h}_{\mathrm{T}} \mathrm{L}_{\mathrm{c}}}{\mathrm{k}_{\mathrm{Ta}}}=0.664 \mathrm{Re}^{0.5} \operatorname{Pr}^{0.333}
$$

Mientras que para flujo turbulento (Re entre 15000 y 300 000), los mismos autores recomiendan

$$
\mathrm{Nu}=0.036 \operatorname{Re}^{0.8} \operatorname{Pr}^{1 / 3}
$$

Por su parte, Genskow y col. (2007) consideran que las correlaciones siguientes, en especial la primera de las dos

$$
\begin{aligned}
& \mathrm{h}_{\mathrm{T}}=8.8 \frac{\mathrm{G}^{0,8}}{\mathrm{~L}_{\mathrm{c}}^{0.2}} \\
& \mathrm{~h}_{\mathrm{T}}=0,0204 \mathrm{G}_{\mathrm{h}}^{0,8}
\end{aligned}
$$

proveen una estimación confiable del coeficiente de transferencia de calor para flujo paralelo a platos, donde $L_{c}$ es la longitud característica del sistema y $G$ el flujo másico del aire en $\mathrm{kg} /\left(\mathrm{m}^{2} \mathrm{~s}\right)$ y $\mathrm{G}_{\mathrm{h}}$ en $\mathrm{kg} /\left(\mathrm{m}^{2} \mathrm{~h}\right)$. Las propiedades físicas utilizadas se tomaron de un curso de posgrado dictado recientemente (Giner, 2009) y se realizó la gráfica que muestra la existencia de una gran disparidad entre las predicciones de las correlaciones (1.9) y (1.10) (línea continua) y las empíricas (1.11) y (1.12) (símbolos) 


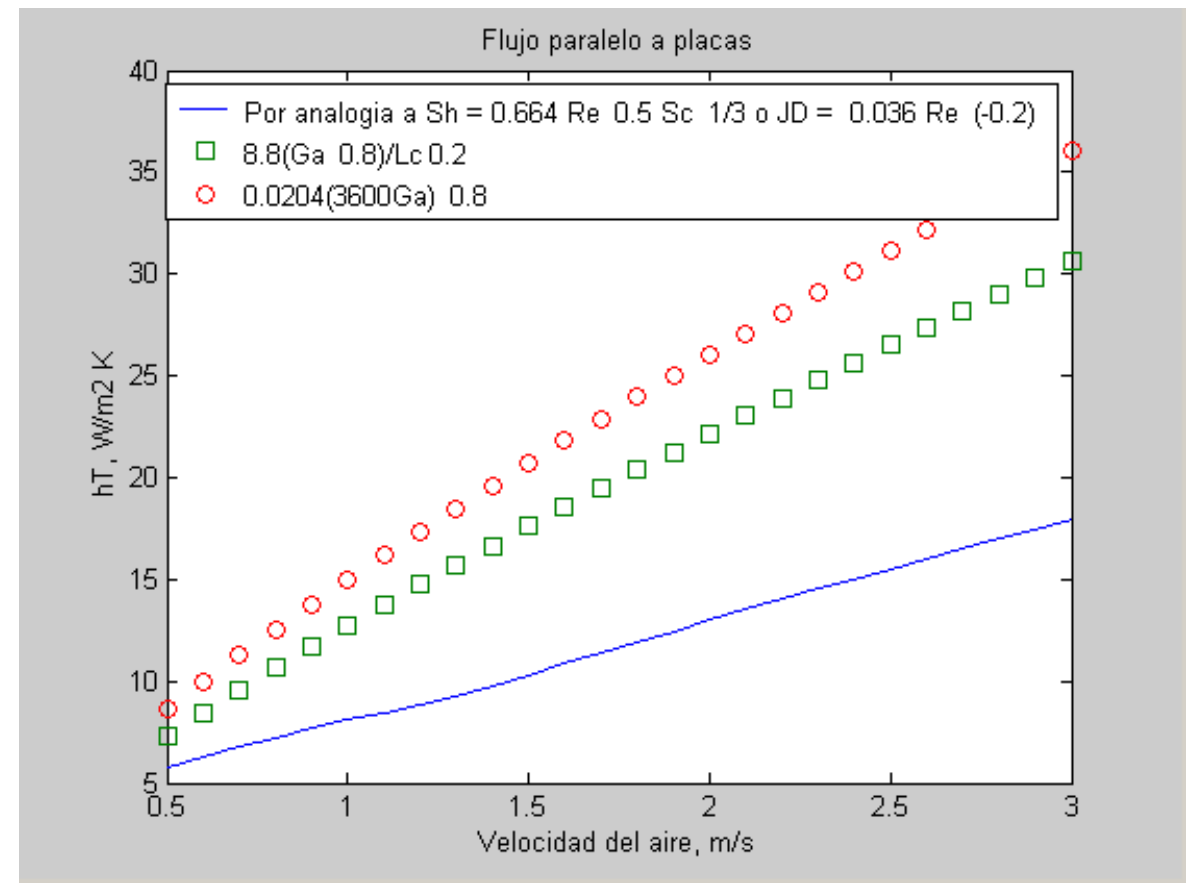

Figura 1.4 . Coeficientes de transferencia de calor calculados con correlaciones Ec. (1.9 a 1.12)

En virtud de la dispersión observada, resulta necesario determinar los coeficientes de transferencia del equipo, a efectos de tener un parámetro adicional para caracterizar el comportamiento fluidodinámico, $\mathrm{y}$, asimismo, a fines contar con propiedades de transporte necesarias para el modelado del secado de alimentos. 


\subsection{RESULTADOS}

Para una temperatura ambiente de $22.5^{\circ} \mathrm{C}$ y una humedad relativa ambiente de $70.4 \%$, el secado realizado a $60^{\circ} \mathrm{C}$, y una velocidad de $1.5 \mathrm{~m} / \mathrm{s}$ permitió obtener los resultados siguientes:

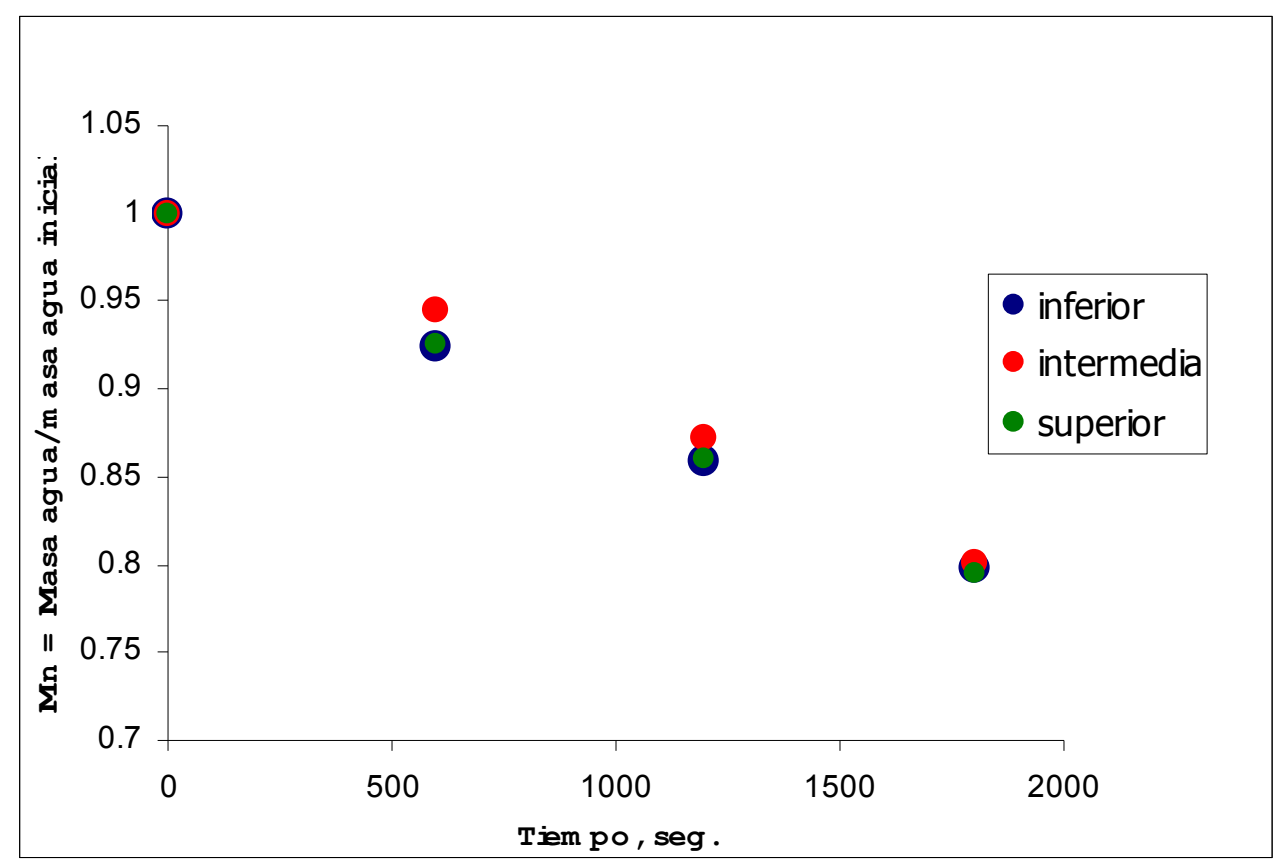

Figura 1.5.Ensayo 1, variación del contenido de agua en las bandejas

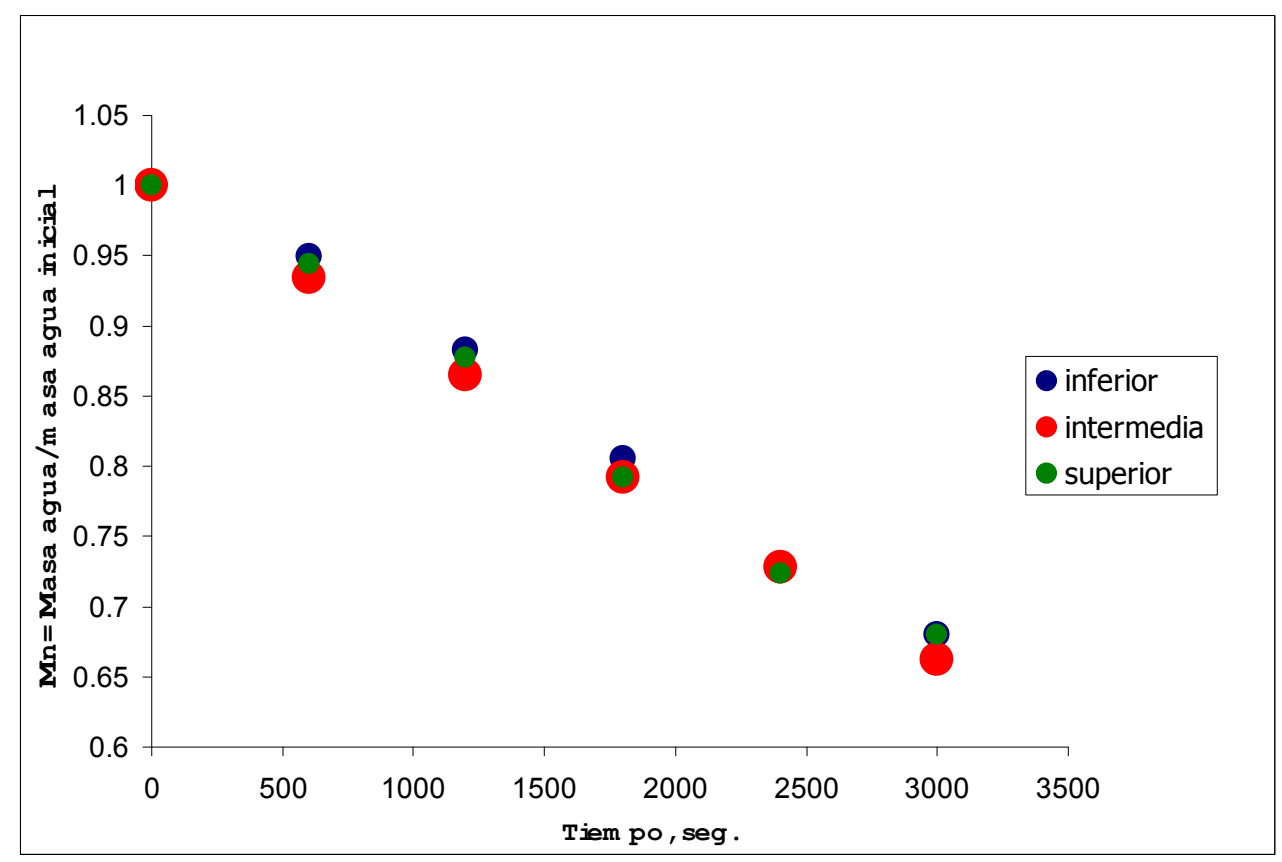

Figura 1.6. Ensayo 2, variación del contenido de agua en las bandejas 
Ajustando una ecuación lineal (Ec (1.3) a los datos obtenidos, se obtuvieron resultados que se vuelcan en la Tabla 1.3

Tabla 1 .3. Ecuación de la recta que correlaciona los parámetros Masa de agua retirada y tiempo

\begin{tabular}{|l|c|c|c|c|}
\hline $\begin{array}{l}\text { Posición de } \\
\text { la bandeja }\end{array}$ & Ensayo 1 & $\mathrm{R}^{2}$ & Ensayo 2. & $\mathrm{R}^{2}$ \\
\hline Inferior & $\mathrm{m}_{\mathrm{n}}=-1.116 \times 10^{-4} \mathrm{t}+0,996$ & 0.997 & $\mathrm{~m}_{\mathrm{n}}=-1.113 \times 10^{-4} \mathrm{t}+1,008$ & 0.995 \\
\hline Intermedia & $\mathrm{m}_{\mathrm{n}}=-1.114 \times 10^{-4} \mathrm{t}+1,005$ & 0.997 & $\mathrm{~m}_{\mathrm{n}}=-1.133 \times 10^{-4} \mathrm{t}+1,000$ & 1 \\
\hline Superior & $\mathrm{m}_{\mathrm{n}}=-1.135 \times 10^{-4} \mathrm{t}+0,997$ & 0.999 & $\mathrm{~m}_{\mathrm{n}}=-1.118 \times 10^{-4} \mathrm{t}+1,004$ & 0.993 \\
\hline
\end{tabular}

Los valores de la pendiente, proporcional a la velocidad de evaporación son muy similares. El promedio (en valor absoluto) fue de $1.121 \times 10^{-4} \mathrm{~s}^{-1}$. Como valor $\mathrm{m}_{\text {wo }}$ de la ec. (1.3) se utilizó el valor medio de $221.46 \mathrm{~g}$. Por tanto empleando la ecuación Ec. (1.1) la velocidad de evaporación de agua resulta:

$$
\dot{\mathrm{m}}_{\mathrm{wev}}=1.121 \times 10^{-4} \mathrm{~s}^{-1} * 0.2215 \mathrm{~kg}=\mathrm{k}_{\mathrm{p}} A\left(\mathrm{p}_{\mathrm{sbh}}-\mathrm{p}_{\mathrm{va}}\right)=2.484 \times 10^{-5} \mathrm{~kg} / \mathrm{s}
$$

Los valores de $\mathrm{W}_{\mathrm{a}}$ (humedad absoluta de secado), y $\mathrm{T}_{\mathrm{bh}}$ (temperatura de bulbo húmedo en las condiciones de secado) se determinaron con el programa AKTON 4.1 (Akton Associates, Edmond, Oklahoma, EEUU). Siendo $W_{a}=0.0119 \mathrm{~kg}$ vapor/ kg aire seco, para la temperatura de secado de $60^{\circ} \mathrm{C}$, corresponde una $\mathrm{T}_{\mathrm{bh}}=28,5^{\circ} \mathrm{C}$. A su vez, utilizando la relación entre la humedad absoluta y la presión parcial de vapor (Giner, 1999), se obtiene

$$
\mathrm{p}_{\mathrm{va}}=\frac{\mathrm{W}_{\mathrm{a}} \mathrm{p}}{0.621+\mathrm{W}_{\mathrm{a}}}
$$

Para una presión barométrica de $\mathrm{p}=1,01325 \times 10^{5} \mathrm{~Pa}$, se obtiene $\mathrm{p}_{\mathrm{va}}=1905.1 \mathrm{~Pa}$. Si $\mathrm{p}_{\mathrm{sbh}}=3863,7 \mathrm{~Pa}$, el coeficiente de transferencia de materia del equipo, despejado de la ec. (1.13) resulta

$$
\mathrm{k}_{\mathrm{p}}=3.170 \times 10^{-7} \mathrm{~kg} /\left(\mathrm{m}^{2} \mathrm{~s} \mathrm{~Pa}\right) \text {. }
$$


En las condiciones de trabajo, el uso de la Ec. (1.5) permite calcular el factor de conversión como

$$
\mathrm{h}_{\mathrm{T}} / \mathrm{k}_{\mathrm{p}}=1,514 \times 10^{8} \mathrm{~J} \mathrm{~Pa} / \mathrm{kg}{ }^{\circ} \mathrm{C}
$$

Este factor no es constante siendo levemente superior a $1.45 \times 10^{8} \mathrm{~J} \mathrm{~Pa} / \mathrm{kg}^{\circ} \mathrm{C}$, valor sugerido por Ratti y Crapiste, (1995) En consecuencia el coeficiente de transferencia de calor en el equipo de secado $h_{\mathrm{T}}$ vale:

$$
\mathrm{h}_{\mathrm{T}}=1,514 \times 10^{8} * \mathrm{k}_{\mathrm{p}}=1,514 \times 10^{8}\left(\frac{\mathrm{JPa}}{\mathrm{kg}^{\circ} \mathrm{C}}\right) 3.173 \times 10^{-7}\left(\frac{\mathrm{kg}}{\mathrm{m}^{2} \mathrm{sPa}}\right)=48,0 \frac{\mathrm{J}}{\mathrm{s} \mathrm{m}^{2} \mathrm{oC}^{-C}}
$$

Este resultado es comparable a los obtenidos por Ratti y Crapiste (1995), quienes determinaron el coeficiente de transferencia de calor mediante una técnica que emplea el secado de alimentos (no estacionaria). Secando rodajas de manzana en equipos de bandejas, los autores obtuvieron valores entre 41.7 y $63.7 \mathrm{~W} / \mathrm{m}^{2} \mathrm{~K}$, para velocidades de 1 a $5 \mathrm{~m} / \mathrm{s}$. Como se puede observar, tanto los valores obtenidos en este trabajo, como aquellos determinados por Ratti y Crapiste (1995) son considerablemente más elevados que los calculados por las correlaciones publicadas (Figura 1.4), lo cual confirma la conveniencia de determinar los coeficientes de transferencia para cada equipo experimental. 


\section{CAPÍTULO II}

OPERACIONES PREPARATORIAS DE LA MATERIA PRIMA 


\section{$2.1 \quad$ INTRODUCCIÓN}

Previo a la utilización de la manzana como ingrediente del laminado Se realizó un tratamiento térmico para inactivar las enzimas presentes, reducir la carga microbiana y promover el desarrollo de un color en la manzana, que al ser transformada en laminado sea atractivo para el consumidor.

La enzima que se desea inactivar es la polifenol oxidasa (PPO); ésta reacciona con compuestos fenólicos presentes en el tejido, entre ellos la o-benzoquinona que luego se combina con el oxigeno formando compuestos coloreados (melaninas), responsables del pardeamiento enzimático en frutas (manzana, peras) y hortalizas (papa) (Damodaran y col., 2010; Martínez y Whitaker, 1995)

Dentro de los tejidos de origen vegetal se encuentra también la enzima peroxidasa. Si bien ésta no genera defectos en los alimentos, presenta una resistencia mayor a la inactivación por tratamiento térmico, por lo cual se considera como un indicador confiable de inactivación enzimática. La peroxidasa es una enzima que cataliza la oxidación de ciertos compuestos dadores de hidrógeno, como fenoles (guayacol, pirogalol) y aminas aromáticas (o-fenilendiamina) por medio de peróxidos $\left(\mathrm{H}_{2} \mathrm{O}_{2}\right)$. El substrato oxidable más usado es el guayacol, que es oxidado a un complejo coloreado de tetraguayacol en presencia de peroxidasa (Schmidt Hebbel y Pennacchiotti Monti, 2001), siendo este el seleccionado para realizar el test de inactivación de la enzima de forma cualitativa.
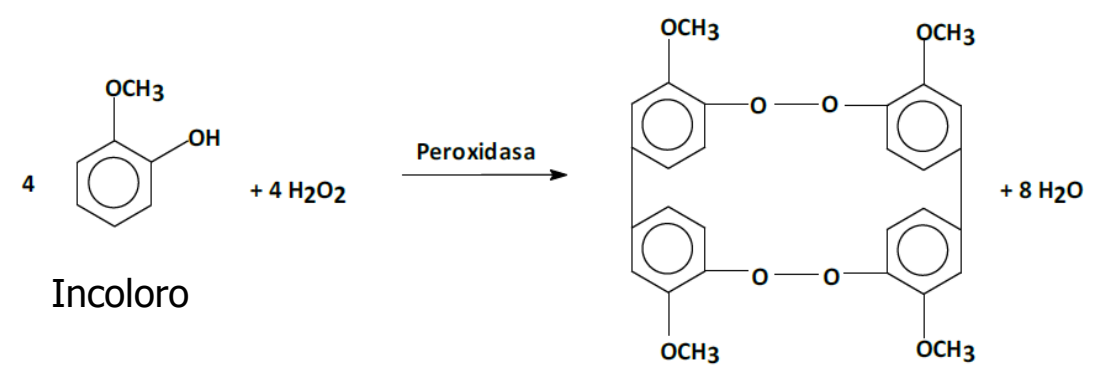

Color rojizo

Figura 2.1. Mecanismo de reacción de la peroxidasa en presencia de peroxido de hidrógeno y guayacol 
El tiempo de escaldado se considera suficiente cuando al realizar un test para evaluar la actividad de peroxidasa se obtiene un resultado negativo (Damodaran y col., 2010). Asimismo, a efectos de tener una herramienta para pronosticar tiempos de tratamiento térmico, se modeló el calentamiento de los cubos de manzana mediante un balance microscópico de energía, comparándose sus predicciones con la historia térmica experimental. Las estimaciones del modelo para un determinado rango de temperaturas de inactivación se compararon con los tiempos determinados mediante el test de peroxidasa. 


\subsection{MATERIALES Y MÉTODOS}

\subsubsection{Adecuación de la materia prima}

Se adquirieron en un comercio local manzanas en estado de madurez comercial (Malus pumila, cultivar Granny Smith). La composición aproximada se muestra en la Tabla 2.1.

Tabła 2 1. Composición de Manzana verde sin cáscara y sin semilla (por 100 g) (FAO, 2002)

\begin{tabular}{|c|c|}
\hline & Cantidad \\
\hline Aporte energético (kcal/100g) & 46 \\
\hline Agua (g) & 86.4 \\
\hline Proteínas(g) & 0.3 \\
\hline Grasa(g) & 0.1 \\
\hline Ceniza(g) & 0.3 \\
\hline Fibra(g) & 1.9 \\
\hline Carbohidratos totales (g) & 12.9 \\
\hline Carbohidratos disponibles (g) & 11.0 \\
\hline
\end{tabular}

Las manzanas fueron lavadas, peladas, descarozadas y luego cortadas en cubos de 1 $\mathrm{cm}$ de lado (Figura 2.2)

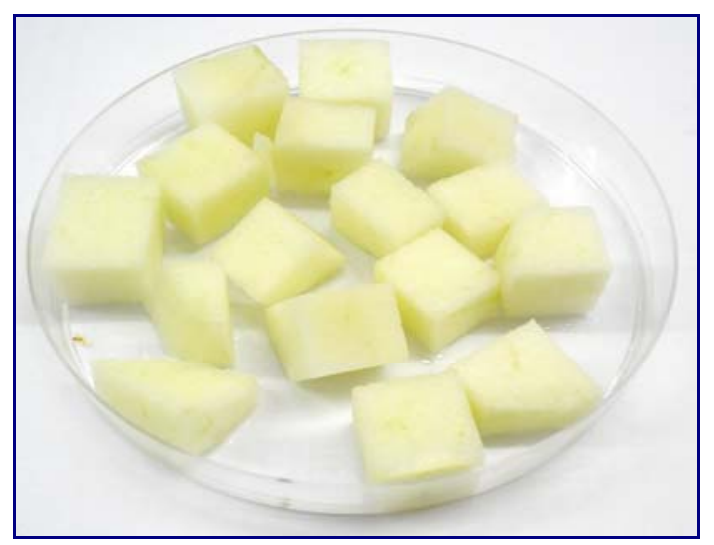

Figura 2 2. Cubos de manzana listos para el tratamiento térmico. 


\subsubsection{Tratamiento térmico}

\subsubsection{Descripción}

Para realizar el tratamiento térmico se utilizó vapor debido a que su aplicación reduce la pérdida de sustancias solubles como vitaminas, azúcares y minerales (Enachescu, 1995) respecto de la inmersión en agua caliente. Con este fin se empleó una vaporera Moulinex, previamente calentada a una temperatura de vapor de $99,5^{\circ} \mathrm{C}$, determinada con una termocupla tipo $\mathrm{K}$ conectada a un equipo Testo $830 \mathrm{~T} 2$. Se cargaban las dos bandejas de la vaporera, con capas de manzana de un cubo de espesor y se las mantenía por distintos tiempos.

\subsubsection{Test de inactivación de peroxidasa}

Se realiza en una cápsula de porcelana blanca, dentro de la cual se agrega un $\mathrm{mL}$ de pulpa de manzana, nueve $\mathrm{mL}$ de agua destilada, un $\mathrm{mL}$ de solución de peróxido de hidrógeno $\left(\mathrm{H}_{2} \mathrm{O}_{2}\right)$ al $3 \% \mathrm{~V} / \mathrm{V}$ y un $\mathrm{mL}$ de solución de guayacol $\left(\mathrm{C}_{7} \mathrm{H}_{8} \mathrm{O}_{2}\right)$ al $1 \% \mathrm{p} / \mathrm{V}$ en etanol, mientras se agita varilla de vidrio.

El resultado del test se considera positivo (Figura 2.3), es decir, se detecta actividad de peroxidasa, si aparece una coloración pardo - rojiza en la mezcla antes de un minuto. En esas condiciones, el escaldado no resulta suficiente (Greensmith, 1998)

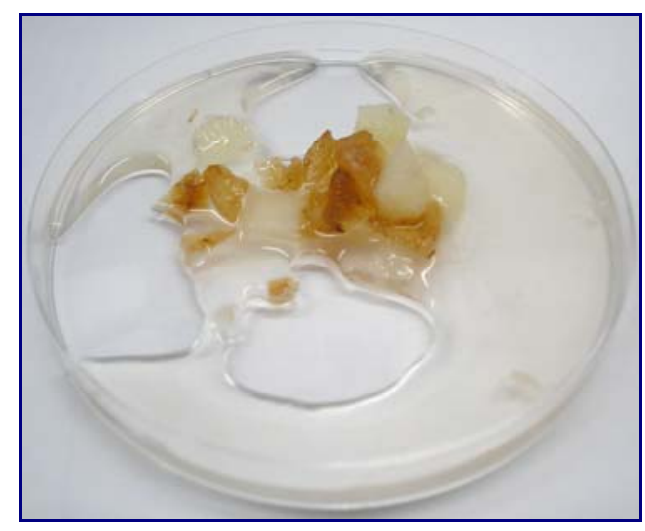

Figura 2 .3. Test de guayacol con resultado positivo 
2.2.2.3 Medición de temperatura de manzana para desarrollar un método matemático de estimación del tiempo de inactivación de peroxidasa

Se insertó la termocupla fina tipo $\mathrm{K}$ en el centro de un cubo de manzana (Figura 2.4), colocado dentro de la vaporera precalentada y previamente cargada con una capa de de cubos de manzana. Se registraron los datos directamente del visor del equipo TESTO 830 -T2 cada 30 segundos, durante un período de 10 minutos. El centro del cubo alcanzó una temperatura similar a la del vapor al cabo de unos 8 minutos. La historias térmica se midió por duplicado y los datos fueron promediados.

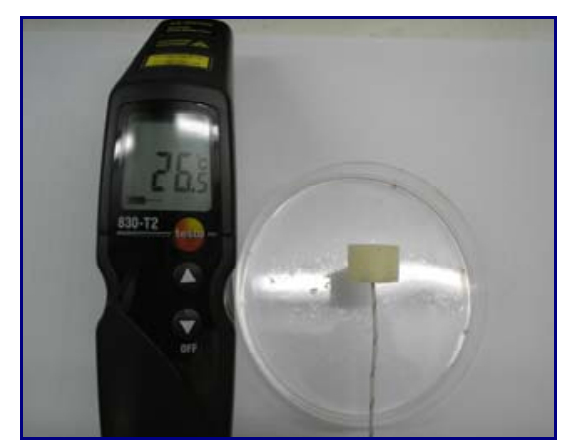

Figura 2 4 . Medición de la temperatura del centro de un cubo de manzana 


\subsection{RESULTADOS}

La historia térmica experimental se lista en la Tabla 2.2.

Tabla 2 . Temperatura en el centro de un cubo de manzana de $1 \mathrm{~cm}$ de lado

\begin{tabular}{|c|c|}
\hline Tiempo (s) & Temperatura $\left({ }^{\circ} \mathrm{C}\right)$ \\
\hline 0 & 26,5 \\
\hline 30 & 40,4 \\
\hline 60 & 48,2 \\
\hline 90 & 57,9 \\
\hline 120 & 74,5 \\
\hline 150 & 80,5 \\
\hline 180 & 84,8 \\
\hline 210 & 90,0 \\
\hline 240 & 93,3 \\
\hline 270 & 95,3 \\
\hline 300 & 96,5 \\
\hline
\end{tabular}

\begin{tabular}{|c|c|}
\hline Tiempo (s) & Temperatura $\left({ }^{\circ} \mathrm{C}\right)$ \\
\hline 330 & 97,2 \\
\hline 360 & 97,7 \\
\hline 390 & 97,9 \\
\hline 420 & 98,1 \\
\hline 450 & 98,9 \\
\hline 480 & 99,5 \\
\hline 510 & 99,5 \\
\hline 540 & 99,5 \\
\hline 570 & 99,5 \\
\hline 600 & 99,5 \\
\hline
\end{tabular}

2.3.1 Estimación teórica del tiempo de inactivación de peroxidasa.

Se modeló la evolución de temperatura en un cubo mediante un balance microscópico de energía no estacionario, asumiendo la validez de la ley de Fourier para la conducción del calor en una placa plana infinita de espesor 2L, (Ec. (2.1))

Balance de energía local $\quad \frac{\partial \mathrm{T}}{\partial \mathrm{t}}=\alpha \frac{\partial^{2} \mathrm{~T}}{\partial \mathrm{x}^{2}}$

Las condiciones iniciales y de contorno fueron las siguientes

Condición inicial $\quad \mathrm{t}=0 \quad \mathrm{~T}=\mathrm{T}_{\mathrm{o}} \quad \mathrm{O} \leq \mathrm{x} \leq \mathrm{L}$ 
$\underset{\text { Contorno }}{\text { Condiciones de }} \quad t>0\left\{\begin{array}{cc}\frac{\partial T}{\partial x}=0 & x=0 \\ -k \frac{\partial T}{\partial x}=h_{T v m}\left(T-T_{v}\right) & x=L\end{array}\right.$

Siendo L la longitud característica. La solución analítica para este sistema (Crank, 1975) permite evaluar la temperatura en cualquier punto de la placa $(x)$ como una función del tiempo $(\mathrm{t})$

$$
1-\frac{T(x, t)-T_{i}}{T_{v}-T_{i}}=\sum_{n=1}^{\infty} \frac{2 B i \cos \left(\beta_{n} \frac{x}{L}\right) \exp \left(-\beta_{n}{ }^{2} \frac{\alpha t}{L^{2}}\right)}{\left(\beta_{n}{ }^{2}+B i^{2}+B i\right) \cos \left(\beta_{n}\right)}
$$

Siendo la versión particular de la Ec. (2.5) para el centro de la placa $(x=0)$ la siguiente:

$$
\mathrm{T}_{\mathrm{c}}=\mathrm{T}_{\mathrm{v}}-\left(\mathrm{T}_{\mathrm{v}}-\mathrm{T}_{\mathrm{i}}\right) \sum_{n=1}^{\infty} \frac{2 \mathrm{Bi} \exp \left(-\beta_{\mathrm{n}}^{2} \frac{\alpha t}{\mathrm{~L}^{2}}\right)}{\left(\beta_{\mathrm{n}}^{2}+\mathrm{Bi}^{2}+\mathrm{Bi}\right) \cos \left(\beta_{n}\right)}
$$

$$
\begin{aligned}
& \text { Donde } \mathrm{B}_{\mathrm{i}}=\frac{\mathrm{h}_{\mathrm{Tvm}} \mathrm{L}}{\mathrm{k}} \\
& \text { y } \alpha=\frac{\mathrm{k}}{\rho \mathrm{C}_{\mathrm{p}}}
\end{aligned}
$$

Los valores de $\beta_{n}$ son las raíces positivas de la ecuación $\beta_{n} \tan \beta_{n}=B i$. Las propiedades físicas de la manzana verde empleadas, se listan en la Tabla 2.3. El tiempo adimensional o número de Fourier se define como $\mathrm{Fo}=\alpha \mathrm{t} / \mathrm{L}^{2}$. 
Tabla 2 .3. Propiedades térmicas y físicas del la manzana

\begin{tabular}{|l|c|c|}
\hline \multicolumn{1}{|c|}{ Propiedad } & Valor & Fuente \\
\hline Conductividad térmica $\mathrm{k}\left(\mathrm{W} / \mathrm{m}^{\circ} \mathrm{C}\right)$ & 0.481 & (Rahman, 2009) \\
\hline Calor especifico $\mathrm{Cp}(\mathrm{J} / \mathrm{kg} \mathrm{K})$ & 3580 & (Rahman, 2009) \\
\hline Densidad $\rho\left(\mathrm{kg} / \mathrm{m}^{3}\right)$ & 790 & (Rahman, 2009) \\
\hline Difusividad térmica $\alpha\left(\mathrm{m}^{2} / \mathrm{s}\right)$ & $1.7 \times 10^{-7}$ & Ecuación 2.8 \\
\hline
\end{tabular}

A efectos de ajustar la Ec. (2.6) a la historia térmica experimental del centro del cubo se utilizó un procedimiento de optimización: buscar el valor de $h_{T v m}$ y por tanto del número de Biot, que minimizara la suma de los cuadrados de las desviaciones entre las temperaturas calculadas y experimentales. Con este fin se predijo la curva para valores de $h_{T v m}$ entre 30 y $100 \mathrm{~W} / \mathrm{m}^{2} \mathrm{~K}$ variando de a $0,1 \mathrm{~W} / \mathrm{m}^{2} \mathrm{~K}$ con estos, se calcularon los correspondientes Biot (Ec. (2.7)). Para calcular las raíces $\beta_{i}(i=1 \ldots 6)$, se utilizaron correlaciones entre éstas y el número de Biot, desarrolladas previamente (Leiva Díaz y col., 2009), basadas en información de Crank (1975). Para cada $h_{T v m}$ propuesto, se calculó la temperatura adimensional del centro de una placa plana hipotética de la misma longitud característica que el cubo en función del tiempo, la que se convertía a temperatura adimensional en el centro del cubo por el método basado en la intersección de tres placas planas que en este caso tienen igual espesor (Singh y Heldman, 2009).

$$
\mathrm{T}_{\mathrm{c} \text { cubo }}^{*}=\left(\frac{\mathrm{T}_{\mathrm{v}}-\mathrm{T}_{\mathrm{c}}}{\mathrm{T}_{\mathrm{v}}-\mathrm{T}_{\mathrm{i}}}\right)_{\text {largo }} *\left(\frac{\mathrm{T}_{\mathrm{v}}-\mathrm{T}_{\mathrm{c}}}{\mathrm{T}_{\mathrm{v}}-\mathrm{T}_{\mathrm{i}}}\right)_{\text {ancho }} *\left(\frac{\mathrm{T}_{\mathrm{v}}-\mathrm{T}_{\mathrm{c}}}{\mathrm{T}_{\mathrm{v}}-\mathrm{T}_{\mathrm{i}}}\right)_{\text {espesor }}=\left(\frac{\mathrm{T}_{\mathrm{v}}-\mathrm{T}_{\mathrm{c}}}{\mathrm{T}_{\mathrm{v}}-\mathrm{T}_{\mathrm{i}}}\right)_{\text {Cubo }}^{3}
$$

Despejando, a su vez, la temperatura dimensional $\mathrm{T}_{\mathrm{c}}\left({ }^{\circ} \mathrm{C}\right)$ del centro del cubo y calculando la suma de las diferencias al cuadrado entre éstas y las temperaturas experimentales $\left(\mathrm{s}^{2}\right)$, se realizó la Figura 2.5 , representando $s^{2}$ en función de $h_{T v m}$. El correspondiente programa de Matlab se incluye en el Anexo 2.

El valor para el cual la curva se hace mínimo corresponde al coeficiente de transferencia de calor en nuestro sistema, $h_{T v m}=58 \mathrm{~W} / \mathrm{m}^{2 \circ} \mathrm{C}$, que conduce a un $\mathrm{Bi}=0.60$, esto es, control interno-externo: ambas resistencias a la transferencia de calor 
son importantes, siendo algo más importante la externa, lo que justifica el procedimiento realizado para evaluar el coeficiente de transferencia de calor.

Al calcular la temperatura del centro del cubo $(x=0)$ en función del tiempo de los datos experimentales para el Biot hallado, se obtiene la Figura 2.6, que permite observar una predicción muy satisfactoria. Damodaran y col. (2010), consideran que la inactivación de la enzima peroxidasa se logra para temperaturas mayores de $80^{\circ} \mathrm{C}$. El modelo predice los $80^{\circ} \mathrm{C}$ para un tiempo de unos 159 segundos. Por tanto la inactivación efectiva se alcanzará a tiempos algo mayores.

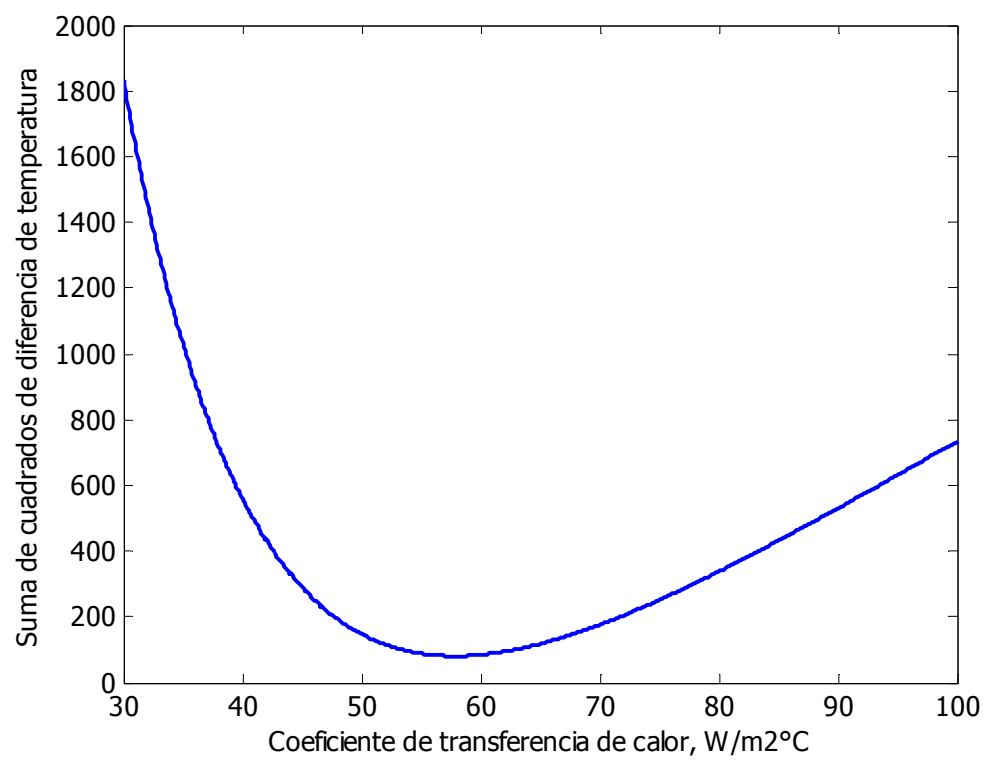

Figura 2 .5 . Suma de cuadrados de diferencia de temperatura en función de $h_{T v m}$

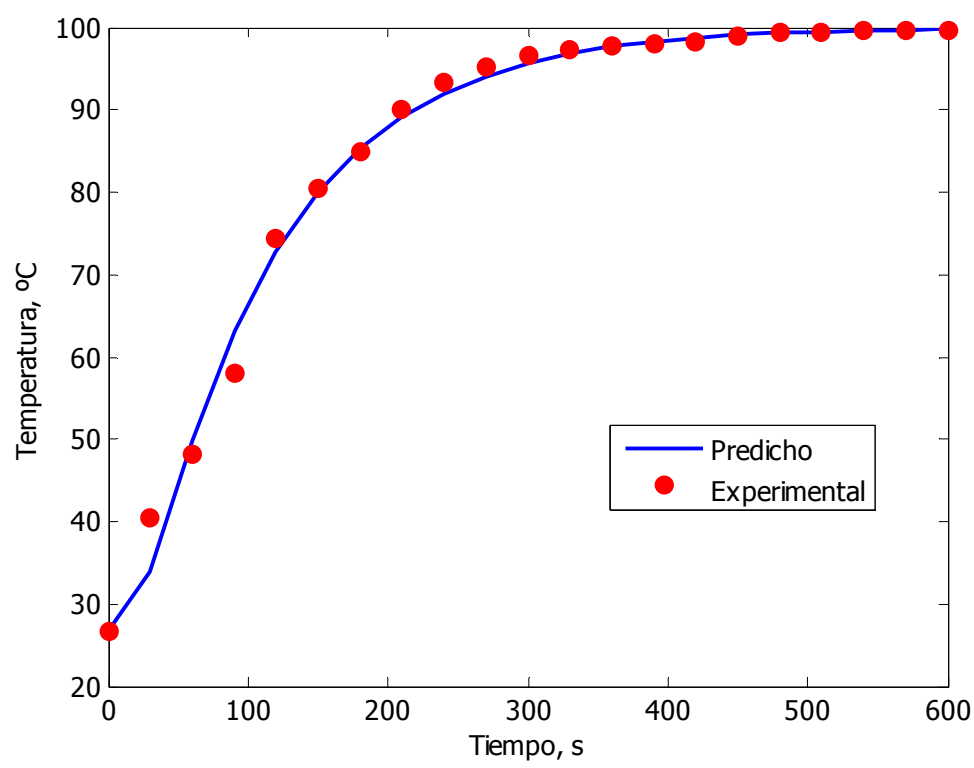

Figura 2.6. Temperatura experimental y predicha por el modelo 
2.3.2 Determinación experimental del tiempo de tratamiento térmico.

Se determinó cualitativamente mediante el test de guayacol si había actividad peroxidasa, luego de 2, 3, 5, 10 y 15 minutos de escaldado, obteniéndose resultados negativos (inactivación de la enzima) a partir de 3 minutos (180 s). Lo cual concuerda con las predicciones del modelo de transferencia de calor.

Para determinar el tiempo definitivo del procesamiento térmico, se realizó una observación visual por parte de los integrantes del grupo de trabajo quienes no encontraron diferencias de color entre los cubos tratados durante 10 y 15 minutos, pero que éstos sí eran diferentes a los calentados por 5 minutos, los que resultaban más pálidos (Figura 2.7). Así, se seleccionó como tiempo de tratamiento térmico de 10 minutos. Esto tiene tres beneficios respecto del procesamiento industrial: disminución del consumo energético, aumento de producción, y mayor posibilidad de retención de micronutrientes, respecto del uso de 15 minutos.

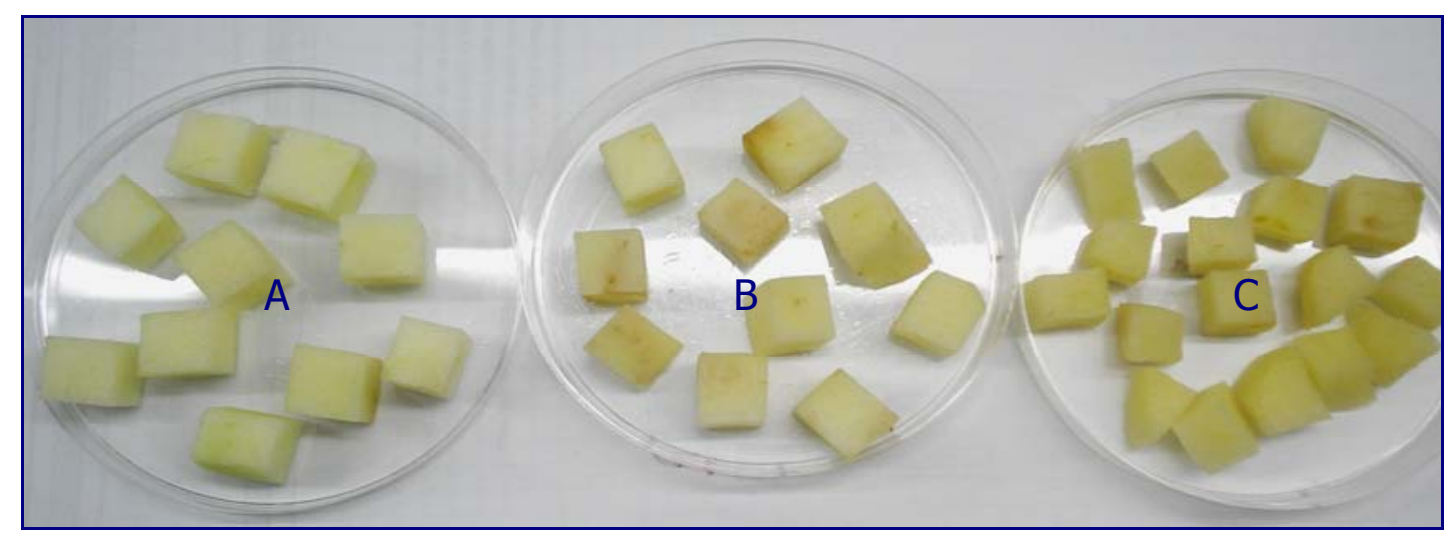

Figura 2 7 . Cubos de manzana A-frescos, B-escaldados 5 minutos, C-escaldados 10 minutos 
CAPÍTULO III

PREPARACIÓN DE GELES PÉCTICOS 


\subsection{INTRODUCCIÓN}

\subsubsection{Aspectos relacionados con la formulación}

Los geles pécticos o laminados de manzana son el producto final del proceso de secado con aire caliente (normalmente realizado a $60^{\circ} \mathrm{C}$ ) de una mezcla a base de puré de manzana. El valor inicial de pH en el puré de manzana es bajo debido a la variedad seleccionada ( $\mathrm{pH}=3,7)$, pero no lo suficiente para que la gelificación se lleve a cabo adecuadamente, es por esto que se hace la adición del ácido cítrico en la formulación. acidulante, acido cítrico al 5,8\% p/p (concentración similar a la del jugo de limón). La formación del gel sigue el mecanismo azúcar - ácido - pectina de alto metoxilo y tiene lugar en el intervalo de contenido de sólidos solubles de 55-65 oBrix con un pH de 33,5 (Visser y Voragen, 1995). Asimismo, se agrega sacarosa para reforzar el contenido de sólidos solubles, pudiendo o no contener otros aditivos, como sorbato y/o metabisulfito de potasio. De acuerdo a trabajos previos (Leiva Díaz y col., 2009) el laminado queda bien formado para humedades finales entre 20 y $35 \% \mathrm{p} / \mathrm{p}$. Esto permite justamente el desarrollo de este tipo de productos, porque las humedades permitidas para el almacenamiento están en el rango de contenido de sólidos que permiten la gelificación.

Con respecto a los aditivos, en la industria de alimentos, éstos se utilizan para lograr beneficios como la retención de un nutriente original o la mejora por fortificación o enriquecimiento, e impedir el deterioro por microorganismos e insectos, entre otros propósitos (Damodaran y col., 2010). Existen diferentes tipos de aditivos y para esto se clasifican según el efecto que generan en el producto.

El gel péctico de manzana obtenido por deshidratación o "laminado" no es un producto definido específicamente dentro del Código Alimentario Argentino (CAA). Si bien se puede incluir como "fruta deshidratada" (capítulo XI del CAA), los niveles permitidos para el conservante $\mathrm{SO}_{2}$ de 1000 ppm resultan demasiado elevados en nuestra opinión, a la luz de los potenciales problemas que puede causar a los alérgicos (Ortolani y 
Pastorello, 2006) En consecuencia, tanto para $\mathrm{SO}_{2}$ como para el antimicrobiano ácido sórbico se decidió respetar el límite establecido para los alimentos azucarados $y$, dentro de éstos, para las confituras (100 ppm de cada aditivo) . Comparado con otras fuentes del dióxido de azufre como los sulfitos y bisulfitos (Beveridge y Weintraub, 1995) los más utilizados actualmente es el metabisulfito de sodio o potasio debido a que tiene la mayor proporción de $\mathrm{SO}_{2}$ por $\mathrm{g}$ de aditivo. De estas sustancias se seleccionaron el metabisulfito de potasio y el sorbato de potasio para no promover la ingesta adicional de sodio, lo que es especialmente importante para combatir la hipertensión arterial (Delgado Marroquin y Martin Espírola, 2006).

A continuación se muestra un esquema de la molécula de metabisulfito de potasio $\left(\mathrm{K}_{2} \mathrm{O}_{5} \mathrm{~S}_{2}\right)(\mathrm{MBK})$, Figura 3.1, peso molecular: $222,32 \mathrm{~g} / \mathrm{mol}$ (Anexo 3)

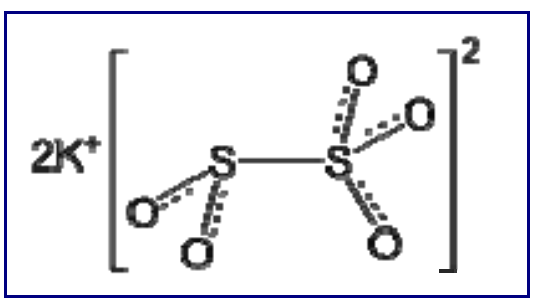

Figura 3.1. Metabisulfito de potasio

Este reductor se usa en jugos, jarabes, frutas deshidratadas y vinos. Es efectivo contra levaduras, hongos y bacterias. Su IDA (Ingesta diaria admisible) es de 0,7 mg/kg de peso corporal (JECFA, 1999). Como característica especial no debe usarse en alimentos que contengan tiamina (vitamina B1) ya que la destruyen. Por su parte, la molécula del preservador Sorbato de potasio, sal de potasio del ácido sórbico en polvo $\left(\mathrm{KC}_{6} \mathrm{H}_{7} \mathrm{O}_{2}\right)$ (SK) se observa en la Figura 3.2, peso molecular: 150,2 g/mol. (Anexo 3)

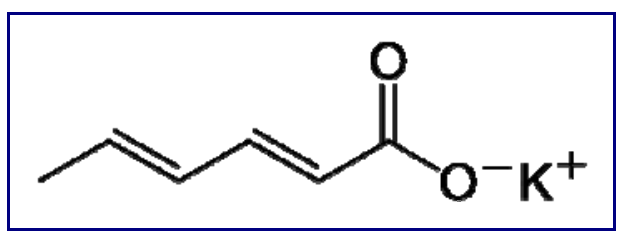

Figura 32 . Sorbato de Potasio

Se considera "GRAS" (Generalmente reconocido como seguro, (Ortolani y Pastorello, 2006) tiene una IDA de $25 \mathrm{mg} / \mathrm{kg}$ de peso corporal (JECFA, 1998) ya que se 
biotransforma a $\mathrm{CO}_{2}$, agua y energía. Se usa contra levaduras y hongos, pero también pueden ser usados para controlar Clostridium botulinum, Stafilococus aureus y Salmonella. (Vega y Florentino, 2000).

\subsubsection{Estudio de la curva experimental de secado y predicción teórica}

Por otra parte se estudió la curva experimental de secado a $60^{\circ} \mathrm{C}$ y $2 \mathrm{~m} / \mathrm{s}$ de velocidad de aire, y se empleó un modelo teórico de difusión no estacionaria desarrollado previamente para describirla (Leiva Díaz y colab., 2009), pero no aplicado a un laminado con un contenido inicial de agua mayor. Asimismo, se comparó la evolución de la cantidad de agua normalizada (masa de agua/masa de agua inicial) en este producto durante el secado, con la observada a lo largo del ensayo de evaporación de agua pura.

El producto obtenido se empacó en pouches hechos en el laboratorio con un material retortable. $Y$ luego se almacenaron a $20^{\circ} \mathrm{C}$ para caracterizar el cambio de actividad acuosa, contenido de sólidos solubles, pH, contenido de antioxidantes presentes, color, sabor, estabilidad microbiológica a distintos tiempos 


\section{MATERIALES Y MÉTODOS}

\subsubsection{EQUIPOS}

- Túnel de secado

Se operó como se indica en el Capitulo II, se utilizaron 2 bandejas de acero inoxidable de base cuadrada de $20 \mathrm{~cm}$ de lado y las condiciones de operación para realizar el secado son las que se listan en la Tabla 3.1.

Tabla 3 1 . Condiciones operacionales del túnel de secado

\begin{tabular}{|l|c|}
\hline \multicolumn{1}{|c|}{ Propiedad } & Condición \\
\hline Temperatura del aire de secado & $60^{\circ} \mathrm{C}$ \\
\hline Velocidad del aire & $2 \mathrm{~m} / \mathrm{s}$ \\
\hline
\end{tabular}

\subsubsection{MATERIALES}

Manzana verde (Malus pumila Borkh. L., cultivar Granny Smith) en cubos previamente escaldada durante diez minutos y con reacción negativa al test de guayacol (Greensmith, 1998), sacarosa (azúcar blanco refinado), solución de ácido cítrico al $5,8 \%$, metabisulfito de potasio (Anedra) y sorbato de potasio (Anedra), en polvo.

\subsubsection{METODOLOGÍA}

\subsubsection{Determinación del contenido de humedad en las muestras}

Se realizó en estufa balanza Mettler LP 16, utilizando entre 7 y 10 gramos de muestra, a $105^{\circ} \mathrm{C}$ (AOAC, 1998) durante 2 horas. Dicho tiempo fue mayor al necesario para alcanzar un peso constante de acuerdo al la precisión de la balanza Ohaus $(0.01 \mathrm{~g})$, de $3100 \mathrm{~g}$ de capacidad. 
3.2.3.2 Determinación de las cantidades de aditivo a utilizar:

- Sorbato de potasio (SK)

Según el CAA la cantidad de ácido sórbico o la concentración correspondiente en sorbato de potasio permitida es de $100 \mathrm{ppm}$ en el producto terminado. No se utiliza el ácido directamente como aditivo, así que se calculó la cantidad de la sal equivalente teniendo en cuenta que el acido sórbico es un acido monoprótico, solo es capaz de intercambiar un hidrógeno Ec. (3.1)

$$
\mathrm{HC}_{6} \mathrm{H}_{7} \mathrm{O}_{2}+\mathrm{KOH} \rightarrow \mathrm{KC}_{6} \mathrm{H}_{7} \mathrm{O}_{2}+\mathrm{H}_{2} \mathrm{O}
$$

100 ppm ác. sórbico $=\frac{100 \mathrm{mg} \text { ác. sórbico }}{\mathrm{kg} \text { prod. terminado }} * \frac{\mathrm{g} \text { ác. sórbico }}{1000 \mathrm{mg} \text { ác. sórbico }} * \frac{\mathrm{mol}}{112,1 \mathrm{~g}}=\frac{8,92 \times 10^{-4} \mathrm{~mol} \text { ác. sórbico }}{\mathrm{kg} \text { prod. terminado }}$

$\frac{8,92 \times 10^{-4} \text { mol ác. sórbico }}{\mathrm{kg} \text { prod. terminado }} * \frac{1 \mathrm{~mol} \text { Sorbato de } \mathrm{K}}{1 \mathrm{~mol} \text { ác. sórbico }} * \frac{150,2 \mathrm{~g} \text { sorbato de } \mathrm{K}}{1 \mathrm{~mol}}=\frac{0,1339 \mathrm{~g} \text { sorbato de } \mathrm{K}}{\mathrm{kg} \text { prod. terminado }}$

$$
\mathrm{C}_{\text {SKpf }}=\frac{0,1339 \mathrm{~g} \text { sorbato }}{\mathrm{kg} \text { prod. terminado }} \rightarrow 133,9 \mathrm{ppm} \text { de sorbato de potasio }
$$

- Metabisulfito de potasio (MBK)

La cantidad de dióxido de azufre que se puede utilizar es de 100 ppm. Para determinar la cantidad correspondiente de metabisulfito de potasio equivalente se tiene en cuenta que a partir de su degradación se pueden obtener 2 moles de anhídrido sulfuroso. Ec.

$$
\begin{gathered}
\mathrm{K}_{2} \mathrm{~S}_{2} \mathrm{O}_{5} \rightarrow 2 \mathrm{SO}_{2}+\mathrm{K}_{2} \mathrm{O} \\
100 \mathrm{ppm}=\frac{100 \mathrm{mg} \mathrm{SO}_{2}}{\mathrm{~kg} \text { prod. terminado }} * \frac{\mathrm{g} \mathrm{SO}_{2}}{1000 \mathrm{mg} \mathrm{SO}_{2}} * \frac{\mathrm{mol} \mathrm{SO}_{2}}{64 \mathrm{~g}}=\frac{1,56 \times 10^{-3} \mathrm{~mol} \mathrm{SO}_{2}}{\mathrm{~kg} \mathrm{prod.} \mathrm{terminado}} \\
\frac{1,56 \times 10^{-3} \mathrm{~mol} \mathrm{SO}_{2}}{\text { kg prod. terminado }} * \frac{1 \mathrm{~mol} \mathrm{MBK}}{2 \mathrm{~mol} \mathrm{SO}_{2}} * \frac{222,32 \mathrm{~g} \mathrm{MBK}}{1 \mathrm{~mol}}=\frac{0,1737 \mathrm{~g} \text { metabisulfito de } \mathrm{K}}{\mathrm{kg} \text { prod. terminado }}
\end{gathered}
$$




$$
\mathrm{C}_{\text {MBKpf }}=\frac{0,1737 \mathrm{~g} \text { metabisulfito de potasio }}{\mathrm{kg} \text { prod. terminado }} \rightarrow 173,7 \mathrm{ppm} \text { de metabisulfito de potasio }
$$

Para calcular la cantidad de aditivo que se debe agregar en la formulación se debe determinar la cantidad de laminado que se obtendrá después del secado. Con este fin se utilizó la Ec. (3.9), el balance de materia total (Figura 3.3) y el balance de agua (Ec. (3.10)) para la formulación base desarrollada por Leiva Díaz y col. (2009) que tiene: 79 $\mathrm{g}$ de puré, $3 \mathrm{~g}$ de solución al $5.8 \% \mathrm{p} / \mathrm{p}$ de ácido cítrico, $18 \mathrm{~g}$ de sacarosa y $30 \mathrm{~g}$ de agua.

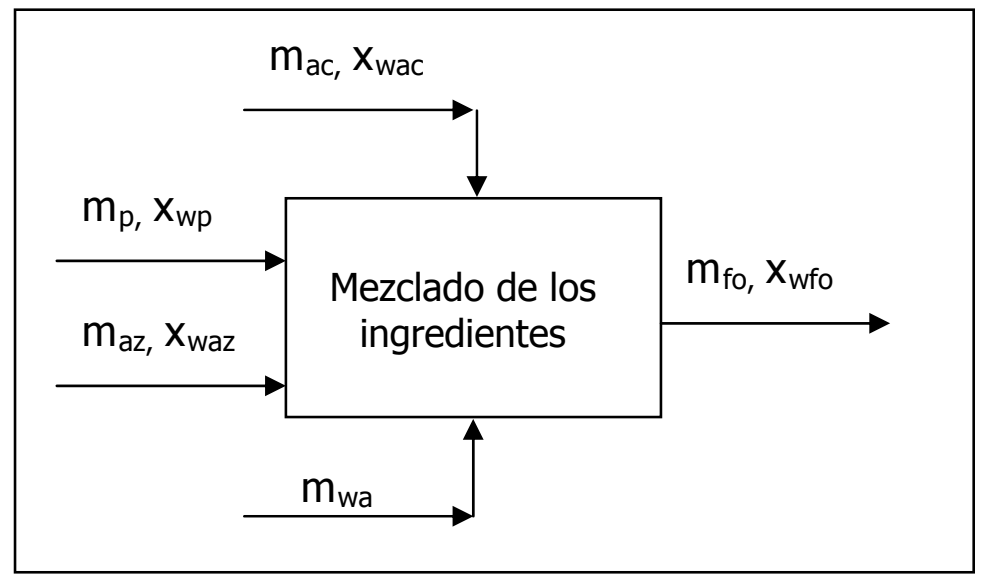

Figura 3.3. Balance de materia para la preparación de la formulación a deshidratar.

$$
\mathrm{m}_{\mathrm{p}}+\mathrm{m}_{\mathrm{az}}+\mathrm{m}_{\mathrm{ac}}+\mathrm{m}_{\mathrm{wa}}=\mathrm{m}_{\mathrm{fo}}
$$

Siendo $m_{p}$ la masa de puré, $m_{a z}$ la masa de azúcar, $m_{a c}$ la masa de solución de ácido cítrico, $\mathrm{m}_{\text {wa }}$ la masa de agua adicional y $\mathrm{m}_{\text {fo }}$ la masa de formulación sin secar.

$$
\mathrm{m}_{\mathrm{p}} * \mathrm{x}_{\mathrm{wp}}+\mathrm{m}_{\mathrm{az}} * \mathrm{x}_{\mathrm{waz}}+\mathrm{m}_{\mathrm{ac}} * \mathrm{x}_{\mathrm{wac}}+\mathrm{m}_{\mathrm{wa}}=\mathrm{m}_{\mathrm{fo}} * \mathrm{x}_{\text {wfo }}
$$

Considerando que la fracción de agua en el azúcar $\left(\mathrm{x}_{\mathrm{waz}}\right)$ es próxima a cero, la fracción de agua en el puré es $x_{\mathrm{wp}}=0,897$ (determinada experimentalmente) y la fracción de agua en la solución de ácido, $x_{w a c}=0,942$, se calculó el agua presente en la formulación con la Ec. (3.10) $x_{\text {wfo }}=0,797$. Este resultado fue corroborado según se indica en 3.2.3.1.

La cantidad de aditivo $\mathrm{m}_{\mathrm{A}}$ se calculó utilizando la masa final del producto, $\mathrm{m}_{\mathrm{pf}}$, (Ec. (3.12)) Esta, por su parte, se determina mediante un balance de conservación de materia seca a partir de la formulación sin secar $\mathrm{m}_{\mathrm{fo}}$, la humedad inicial $\mathrm{W}_{\mathrm{fo}} \mathrm{y}$ la final $\mathrm{W}_{\mathrm{pf}}$ en $\mathrm{kg}$ agua $/ \mathrm{kg}$ materia seca (Ec. (3.11)). El valor de $\mathrm{W}_{\mathrm{f} 0}$ se calculó mediante la 
conversión de humedad en base húmeda y seca, $\mathrm{W}_{\mathrm{f} 0}=\mathrm{x}_{\mathrm{wf0}} /\left(1-\mathrm{x}_{\mathrm{wf0}}\right)$, resultando de $3.93 \mathrm{~kg}$ agua $/ \mathrm{kg}$ materia seca. El valor de $W_{\mathrm{pf}}$ se fijó en $0.25 \mathrm{~kg}$ agua $/ \mathrm{kg}$ masa seca.

$$
\begin{aligned}
& \mathrm{m}_{\mathrm{pf}}=\left(\frac{1+\mathrm{W}_{\mathrm{pf}}}{1+\mathrm{W}_{\mathrm{fo}}}\right) * \mathrm{~m}_{\mathrm{fo}} \\
& \mathrm{m}_{\mathrm{A}}=\mathrm{C}_{\mathrm{Apf}} * \mathrm{~m}_{\mathrm{pf}}
\end{aligned}
$$

Donde $\mathrm{C}_{\mathrm{Apf}}$ es la concentración de aditivo a utilizar en el producto final (Ecuaciones (3.4) y (3.8))

\subsubsection{Preparación de la formulación}

El ingrediente principal es el puré de manzana, obtenido mediante la trituración con una procesadora de mano Philips de los cubos de manzana tratados térmicamente. A éste puré se le adicionaron una solución de ácido cítrico, azúcar, aditivos (metabisulfito de potasio y sorbato de potasio) y el agua, todos pesados previamente. La adición de agua permite tener una formulación fluida que permite una distribución nivelada de la formulación en la bandeja, aunque demandará un consumo algo mayor de energía durante la deshidratación.

Se prepararon 4 formulaciones que se identificaron de la siguiente manera:

- Formulación A (Formulación base o control): $79 \mathrm{~g}$ de puré, $3 \mathrm{~g}$ de solución al $5.8 \% \mathrm{p} / \mathrm{p}$ de ácido cítrico, $18 \mathrm{~g}$ de sacarosa y $30 \mathrm{~g}$ de agua.

- Formulación B: Formulación base con adición de $0.0057 \mathrm{~g}$ de Metabisulfito de potasio

- Formulación C: Formulación base con adición de $0.0044 \mathrm{~g}$ de sorbato de potasio

- Formulación D: Formulación base con adición de $0.0057 \mathrm{~g}$ de metabisulfito de potasio y $0.0044 \mathrm{~g}$ de sorbato de potasio 


\subsection{RESULTADOS Y DISCUSIÓN}

\subsubsection{Deshidratación de la muestra - formación del producto}

Para lograr un producto final de espesor aproximado de $1,5 \mathrm{~mm}$ se debe cargar la bandeja con seis milímetros de formulación (Leiva Díaz y col., 2009). La misma tiene una masa inicial de $250 \mathrm{~g}$ (Tabla 3.2).

Tabla 32 . Cantidad de ingredientes necesarios para preparar $130 \mathrm{~g}$ de muestra

\begin{tabular}{|c|c|c|c|c|c|c|}
\hline Formulación & $\begin{array}{c}\text { Puré } \\
(\mathrm{g})\end{array}$ & $\begin{array}{c}\text { Azúcar } \\
(\mathrm{g})\end{array}$ & $\begin{array}{c}\text { Ácido cítrico } \\
(\mathrm{g})\end{array}$ & $\begin{array}{c}\text { Agua } \\
(\mathrm{g})\end{array}$ & $\begin{array}{c}\text { Metabisulfito de } \\
\text { potasio }(\mathrm{g})\end{array}$ & $\begin{array}{c}\text { Sorbato de } \\
\text { potasio }(\mathrm{g})\end{array}$ \\
\hline A & 79 & 18 & 3 & 30 & - & - \\
\hline B & 78,995 & 18 & 3 & 30 & 0,0057 & - \\
\hline C & 78,996 & 18 & 3 & 30 & - & 0,0044 \\
\hline D & 78,990 & 18 & 3 & 30 & 0,0057 & 0,0044 \\
\hline
\end{tabular}

Se realizó una determinación de humedad inicial de cada formulación y con éste valor, mediante el uso del la Ec. (3.11) de balance de materia seca en el secado, se calculó la masa de producto requerida para alcanzar el contenido de agua final $\mathrm{W}_{\mathrm{pf}}$.

Las bandejas de acero inoxidable cargadas con formulación se colocaron dentro del túnel para ser secadas a las condiciones de la Tabla 3.1.

Al terminar el secado se obtiene un producto flexible, translúcido y con aroma característico de manzana (Figura 3.4), listo para ser envasado.

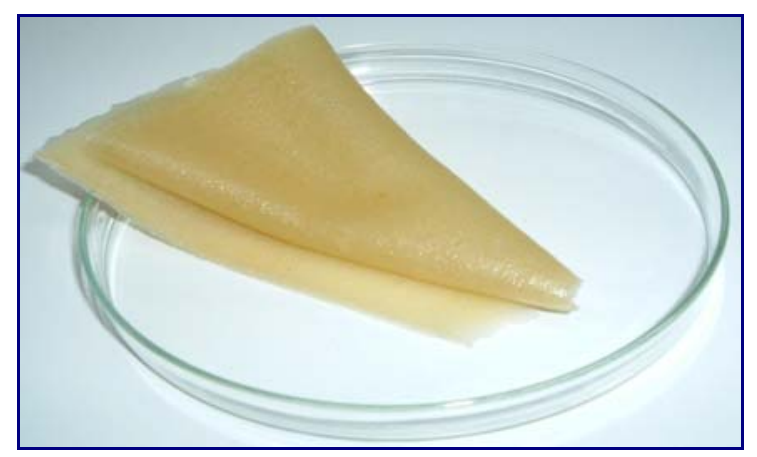

Figura 3.4. Gel péctico deshidratado de manzana 


\subsubsection{Curva de Secado}

Se graficaron los datos experimentales de humedad media de la muestra en función del tiempo, obteniéndose curvas que, inicialmente, muestran un descenso rápido del contenido de humedad. Hasta aproximadamente 50 minutos, la caída de humedad mantiene una relación aproximadamente lineal con el tiempo. Este período de velocidad de secado aproximadamente constante es sucedido luego por un período de velocidad de secado decreciente, donde la curva va progresivamente tendiendo a una asíntota inferior, representativa de la humedad de equilibrio en las condiciones de secado.

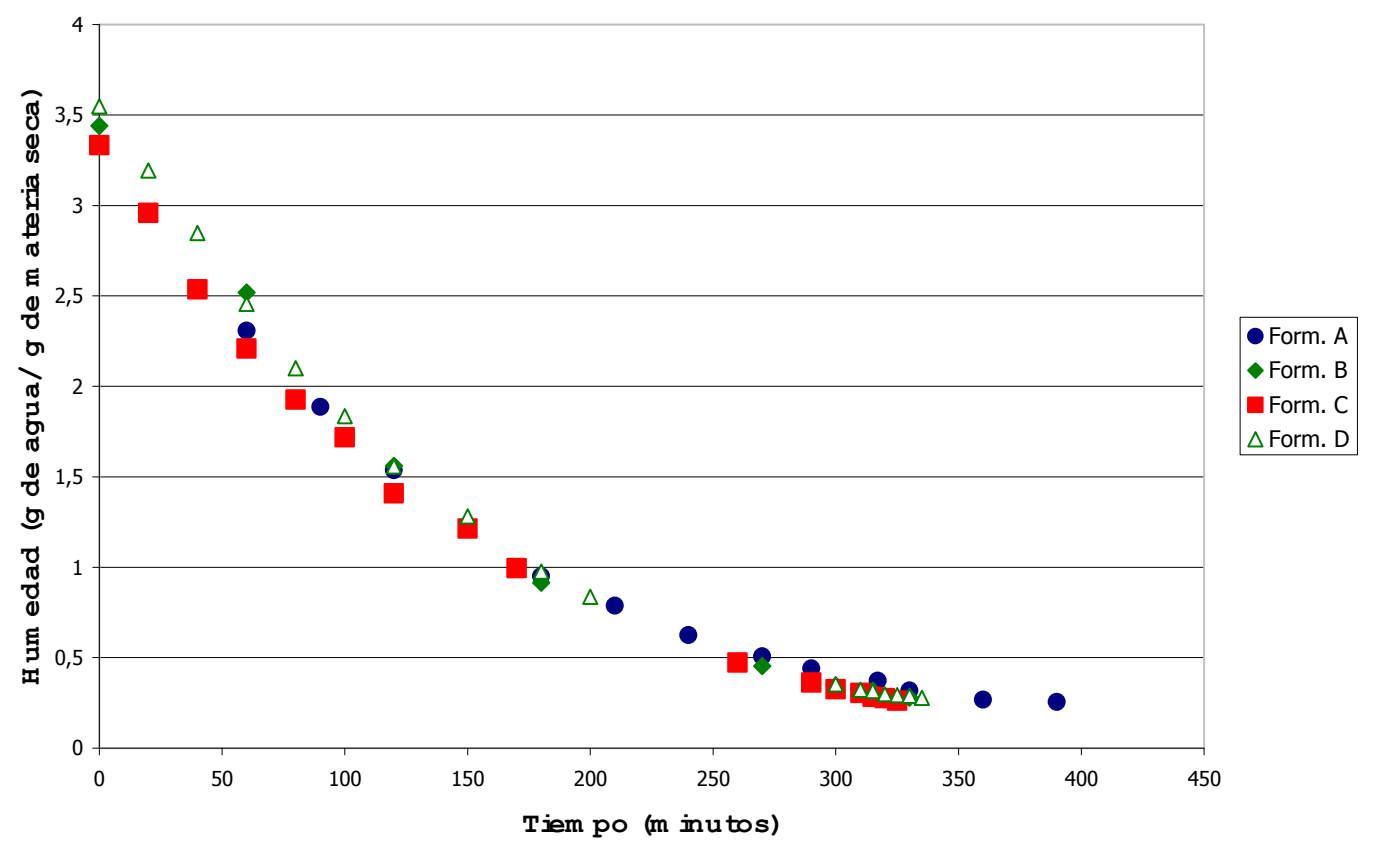

Figura 3 3 . Cinéticas de secado para los geles pécticos deshidratados de manzana.

Más allá del hecho de que las distintas formulaciones no parten de la misma humedad inicial, no se advierte una diferencia clara entre las curvas de secado en la Figura 3.5. Esto se puede confirmar mediante la normalización de los datos respecto de la humedad inicial (Figura 3.6). 


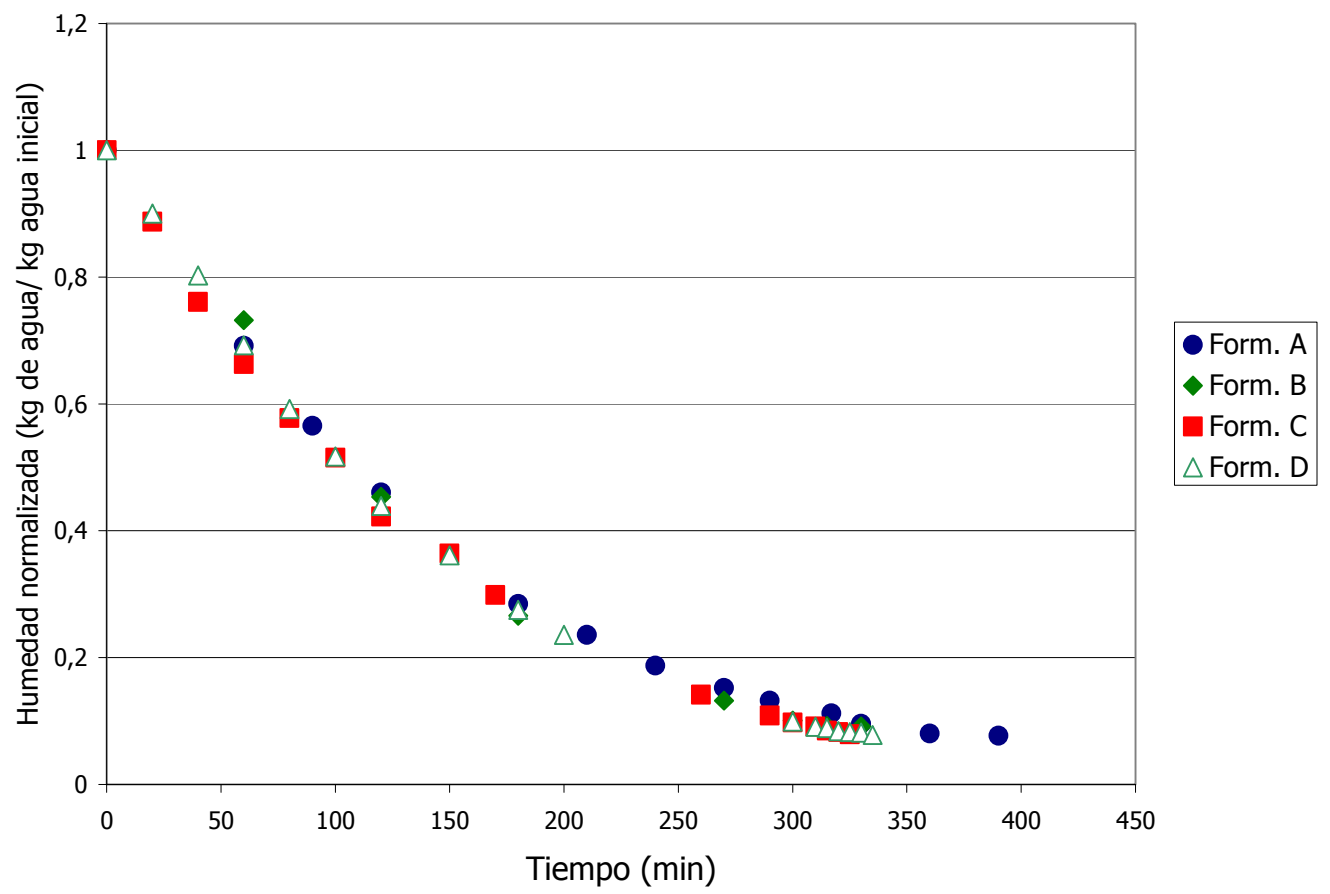

Figura 3.6. Curvas de secado normalizadas para las 4 formulaciones preparadas.

Se aplicaron dos modelos matemáticos, uno para altos contenidos de humedad Ec. (3.13 y 3.14) y otro para bajos contenidos de humedad Ec. (3.16 y 3.17) para describir el comportamiento del laminado durante el secado. En la zona de altas humedades, el numero de Biot promedio utilizado fue de 2 denotando control interno externo de la velocidad de secado (Leiva Díaz y col., 2009).

$$
W_{a d}=\frac{W-W_{e}}{W_{0}-W_{e}}=\sum_{n=1}^{\infty} \frac{2 B i^{2} \exp \left(-\beta_{n}{ }^{2} \frac{D_{h m} t}{e_{m h m}{ }^{2}}\right)}{\left(\beta_{n}{ }^{2}+B i^{2}+B i\right)\left(\beta_{n}^{2}\right)}
$$

Siendo $\mathrm{e}_{\mathrm{mhm}}$ el espesor medio en la muestra con alto contenido de humedad, $\mathrm{W}_{\mathrm{e}}$ la humedad en el equilibrio Ec. (3.15) y $D_{h m}$ el coeficiente de difusión a altas humedades correlacionado con la temperatura mediante una expresión preliminar de Arrhenius

$$
D_{h m}=D_{0 h m} \exp \left(\frac{-E_{a h m}}{R(T+273.16)}\right)
$$

Con $E_{a h m}=15259 \mathrm{~J} / \mathrm{mol}$ y $D_{0 h m}=3.673 \times 10^{-7} \mathrm{~m}^{2} / \mathrm{s}$. 


$$
\mathrm{W}_{\mathrm{e}}=\mathrm{C}_{1} \exp \left(\mathrm{C}_{2} \mathrm{~W}_{\mathrm{r}}^{\mathrm{C}_{3}}\right)
$$

Siendo $C_{1}=0.0994, C_{2}=3.584, C_{3}=3.307$ y $W_{r}$ la humedad relativa del aire de secado.

Para la zona de bajos contenidos de humedad se aplica una solución analítica de difusivo par control interno estricto de la velocidad de transferencia de materia a tiempos largos

$$
W_{a d}=\frac{W-W_{e}}{W_{0}-W_{e}}=\frac{8}{\pi^{2}} \exp \left(-\frac{\pi^{2} D_{l m} t}{4 e_{m l m}^{2}}\right)
$$

Siendo $e_{m l m}$ el espesor medio en la muestra con bajo contenido de humedad y $D_{\operatorname{lm}}$ el coeficiente de difusión a bajas humedades.

$$
D_{\operatorname{lm}}=D_{0 \mid m} \exp \left(\frac{-E_{a l m}}{R(T+273.16)}\right)
$$

Con $E_{a l m}=16800 \mathrm{~J} / \mathrm{mol}$ y $D_{0 l m}=6.97 \times 10^{-8} \mathrm{~m}^{2} / \mathrm{s}$.

Estos modelos se codificaron en un programa Matlab y se graficaron junto con los datos experimentales (Figura 3.7).

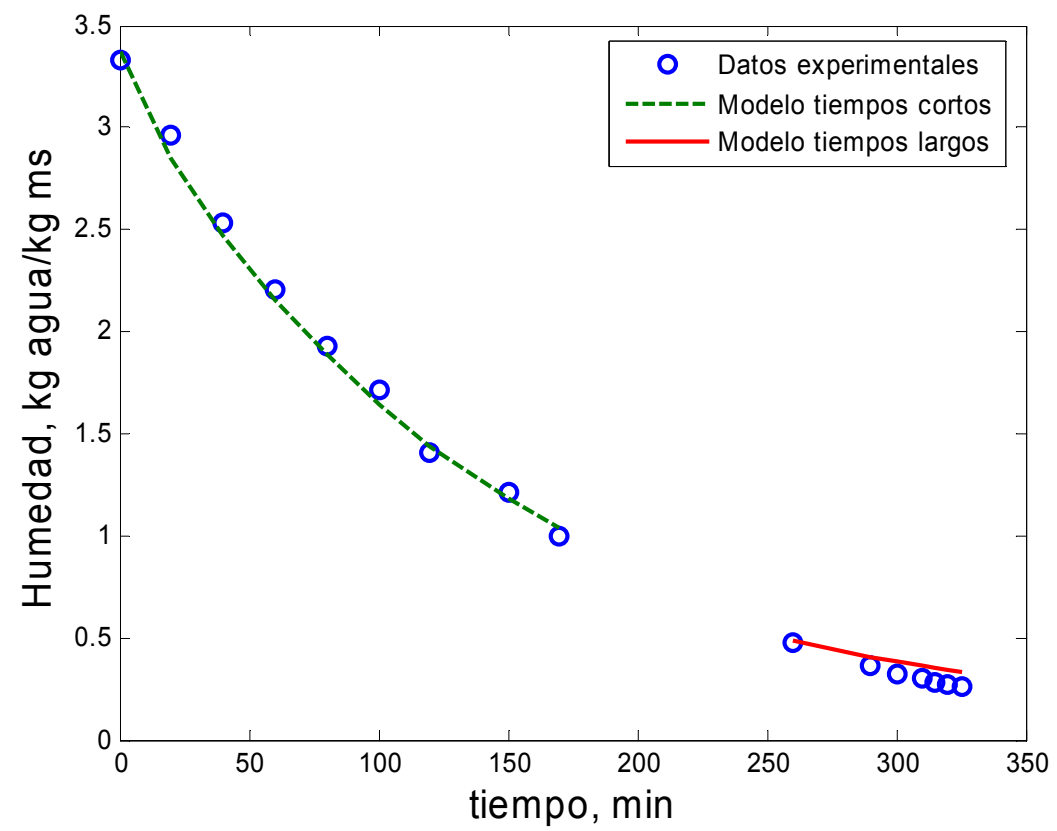

Figura 3.7. Curva de secado experimental de la formulación C. en el túnel de secado con pesada in situ, Temperatura del aire $60^{\circ} \mathrm{C}$, Velocidad del aire $2 \mathrm{~m} / \mathrm{s}$ y predicción de los modelos de zona húmeda y seca. 
Para comparar la velocidad de secado experimental de la formulación con la de evaporación de agua pura, se utilizó la ecuación (1.3) del Capítulo I.

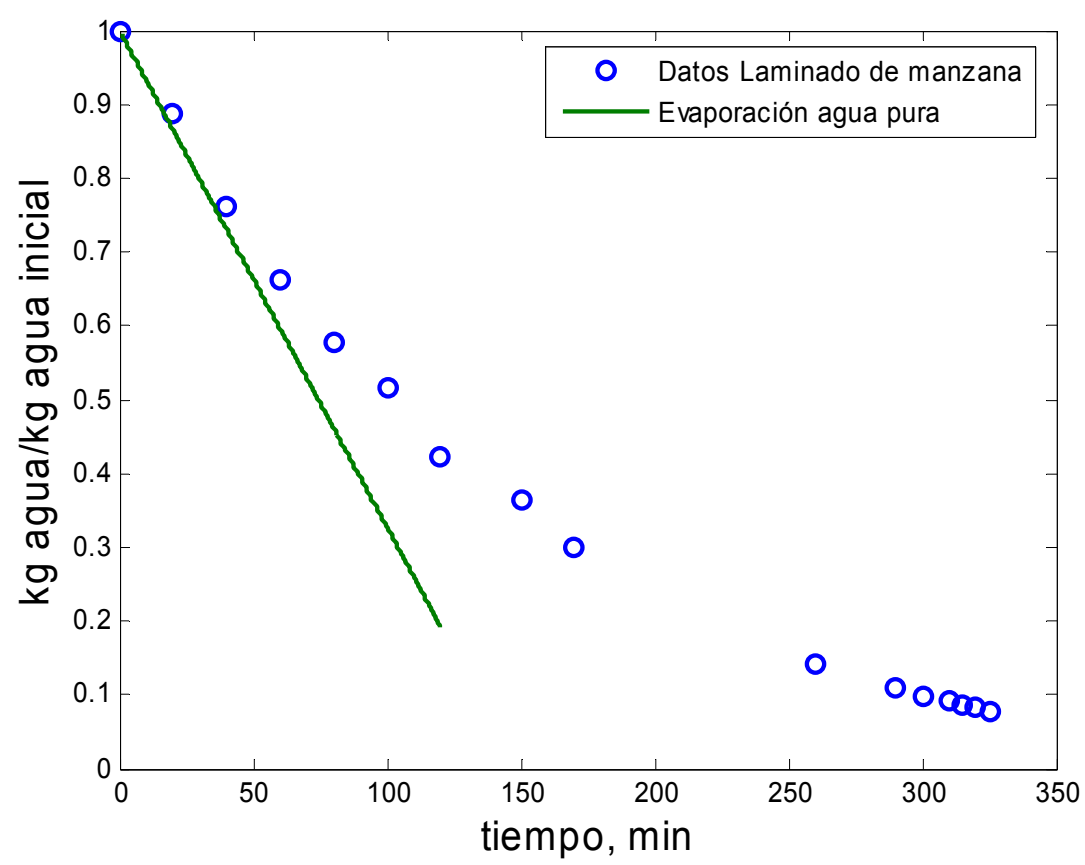

Figura 3 8. Curvas de secado para la Formulación $\mathrm{C}\left(\mathrm{W} / \mathrm{W}_{0}\right)$ y evaporación agua pura $\left(\mathrm{m}_{\mathrm{w}} / \mathrm{m}_{\mathrm{wo}}\right)$, temperatura del aire $60^{\circ} \mathrm{C}$, Velocidad del aire $2 \mathrm{~m} / \mathrm{s}$.

Se observa en la Figura 3.8 que al inicio del secado tanto el agua pura como la formulación tienen una velocidad de deshidratación comparable. En rigor es algo menor en esta última, la que luego disminuye más todavía por la resistencia difusional y la reducción de la fuerza impulsora para la transferencia de materia, causada por la disminución de humedad.

\subsubsection{Envasado del producto}

Para preservar los productos deshidratados durante el almacenamiento se reconocen los factores siguientes como causantes de deterioro: humedad, temperatura del medio y tiempo de almacenamiento, nivel de oxigeno y luz (Krochta, 2007). Por esta razón para la conservación de los geles se consideró un material de envase que proporcionara barreras al oxigeno, muy baja permeabilidad al vapor de agua y que evitara el paso de la luz. Un rango de materiales de envase que tienen estas características son los conocidos como envases retortables. Estos pueden ser laminados flexibles que pueden 
ser sometidos a procesos térmicos hasta cierto límite sin perder sus características estructurales, combinando las ventajas de los envases metálicos y plásticos. Se los puede adquirir en la forma de película (en rollos), o bien en envases preformados (Holdsworth y Simpson, 2007).

El envase utilizado para conservar los geles durante el almacenamiento fue el denominado CRYOVAC M7340, provisto gentilmente por la empresa Sealed Air (Figura 3.9 y 3.10). Este material para envase está compuesto por capas de: PET (polietileno tereftalato) para la resistencia al calor, Aluminio como barrera a la luz y la humedad, Poliamida (nylon) para la resistencia mecánica y EVOH (Etilen Vinil Alcohol) como barrera al oxígeno (Holdsworth y Simpson, 2007). Las características técnicas del laminado se encuentran en la Tabla 3.3

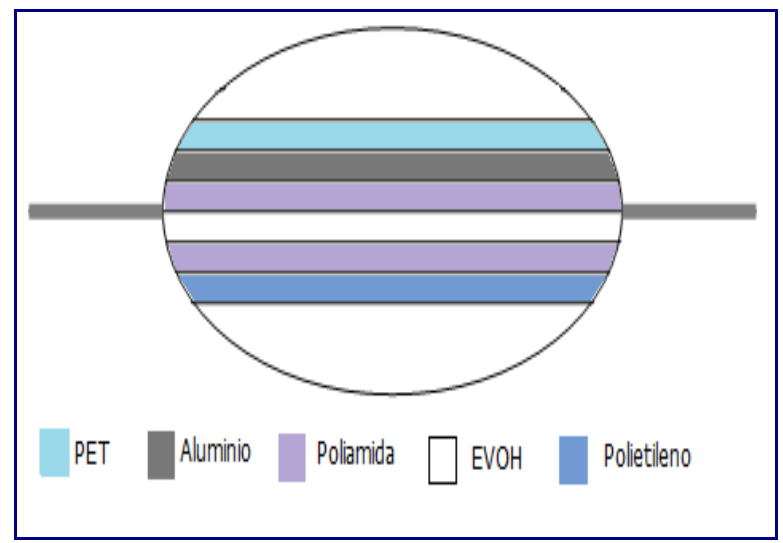

Figura 3 9. Capas que forman el material de envase.

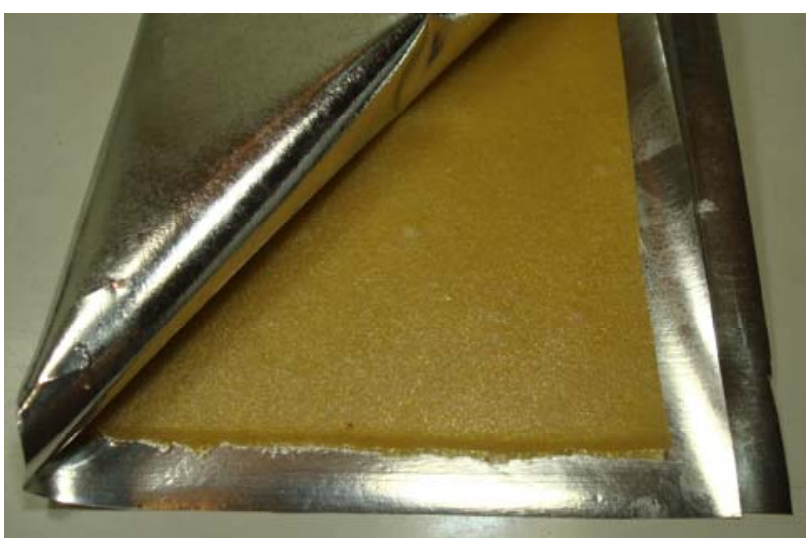

Figura 3 10. Gel péctico en el envase CRYOVAC M7340 
Tabla 3 3 Características técnicas del laminado para empaque

\begin{tabular}{|c|c|c|c|}
\hline DATOS DEL LAMINADO & Unidad & Vabres & Detem in ación \\
\hline \multicolumn{4}{|c|}{ PROPIEDADES DE APLICACIÓN } \\
\hline Temperatura de Sellado & ${ }^{\circ} \mathrm{C}$ & $130-200$ & \\
\hline Tratamiento Térmico & ${ }^{\circ} \mathrm{C}$ & hasta 100 & \\
\hline \multicolumn{4}{|l|}{ PROPIEDADES FÍSICAS } \\
\hline Rotura por elongación & $\%$ & $50 / 70$ & ASTMD-882 \\
\hline Fuerza Tensil & $\mathrm{Kg} / \mathrm{cm}^{2}$ & --- & ASTMD-882 \\
\hline Fuerza de sellado & $\mathrm{Kg} / 25 \mathrm{~mm}$ & 4 & COV-E243 \\
\hline Opacidad & $\%$ & --- & ASTMD-1003 \\
\hline Brillo & Unidad de Brillo & 90 & ASTMD-2457 \\
\hline \multicolumn{4}{|l|}{ PERMEABILIDAD } \\
\hline - $\mathrm{O}_{2}$ a $23^{\circ} \mathrm{C}, 0 \%$ R.H. & $\mathrm{cm}^{3} / 24 \mathrm{~h} \mathrm{~m} \mathrm{~m}^{2}$ bar & Max. 1,0 & ASTMD-3985 \\
\hline - $\mathrm{CO}_{2}$ a $23^{\circ} \mathrm{C}, 0 \%$ R.H. & $\mathrm{cm}^{3} / 24 \mathrm{~h} \mathrm{~m}^{2}$ bar & Max. 1,0 & ASTMD-1434 \\
\hline - MVTR $^{1}$ a $23^{\circ} \mathrm{C}, 90 \%$ R.H. & $\mathrm{gr} / 24 \mathrm{~h} \mathrm{\textrm {m } ^ { 2 } \text { bar }}$ & Max. 1,0 & ASTME-96 \\
\hline \multicolumn{4}{|c|}{ LEYES QUE LO APRUEBAN: Legislación de la FDA, la EU y SENASA } \\
\hline${ }^{1} \mathbf{M T}$ & nisión de vapor & agua & \\
\hline
\end{tabular}


CAPÍTULO IV

EVOLUCIÓN DE PARÁMETROS FISICOQUÍMICOS Y POBLACIÓN MICROBIANA 


\section{$4.1 \quad$ INTRODUCCIÓN}

Para evaluar la calidad durante el almacenamiento a temperatura ambiente, se realizó el seguimiento de los siguientes parámetros fisicoquímicos: actividad acuosa $\left(a_{w}\right)$, Humedad, pH, y contenido de sólidos solubles ('Brix).

Las muestras evaluadas se encontraban envasadas individualmente $\mathrm{y}$ almacenadas en un cuarto acondicionado para mantener constantes la humedad relativa a $60 \%$ y la temperatura a $20^{\circ} \mathrm{C}$; los análisis se realizaron durante siete meses con una periodicidad de un mes. Para determinar si existían diferencias a lo largo del tiempo, a los resultados obtenidos se les realizó un análisis estadístico de varianza (ANOVA) $(p<0,05)$.

Inicialmente se determinó el contenido de agua y la cantidad de sólidos solubles presente en los geles, ya que estos parámetros definen en parte la estructura final que estos tendrán; si hay mucha agua presente no se formará el gel y si hay muy poca el gel será poco flexible debido a que el alto contenido de sólidos endurece la estructura.

Se hace necesaria la determinación de la actividad acuosa $\left(a_{w}\right)$, porque su valor puede relacionarse con la perdida de calidad de los productos deshidratados ya que puede promover o inhibir algunos fenómenos dentro de la matriz del alimento, entre estos la reacciones de Maillard (que generan el pardeamiento no enzimático) y el desarrollo de los microorganismos, según se muestra cualitativamente en un mapa de estabilidad general de alimentos (Figura 4.1.). (Valentas y colab., 1997) 


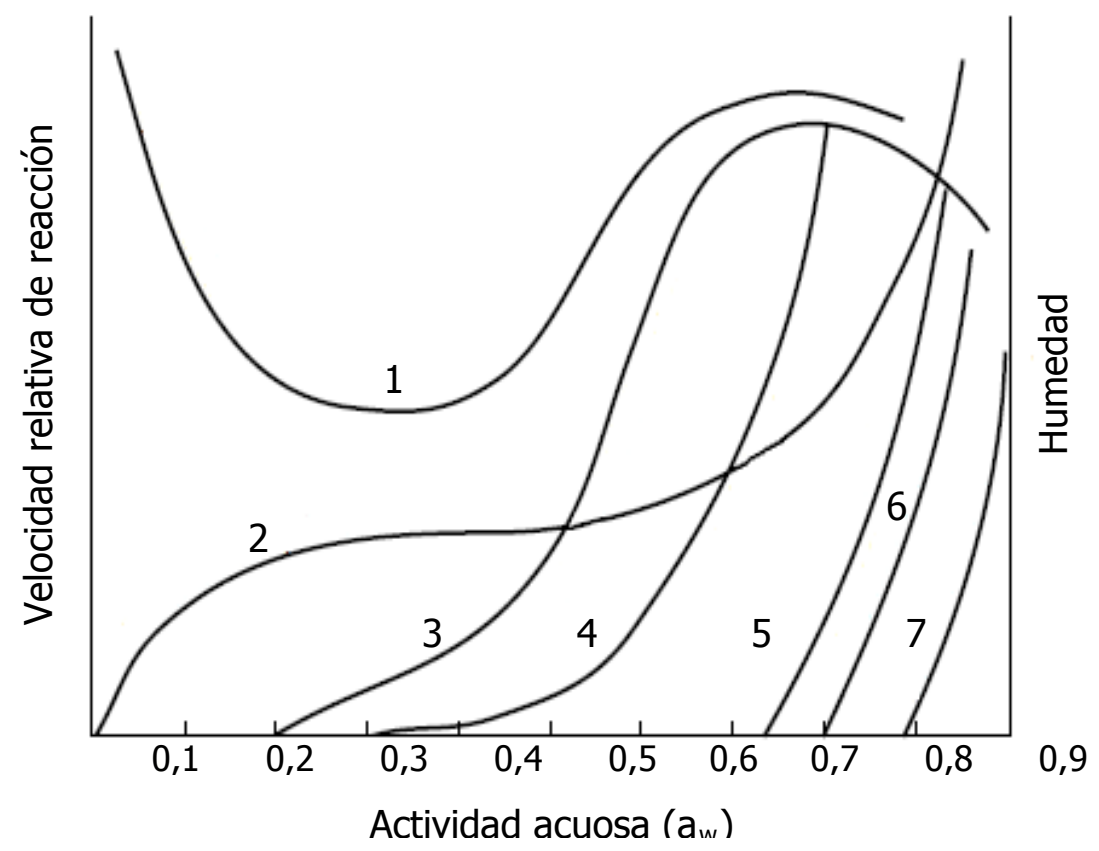

Figura 4.1 . Velocidad de alteración de los alimentos según su actividad acuosa

(1- Oxidación de lípidos, 2- Isoterma de porción (lectura de las ordenadas del lado derecho), 3- Pardeamiento no enzimático, 4- Actividad enzimática, 5-Mohos, 6-Levaduras, 7-Bacterias)

La actividad acuosa es una propiedad termodinámica definida como el cociente entre la presión de vapor de saturación del agua en una solución o alimento $\left(p_{v}\right)$ y la presión de saturación de vapor del agua pura a la misma temperatura $\left(\mathrm{p}_{\mathrm{s}}\right)$ (Rahman, 2009). Esta propiedad puede determinarse una atmósfera de aire en equilibrio que rodee la muestra en una pequeña cámara:

$$
\mathrm{a}_{\mathrm{w}}=\frac{\mathrm{p}_{\mathrm{v}}}{\mathrm{p}_{\mathrm{s}}}=\frac{\operatorname{HRE}(\%)}{100}
$$

Donde HRE es la humedad relativa de equilibrio (\%) de la atmósfera previamente mencionada. De hecho, la actividad acuosa del aire coincide con su humedad relativa expresada en forma decimal y es igual a la del alimento, al lograrse el equilibrio con éste (Giner y Gely, 2005).

La actividad del agua pura se considera igual a la unidad, de manera que la de una solución o alimento es inferior. Esto se debe a la reducción de la presión de vapor debido a los diferentes tipos de unión que forma con el alimento (Cheftel y Cheftel, 1992). 
Por último se realizó el seguimiento de la población microbiana. Este análisis se realizó para asegurar que el producto fuera inocuo para los potenciales consumidores. Los laminados deshidratados de fruta tienen características que previenen el crecimiento de las bacterias, dado que éstas, como se ve en la Tabla 4.1 (Beuchat, 1981), sólo crecen a valores de $a_{w}$ superiores a 0,86 . El bajo $\mathrm{pH}$ crea otra barrera para el crecimiento (Leistner y Gould, 2002) permitiendo que solo los considerados acidófilos puedan reproducirse; los microorganismos que son capaces de proliferar en este medio y que por tanto se pueden encontrar en productos vegetales son los mohos y levaduras, éstos son fácilmente encontrados en alimentos donde la matriz es menos favorable para el crecimiento bacteriano por el bajo $\mathrm{pH}(5 \circ<5)$, baja humedad, $\mathrm{a}_{\mathrm{w}} \approx 0.75$, alto contenido en sal o azúcar, baja temperatura de almacenamiento y la presencia de antibióticos. Por tal razón, fue éste el grupo de microorganismos seleccionado para realizar los análisis de población microbiana. 
Tabla 4.1. Valores críticos de $a_{w}$ para el almacenamiento de microorganismos en los alimentos

\begin{tabular}{|c|c|c|c|c|}
\hline$a_{w}$ & Bacteria & Moho & Levadura & Producto típico \\
\hline 0.97 & $\begin{array}{l}\text { Clostridium botulinum } \\
\text { Pseudomonas }\end{array}$ & ---- & ----- & \multirow{2}{*}{$\begin{array}{l}\text { carne fresca, frutas } \\
\text { y verduras, frutas y } \\
\text { verduras enlatadas }\end{array}$} \\
\hline 0.95 & $\begin{array}{c}\text { Escherichia coli } \\
\text { Clostridium perfringens } \\
\text { Salmonella spp. } \\
\text { Vibrio cholerae }\end{array}$ & ---- & ----- & \\
\hline 0.94 & $\begin{array}{c}\text { Clostridium botulinum } \\
\qquad A, B \\
\text { Vibrio parahemolyticus }\end{array}$ & Stachybotrys atra & ----- & \multirow{5}{*}{$\begin{array}{l}\text { Algunos quesos, } \\
\text { carne curada } \\
\text { (jamón), productos } \\
\text { de panadería }\end{array}$} \\
\hline 0.93 & Bacillus cereus & Rhizopus nigricans & ----- & \\
\hline 0.92 & Listeria moncytogenes & ----- & ----- & \\
\hline 0.91 & Bacillus subtilis & ----- & ----- & \\
\hline 0.9 & $\begin{array}{c}\text { Staphylococcus aureus } \\
\text { (anaerobio) }\end{array}$ & Trichotheciun roseum & $\begin{array}{c}\text { Saccharomyces } \\
\text { cerevisiae }\end{array}$ & \\
\hline 0.88 & ----- & ----- & candida & \multirow{8}{*}{$\begin{array}{l}\text { leche condensada, } \\
\text { quesos madurados, } \\
\text { salamines, carne } \\
\text { seca, jugo de fruta } \\
\text { concentrado, }\end{array}$} \\
\hline 0.87 & $\begin{array}{c}\text { Staphylococcus aureus } \\
\text { (aerobio) }\end{array}$ & ----- & ----- & \\
\hline 0.85 & ----- & Aspergillus clavatus & ----- & \\
\hline 0.84 & $\begin{array}{ll}---- \\
\end{array}$ & Byssochlamys nivea & $\begin{array}{ll}---- \\
\end{array}$ & \\
\hline 0.83 & ----- & $\begin{array}{l}\text { Penicillium expansum } \\
\text { Penicillium islandicum } \\
\text { Penicillium viridicatum }\end{array}$ & $\begin{array}{c}\text { Debarymoces } \\
\text { hansenii }\end{array}$ & \\
\hline 0.82 & ----- & $\begin{array}{l}\text { Aspergillus fumigatus } \\
\text { Aspergillus parasiticus }\end{array}$ & ----- & \\
\hline 0.81 & ----- & $\begin{array}{l}\text { Penicillium cyclopium } \\
\text { Penicilium patulum }\end{array}$ & & \\
\hline 0.8 & ---- & & $\begin{array}{c}\text { Saccharomyces } \\
\text { bailii }\end{array}$ & \\
\hline 0.79 & ----- & Penicillium martensii & & \multirow{5}{*}{$\begin{array}{c}\text { Mermelada, } \\
\text { mazapan, frutas } \\
\text { crsitalizadas, higos } \\
\text { deshidratados, } \\
\text { pescado salado y } \\
\text { seco. }\end{array}$} \\
\hline 0.78 & ----- & Aspergillus flavus & & \\
\hline 0.77 & ----- & $\begin{array}{c}\text { Aspergillus niger } \\
\text { Aspergillus ochraceous }\end{array}$ & ---- & \\
\hline 0.75 & ----- & $\begin{array}{l}\text { Aspergillus restrictus } \\
\text { Aspergillus candidus }\end{array}$ & ----- & \\
\hline 0.71 & ----- & Eurotium chevalieri & ---- & \\
\hline 0.7 & ----- & Eurotium amstelodami & ----- & \multirow{4}{*}{$\begin{array}{l}\text { Frutas secas, } \\
\text { licores, goma de } \\
\text { mascar alimento } \\
\text { para mascotas. }\end{array}$} \\
\hline 0.62 & ----- & ----- & $\begin{array}{c}\text { Saccharomyces } \\
\text { rouxii }\end{array}$ & \\
\hline 0.61 & ----- & Monascus bisporus & ----- & \\
\hline 0.6 & \multicolumn{3}{|c|}{ no hay crecimiento microbiano } & \\
\hline $0.2-0.5$ & \multicolumn{3}{|c|}{ no hay crecimiento microbiano } & $\begin{array}{l}\text { caramelos, miel, } \\
\text { pasta, galletas. }\end{array}$ \\
\hline
\end{tabular}




\section{MATERIALES Y MÉTODOS}

4.2.1 Determinación del contenido de sólidos solubles.

Para determinar la concentración de sólidos solubles se utilizó un refractómetro de Abbé siguiendo la norma 932.12(AOAC). La lectura obtenida se reportó como ${ }^{\circ} B r i x$.

\subsubsection{Determinación de $\mathrm{pH}$}

A efectos de medir el pH se utilizó un instrumento marca Altronix TPA-V, de lectura digital que consiste en un potenciómetro conectado a un electrodo alpha PW-40 y a un sensor de temperatura.

Antes de cada determinación se calibró el equipo con dos soluciones reguladoras, de $\mathrm{pH} 4$ y 7 (Anedra). Para las mediciones, se adicionaron cinco mililitros de agua destilada previamente hervida a dos gramos de muestra. Esto permite formar una pasta uniforme. La temperatura se dejo estabilizar en un cuarto a $20 \pm 0,5^{\circ} \mathrm{C}$. Se sumergió el electrodo en la muestra y el valor del pH se leyó directamente en el visor digital del potenciómetro, luego de aproximadamente un minuto. La diferencia máxima admisible en el resultado de pruebas efectuadas por triplicado, no debe exceder las 0.1 unidades de pH. En caso contrario se debe repetir la determinación.

\subsubsection{Determinación de actividad de agua}

El equipo AQUALAB serie 3 (Figura 4.2.), emplea el método de determinación de punto de rocío. En él, la muestra es equilibrada con el aire presente en el espacio de cabeza de una cámara sellada que contiene un espejo, un sensor óptico, un ventilador y un termómetro infrarrojo (Figura 4.3). El ventilador interno genera una circulación de aire que reduce el tiempo de equilibrio entre muestra y espacio de cabeza. El equilibrio se logra sin pérdida ni ganancia considerable de humedad para la muestra en virtud de que ésta es mucho mayor a la del aire de cabeza y, sobre todo, que la del vapor contenido en él. 
En el equilibrio, la humedad relativa del aire en la cámara es la misma que la actividad acuosa de la muestra. Una celda termoeléctrica por efecto Peltier controla la temperatura del espejo. Un diodo emisor de luz ilumina directamente al espejo, siendo esta luz reflejada hacia el sensor óptico, que registra un cambio en la reflectividad cuando se produce condensación sobr el espejo. Al cabo de una sucesión de condensaciones y evaporaciones, un sensor de temperatura embutido en el espejo mide la temperatura de rocío.

Adicionalmente un termómetro infrarrojo sin contacto mide la temperatura de la superficie de la muestra, que está en equilibrio con la temperatura de bulbo seco del aire del espacio de cabeza. Las dos temperaturas mencionadas se utilizan para calcular la humedad relativa del aire, que en equilibrio con la muestra se visualiza como actividad acuosa de ésta.

El rango de medición de $a_{w}$ se encuentra ente 0,03 y 1 , con una resolución de $\pm 0,001$. La medición normalmente se logra en 5 minutos. El equipo exhibe los datos de actividad acuosa y temperatura de equilibrio en un visor digital.

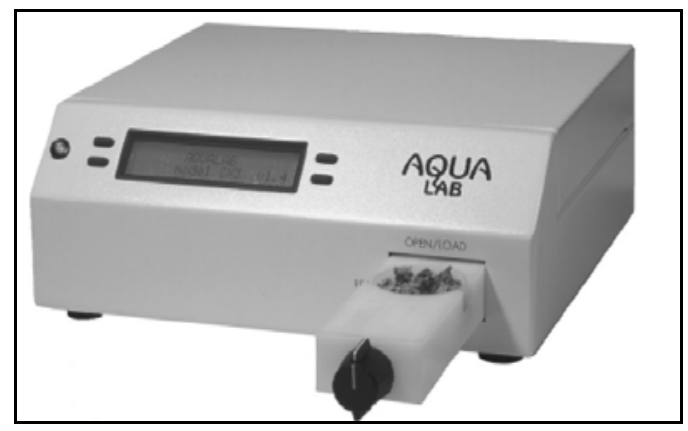

Figura 42 Equipo AQUALAB serie 3

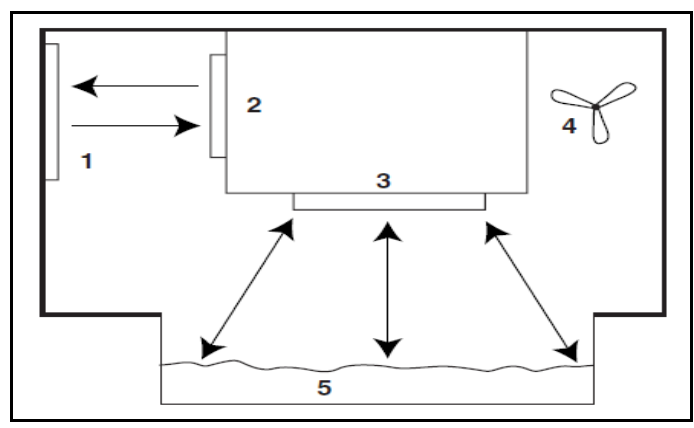

Figura 4.3. Modelo del funcionamiento interno del AQUALAB

(1-espejo, 2-sensor óptico, 3-termómetro infrarrojo, 4-micro ventilador, 5-porta muestra cargado)

Esta determinación de $a_{w}$ en vegetales está avalada por el Método oficial AOAC 978.18 (AOAC, 1998). 


\subsubsection{Determinación de mohos y levaduras}

Todos los procedimientos deben realizarse en zonas estériles y por duplicado, con este fin se trabajó dentro de una cámara de flujo laminar para asegurar que no haya contaminación proveniente del ambiente.

Un ventilador fuerza el paso del aire en flujo laminar a través de un filtro de gran superficie (filtro HEPA, High Efficiency Particulate Absorbing) situado en la pared frontal (flujo horizontal) y que con una eficiencia del $99.999 \%$ retiene las partículas de un tamaño superior a un cierto límite, que en este caso es de $0.2 \mu \mathrm{m}$ (Carlberg, 2005).

Se introdujeron cinco gramos de muestra y $45 \mathrm{~mL}$ de agua peptona estéril para crear una dilución de 1:10 en una bolsa de Stomacher. Esta se colocó en el Homogeneizador (Figura 4.4) durante un minuto para lograr la homogeneización de la muestra.

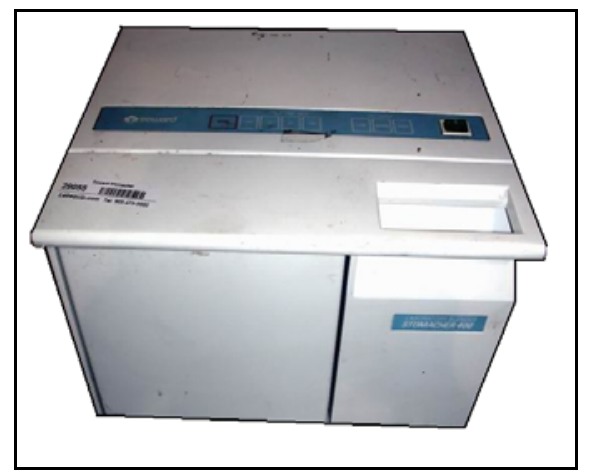

Figura 4 .4 . Homogenizador Seward Stomacher 400

El método de siembra que se utilizó es la denominada siembra por inmersión: se coloca un mililitro de inóculo en una placa o caja de Petri y sobre el mismo se vierte el medio de cultivo agar YGC (yeast glucose chloramphenicol) previamente fundido (Anexo 4).

Se agitan las cajas y se espera a que el medio solidifique para luego incubarlo durante 5 días a $25^{\circ} \mathrm{C}$. Pasado el tiempo de incubación se contaron las colonias presentes de hongos y levaduras por separado.

Para calcular las unidades formadoras de colonias por gramo o por mililitro de muestra dependiendo del estado físico de la muestra analizada. Si se observan más de 10 colonias en la caja, se multiplica el número de éstas por el inverso de la dilución correspondiente. 
En el caso de las cajas que contengan menos de 10 colonias (UFC) de hongos y/o levaduras, se debe informar el número obtenido de UFC indicando la dilución correspondiente, sin trasladar el resultado a la muestra. En el caso de no encontrar colonias características de hongos y/o levaduras, el resultado a informar es: "menos de $10 \mathrm{UFC} / \mathrm{g}$ ó bien menos de $10 \mathrm{UFC} / \mathrm{mL}^{\prime}$ (Sensibilidad del Método). Para cualquiera de los casos citados se deberá reportar el tiempo de incubación empleado en la determinación (Velázquez, 2009). 


\subsection{RESULTADOS}

\subsubsection{Humedad y sólidos solubles}

El objetivo inicial fue el de generar muestras que tuvieran un contenido de humedad menor al exigido por la reglamentación y que no generara un gel demasiado duro, para esto el valor de humedad de los laminados preparados por deshidratación fue de $25 \%$ b.h. o 0,333 en base seca al comenzar el almacenamiento.

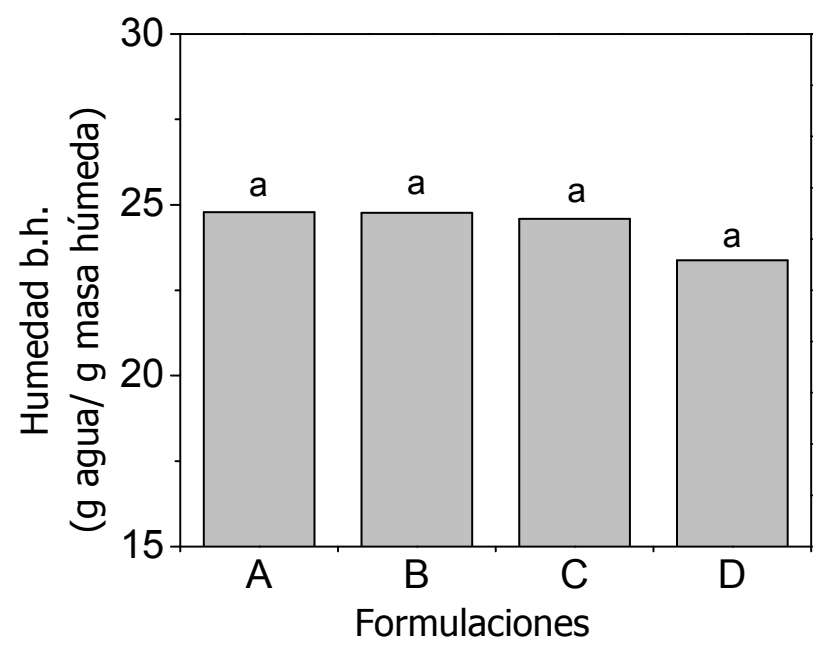

Figura 4 .5. Humedad media de las diferentes formulaciones evaluadas.

La Figura 4.5 muestra los valores de humedad media para las formulaciones, durante el almacenamiento del producto envasado. Letras iguales denotan la inexistencia de diferencias significativas (Tukey, $\mathrm{p}<0.05)$ )

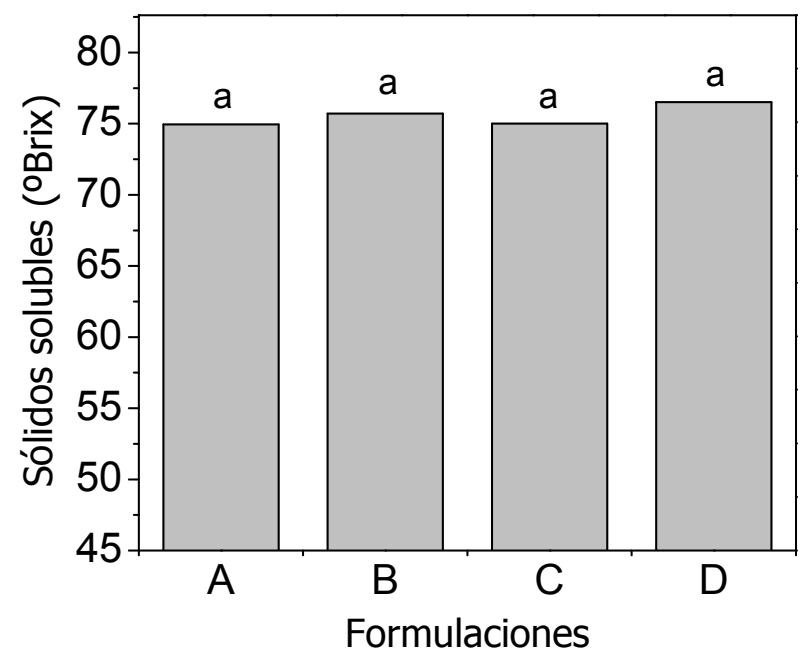

Figura 4 .6. Valor medio de la concentración de sólidos solubles para las formulaciones. 
Por su parte la concentración de sólidos solubles en los laminados preparados, de alrededor de $75^{\circ}$ Brix es mayor que la necesaria para producir la gelificación azúcar ácido pectina de alto metoxilo (55-65ºrix). Figura 4.6. Al cuantificar los valores de humedad y los sólidos solubles, la suma de ambos alcanza en la práctica el 100\%, debido a que el material poco soluble o no soluble está en pequeñas proporciones.

\subsection{2 $\mathrm{pH}$}

El valor de pH inicial del puré de manzana con el que se realizaron las formulaciones fue de 3,50. Luego de la adición de ácido cítrico y los demás componentes, la formulación redujo su pH a 3,30 el que no cambió significativamente durante el tiempo de almacenamiento (Figura 4.7)

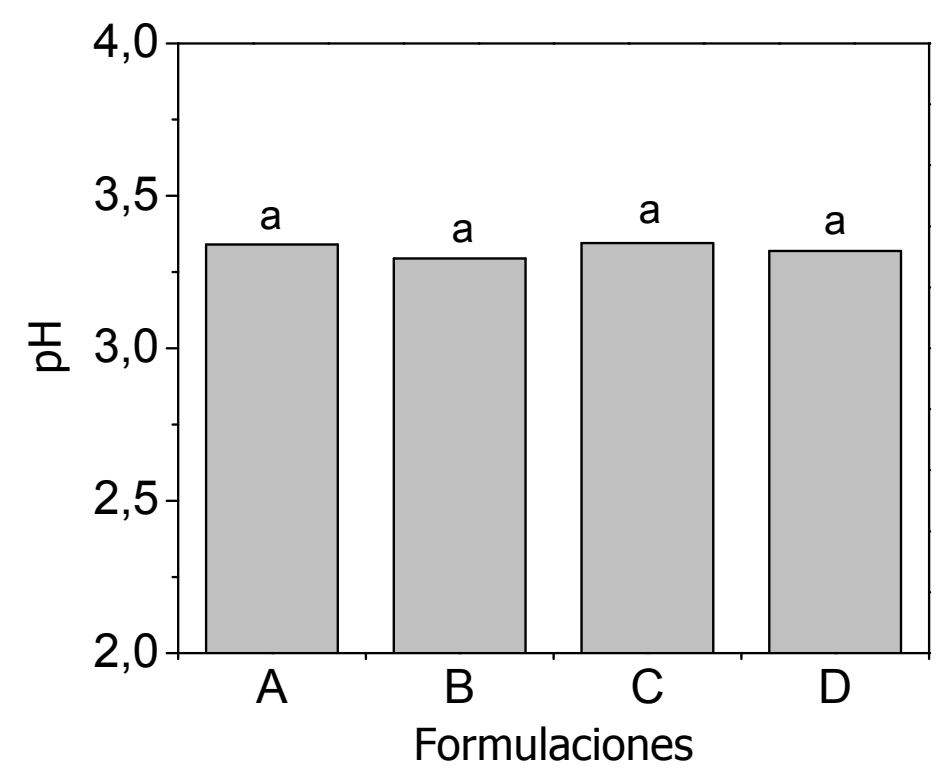

Figura 4 .7 . Valores de pH medio para cada formulación a lo largo del tiempo de almacenamiento.

Letras iguales denotan la inexistencia de diferencias significativas (Tukey, $p<0.05$ )

\subsubsection{Actividad acuosa}

Las mediciones de actividad acuosa se realizaron por triplicado para cada formulación y el promedio de éstas se mantuvo durante el almacenamiento en un valor de 0,7 que no 
cambió significativamente entre ellas (Figura 4.8) siendo éste un valor práctico de seguridad para almacenado de alimentos (Chirife, 2010).

En este valor de $a_{w}$, el pardeamiento no enzimático y la actividad enzimática presentan velocidades relativas considerables, de acuerdo con la Figura 4.1, pero como las enzimas del producto han sido inactivadas, se evaluará el cambio de color en el capítulo siguiente como causado por pardeamiento no enzimático. Este fenómeno puede determinar la duración del almacenamiento y se verá en el capítulo siguiente.

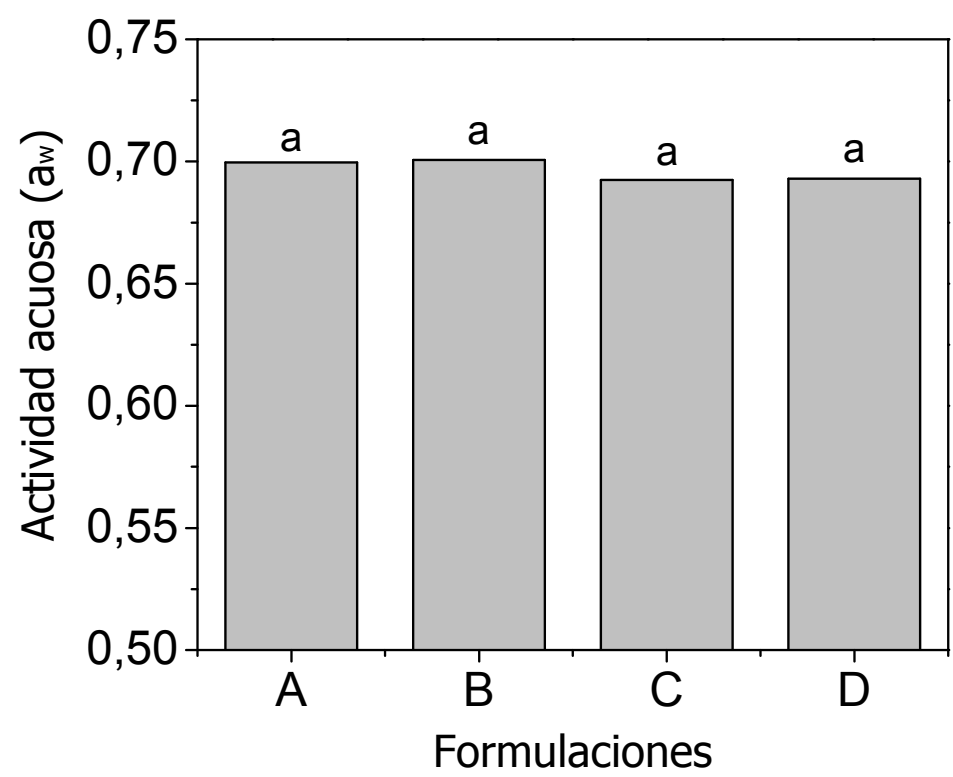

Figura 4 .8. Valor medio de la actividad acuosa $\left(a_{w}\right)$ durante el almacenamiento. (Letras iguales denotan la inexistencia de diferencias significativas (Tukey, $\mathrm{P}<0.05$ ))

\subsubsection{Población microbiana}

A pesar de las características del laminado (bajo $\mathrm{pH}$ y $\mathrm{a}_{\mathrm{w}}$ intermedia), se realizó un análisis para determinar la posible existencia de bacterias en el medio, obteniéndose un resultado negativo.

El número de unidades formadoras de colonias (UFC) de mohos y levaduras por gramo de muestra no deben sobrepasar el valor admitido para alimentos deshidratados que es de unas 1000 UFC/ g, según Greensmith, (1998).

Se encontró un número escaso de mohos y levaduras. La Figura 4.9 muestra una placa incubada con colonias típicas de levaduras obtenida en los ensayos y en la Figura 4.10 una placa incubada con un moho. 


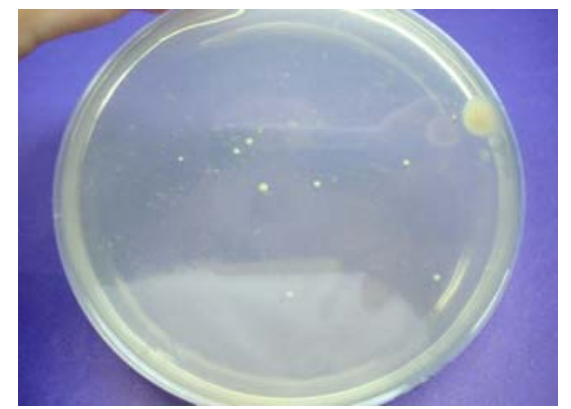

Figura 4 .9 Placa con crecimiento de levaduras, incubada durante 5 dias a $25^{\circ} \mathrm{C}$ en agar YGC.

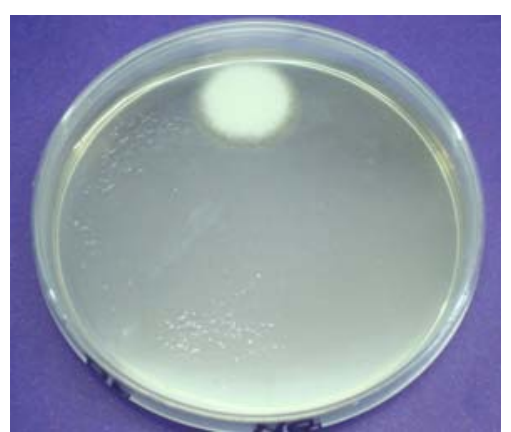

Figura 4 .10. Placa con desarrollo de un moho, incubada durante 5 dias a $25^{\circ} \mathrm{C}$ en agar YGC.

Para todas las placas analizadas en el almacenamiento, el valor de UFC/g fue menor al establecido como máximo admitido y estuvo en el rango de 50 - $100 \mathrm{UFC} / \mathrm{g}$ de levaduras y menos de $10 \mathrm{UFC} / \mathrm{g}$ de mohos para los laminados de las formulaciones $\mathrm{A}$, C, y D. El laminado de la formulación B para todo el almacenamiento no presentó crecimiento de microorganismos, por lo que se informa que tiene en su matriz menos de $10 \mathrm{UFC} / \mathrm{g}$ tanto de levaduras como de mohos.

Al no haberse observado diferencia en el contenido de humedad, aw, $\mathrm{pH}$ y contenido de sólidos solubles entre las formulaciones que contienen aditivos, se seleccionó de acuerdo al recuento de microorganismos la formulación $B$ (adicionada con metabisulfito de potasio). La calidad de la misma se evaluará junto a la formulación $\mathrm{A}$ (control), utilizando varios parámetros de calidad: variación de color, poder antioxidante y análisis sensorial. 
CAPÍTULO V

VARIACIONES DE COLOR DURANTE EL ALMACENAMIENTO 


\section{$5.1 \quad$ INTRODUCCIÓN}

El color es un atributo muy importante porque puede afectar la determinación del tiempo de vida útil. De hecho, el poder ser determinado a simple vista sin necesidad de probar el producto hace que las variaciones de color se constituyan en indicadores esenciales dentro de los análisis de calidad que se realizan a lo largo del almacenamiento.

Los cambios de color en productos de frutas y vegetales suelen vincularse a dos mecanismos: pardeamiento enzimático y pardeamiento no enzimático. De este último hay dos tipos de reacciones que pueden generar cambios de color, siendo una de ellas la reacción de Maillard, que se lleva a cabo entre azúcares reductores y aminoácidos y la otra son las reacciones de oxidación, por ejemplo de la vitamina C (MacDougall, 2002).

En el caso de los laminados de manzana, la materia prima se somete a un proceso térmico que inactiva las enzimas responsables del pardeamiento enzimático, motivo por el cual en el presente capítulo se estudiará la variación de color producida por mecanismos de pardeamiento no enzimático.

Para realizar una medición que sea similar a la percepción del ojo humano, se desarrollaron diferentes sistemas de color, equipos de medición y programas de análisis de imágenes digitales.

Para realizar el seguimiento del color de los productos pueden utilizarse varios métodos: colorimetría triestímulo, espectrofotometría (densidad óptica), escalas de color y programas de análisis de imágenes digitales, entre otros. Cada uno de ellos evalúa de forma particular el color utilizando diferentes escalas o patrones. Se hace necesario, en consecuencia, seleccionar una metodología adecuada para el sistema en estudio. Los más usados en la industria de los alimentos son los sistemas de determinación de color superficial triestímulo HunterLab o CIELAB (Commission Internationale de l'É clairage) y la determinación de densidad óptica a 420nm (CYTED, 2002). 
Por medio de estos sistemas se busca identificar las diferencias de color entre las muestras evaluadas y una de referencia, por ejemplo el valor a tiempo cero. Debido a las características de la matriz en estudio, la determinación de densidad óptica no se recomienda (Petriella y col., 1985). Uno de los parámetros que puede utilizarse para representar el pardeamiento es el "Índice de Pardeamiento", mejor conocido por su nombre en Inglés "Browning index" (BI), este parámetro que se puede determinar combinando las distintas coordenadas del espacio de color CIELAB para definir la variación de color en productos alimenticios que contienen azúcar (Buera y col., 1985/1986; Perez-Gago y col., 2006)

En este trabajo se utilizó un colorímetro Minolta CR-400, que reporta los parámetros triestímulo del espacio de color CIELAB, siendo estos L* (luminosidad, que va del blanco (valor $=100)$ al negro (valor $=0)$ ), a* (coordenada cromática en el eje del verde (valores negativos) al rojo (valores positivos)), b* (coordenada cromática en el eje del amarillo (valores negativos) al azul (valores positivos)). Con estos valores se calculó el BI, y a los resultados obtenidos de este se les ajustó un modelo matemático del tipo logístico para poder predecir las variaciones de color del producto a lo largo del tiempo durante el almacenamiento. 


\section{DETERMINACIÓN DEL COLOR}

\subsubsection{Equipo}

El instrumento utilizado para determinar el color de los laminados fue un colorímetro triestímulo Konica-Minolta CR-400 (Figura 5.1). Consta de un procesador de información y un cabezal, el que funciona conectado o independiente del procesador, por medio de un botón se dispara un haz de luz generado por una lámpara de xenón, que ilumina la muestra desde todas las direcciones mediante iluminantes de brillo y recibe la luz que la muestra refleja verticalmente mediante unas fibras de medición. Así se recrean las condiciones de iluminación difusa con las que normalmente se perciben los objetos.

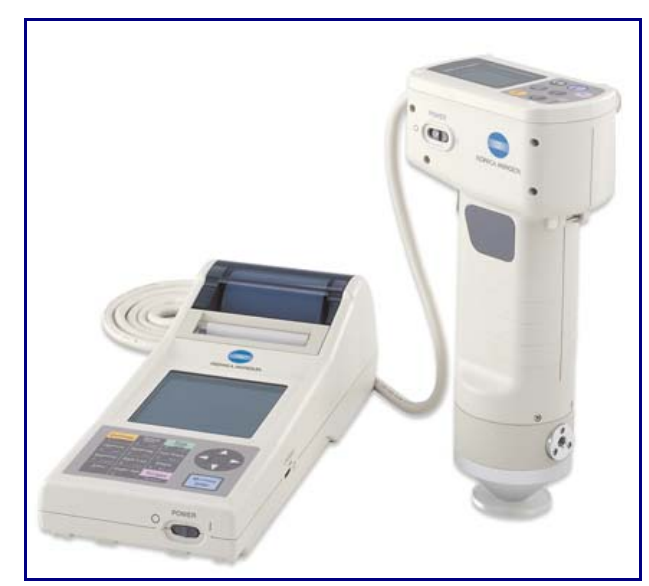

Figura 5 .1. Colorímetro Konica-Minolta CR-400, Cabezal y procesador de datos

\subsubsection{Metodología}

Para medir color en la muestra, se colocó el cabezal verticalmente sobre la superficie de ésta y se pulsó el botón para disparar el haz de luz (sin mover el cabezal durante la medida). Los valores obtenidos se visualizaron en la pantalla del instrumento.

Los valores mencionados, que se leyeron en la escala $L^{*} a * b *$, se transformaron a posteriori a la escala X (rojo), Y (verde), Z (azul) Ec. (5.1), (5.2) y (5.3) (Kang, 2006) y luego a la escala $x, y, Y$ Ec. (5.4), (5.5) y (5.6) con los que luego se calculará el índice de pardeamiento Ec (5.7) (Buera y col., 1985/1986; Gonzales y col., 1999). 


$$
\begin{gathered}
X=X_{n} *\left(\frac{a *}{500}+\frac{\left(L^{*}+16\right)}{116}\right)^{3} \\
Y=Y_{n} *\left(\frac{(L *+16)}{116}\right)^{3} \\
Z=Z_{n} *\left(\frac{-b *}{200}+\frac{\left(L^{*}+16\right)}{116}\right)^{3}
\end{gathered}
$$

Donde los valores del patrón son $\mathrm{Xn}=91,97, \mathrm{Yn}=93,8$ y Zn=107,98.

$$
\begin{aligned}
& X=\frac{X}{(X+Y+Z)} \\
& y=\frac{Y}{(X+Y+Z)} \\
& Y=Y \\
& B I=\frac{(x-0,31)}{0,172} * 100
\end{aligned}
$$




\subsection{RESULTADOS}

Las mediciones con el colorímetro triestímulo se realizaron por triplicado en la formulación A (control) y la formulación B (adicionada con metabisulfito de potasio), colocando sobre una superficie blanca el laminado de manzana. Esta superficie siempre fue la misma para evitar errores de medición debida a algún tipo de interferencia de color por parte de la superficie de apoyo.

Se observó que existe una tendencia a la variación del índice de pardeamiento, calculado con los promedios de los valores de $L^{*}, a^{*}$ y $b^{*}$ y por medio de las Ecs. (5.1) a (5.7) (Figura 5.2).

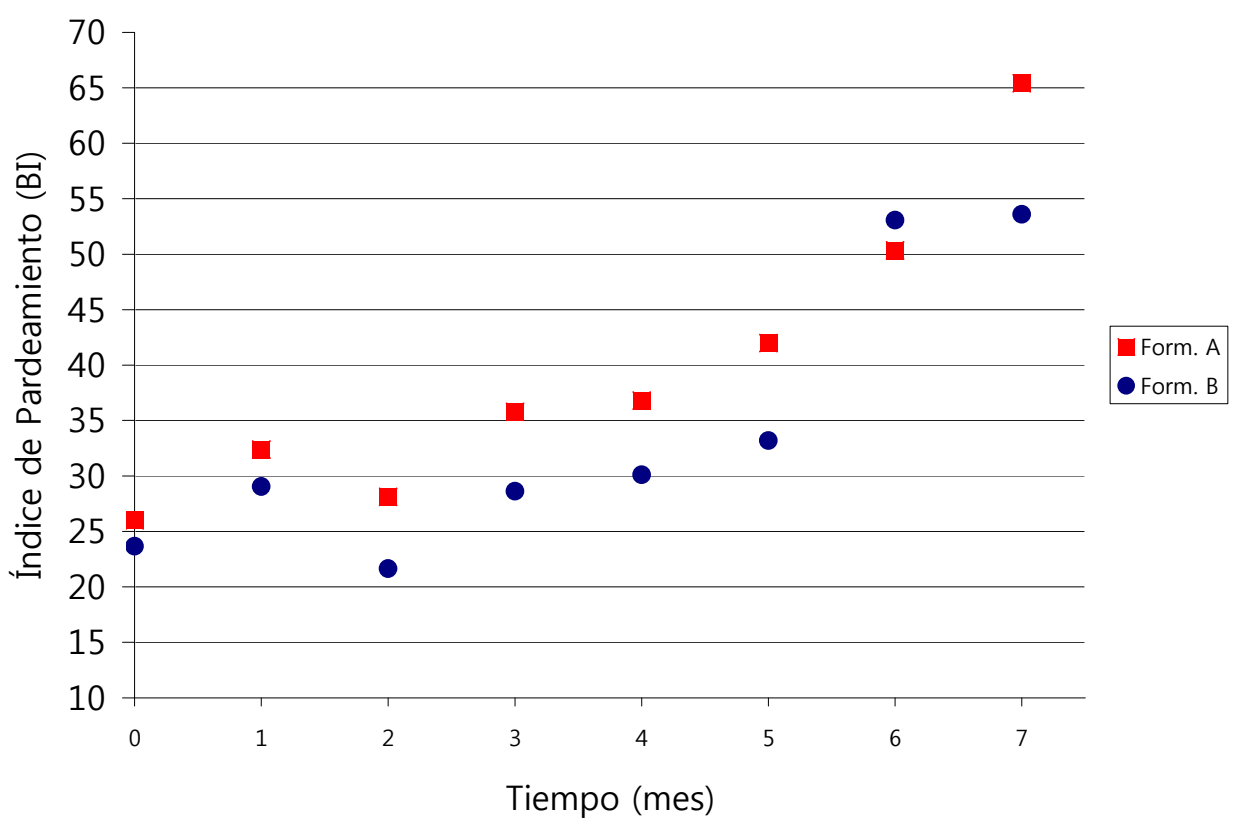

Figura 52 . Cambio del parámetro BI durante el almacenamiento.

El incremento del índice de pardeamiento se relaciona con la producción gradual de pigmentos producido por la reacción de Maillard de los azúcares reductores y la oxidación del ácido ascórbico, que se promueven en las condiciones de $\mathrm{a}_{\mathrm{w}}$ durante el almacenamiento, las que se sitúan en el intervalo de mayor efecto de estas reacciones, que va de $a_{w}=0,5$ a 0,8 (Sikorski, 2007). 
Se ajustaron diferentes modelos matemáticos a los datos: cinético de orden cero Ec. (5.8), cinético de primer orden Ec. (5.9) y modelo logístico Ec. (5.10) (Vaikousi y col., 2008), a efectos de describir el comportamiento de estos.

Cinética de orden cero $\quad B I=B I_{i}+k_{c} t$

Cinética de primer orden $\quad B I=B_{i} * \exp \left(k_{c} t\right)$

Modelo logístico $\quad B I=\frac{B I_{i}-B I_{\max }}{1+\left(t / t_{m}\right)^{p}}+B I_{\max }$

Donde $\mathrm{BI}_{\mathrm{i}}$ es un parámetro de ajuste, relacionado con el valor inicial del índice de pardeamiento, mientras $\mathrm{k}_{\mathrm{c}}\left(\mathrm{mes}^{-1}\right)$ es la constante cinética para los modelos de orden cero o uno. Con respecto al modelo logístico, $\mathrm{BI}_{\max }$ es el valor máximo que puede alcanzar el índice de pardeamiento, $\mathrm{p}$ un parámetro de ajuste fenomenológico y $\mathrm{t}_{\mathrm{m}} \mathrm{el}$ tiempo necesario para que $\mathrm{BI}$ alcance el valor $\left(\mathrm{BI}_{\mathrm{i}}+\mathrm{BI}_{\max }\right) / 2$, en mes.

Los modelos se ajustaron a los datos utilizando el programa OriginPro v8.1 (Origin, 2009). En la Tabla 5.1 se muestran los parámetros calculados para cada modelo y los índices de bondad de ajuste.

Tabla 5 .1. Parámetros de ajuste de los modelos cinéticos.

\begin{tabular}{|c|l|c|c|c|c|c|c|c|}
\hline \multirow{2}{*}{ Formulación } & \multirow{2}{*}{ Modelo } & \multirow{2}{*}{$\mathrm{r}^{2}$} & \multirow{2}{*}{$\mathrm{s}_{\mathrm{y}}$} & \multicolumn{5}{|c|}{ Parámetros de ajuste ( \pm desviación estándar) } \\
\cline { 5 - 10 } & & & $\mathrm{BI}_{\mathrm{i}}$ & $\mathrm{BI}_{\max }$ & $\mathrm{k}_{\mathrm{c}}$ & $\mathrm{t}_{\mathrm{m}}$ & $\mathrm{p}$ \\
\hline \multirow{3}{*}{$\mathrm{A}$} & Lineal & 0,815 & 5,57 & $22,59 \pm 3,59$ & ---- & $4,86 \pm 0,85$ & ---- & ---- \\
\cline { 2 - 9 } & Exponencial & 0,897 & 4,16 & $23,61 \pm 2,14$ & --- & $0,13 \pm 0,02$ & ---- & --- \\
\cline { 2 - 9 } & logístico & 0,941 & 3,14 & $29,28 \pm 2,18$ & $64,46 \pm 9,66$ & --- & $5.68 \pm 2,18$ & $2,86 \pm 2,25$ \\
\hline \multirow{3}{*}{$\mathrm{B}$} & Lineal & 0,697 & 6,82 & $18,87 \pm 4,40$ & --- & $4,35 \pm 1,05$ & ---- & ---- \\
\cline { 2 - 8 } & Exponencial & 0,789 & 5,69 & $19,62 \pm 2,88$ & --- & $0,14 \pm 0,03$ & --- & --- \\
\cline { 2 - 8 } & logístico & 0,910 & 3,71 & $26,59 \pm 1,66$ & $53,77 \pm 3,88$ & ---- & $5,23 \pm 0,37$ & $24,67 \pm 33,51$ \\
\hline
\end{tabular}

Donde $r^{2}$ es el coeficiente de determinación y $s_{y}$ el desvío típico de la predicción, definida como sigue

$$
\mathrm{s}_{\mathrm{y}}=\sqrt{\frac{\sum_{\mathrm{i}=1}^{\mathrm{N}}\left(\mathrm{y}_{\text {exp }, \mathrm{i}}-\mathrm{y}_{\text {calc, }}\right)^{2}}{\mathrm{GDL}}}
$$


Siendo GDL el número de grados de libertad, definidos como la diferencia entre el

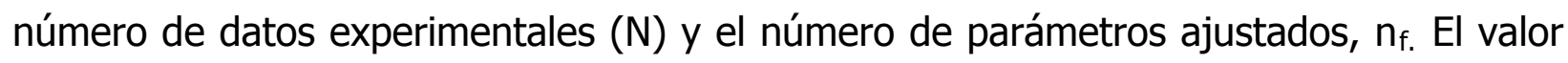
de $s_{y}$ se mide en las mismas unidades que la variable dependiente, en este caso el índice de pardeamiento, BI.

El modelo que presentó el mejor ajuste de acuerdo al coeficiente de determinación fue el logístico, representado en la Figura 5.3. Ésta, muestra los datos experimentales y el ajuste para las formulaciones.
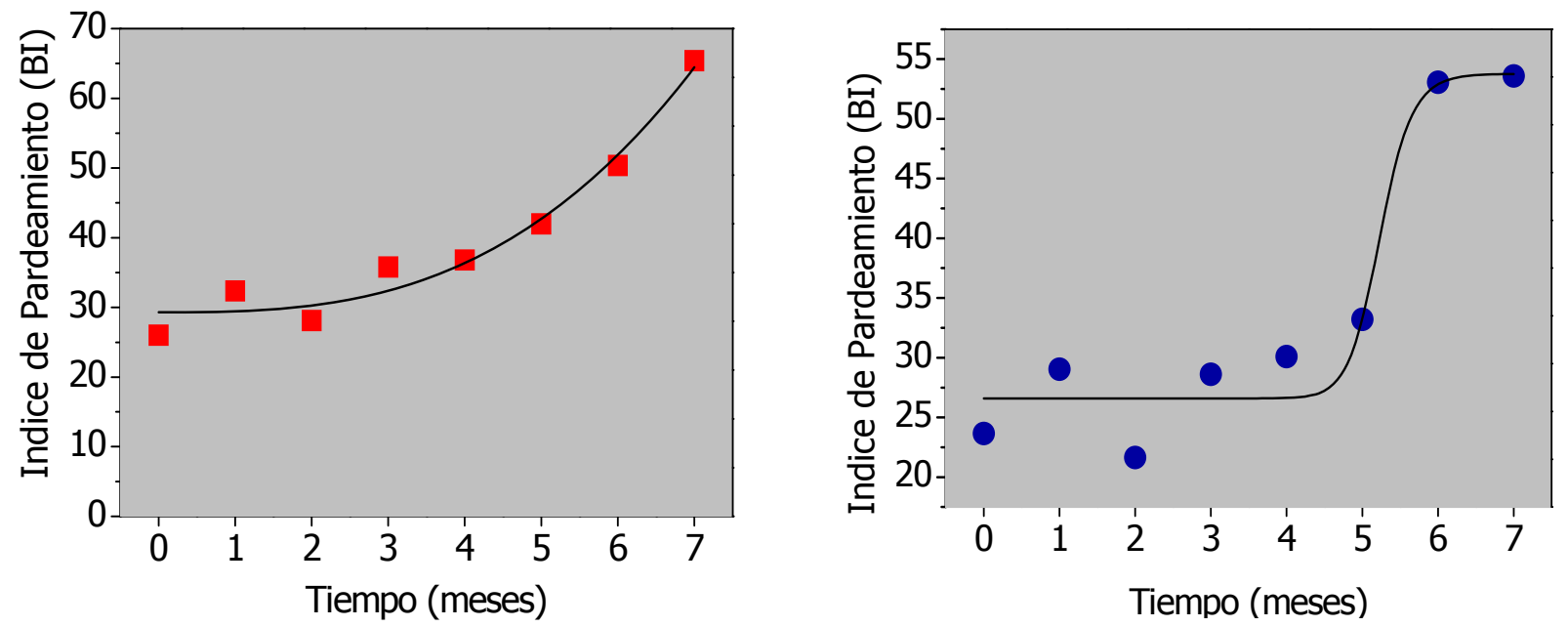

Figura 5 3. Variación de color en la laminados de manzana como Índice de pardeamiento (BI) para las formulaciones $A(\square)$ y $B(\bullet)$ Datos Experimentales, (---) modelo logístico.

Para realizar una comparación del cambio porcentual de color se tomaron los datos obtenidos por Picouet y col. (2009) para puré de manzanas Granny Smith con adición de jugo de limón (ácido cítrico), jarabe de fructosa-glucosa y extracto de acerola (rico en vitamina $\mathrm{C}$, como antioxidante). Este puré fue tratado con microondas, y se eligió por ser la formulación mas parecida a la desarrollada para los geles pécticos, aunque el tiempo de almacenamiento y las condiciones de proceso fueron diferentes.

El cambio de color del puré tratado con microondas, calculado como Indice de Pardeamiento a partir de los datos originales de $L^{*}$, $a^{*}$ y $b^{*}$, fue de $49,26 \%$ para 14 días de almacenamiento a $5^{\circ} \mathrm{C}$.

Para tener un marco de referencia, las variaciones de color encontradas en este trabajo de Tesis fueron expresadas como cambio porcentual respecto del valor inicial. 
Así, la variación en la formulación control durante el primer mes de almacenamiento fue de $24,5 \%$, mientras que para la formulación B no se observó una tendencia clara de cambio en el primer mes. El desarrollo de pardeamiento, fue entonces más rápido en la matriz publicada en la literatura. Una de las causas posibles es la mayor concentración inicial de monosacáridos reductores que facilita la reacción de Maillard; otra puede ser el pardeamiento de la vitamina $C$ agregada, y otra razón que podría citarse es que el índice de pardeamiento inicial fue más alto que en ésta Tesis: si predominara una cinética de primer orden, un mayor contenido inicial de pigmentos podría acelerar la reacción. 
CAPÍTULO VI

ACTIVIDAD ANTIOXIDANTE 


\subsection{INTRODUCCIÓN}

El consumo de alimentos que contengan antioxidantes en su mayoría frutas y verduras se ha incrementado en la actualidad ya que son sustancias químicas que se caracterizan por impedir o retrasar la oxidación de diversas sustancias principalmente de los ácidos grasos cuyas reacciones se producen tanto en los alimentos como en el organismo humano, otra de las funciones de los antioxidantes es facilitar el uso fisiológico del oxígeno ayudando a reducir los efectos del estrés oxidativo y la falta de oxígeno, formando complejos que mitigan las reacciones productoras de radicales libres (moléculas inestables de alta energía con electrones desapareados en sus órbitas exteriores, que tienden a reaccionar con otros compuestos). Se ha documentado científicamente en muchos casos que los antioxidantes son potenciadores de la salud y que su utilización supone entre otras cosas la prevención de riesgos de contraer cáncer, de problemas del corazón, degeneración macular y a la disminución del colesterol (Eberhardt y col., 2000).

Por estas razones se consideró importante estudiar el cambio de la actividad antioxidante en la matriz del laminado deshidratado de manzana para las formulaciones A (control) y B (adicionada con metabisulfito de potasio) durante el tiempo de almacenamiento.

La actividad antioxidante se determinó utilizando el ensayo de decoloración del radical catión estable $\mathrm{ABTS}^{*+}$ de la sal 2,2'azinobis-(3-etilbenzotiazolin 6-ácido sulfónico) diamonio (ABTS) (Re y col., 1999). Esta metodología se seleccionó por ser fácil de realizar, no ser costosa comparada con otras pruebas de este tipo (DPPH) y por permitir la obtención de resultados en forma relativamente rápida (Zulueta y col., 2009). El ensayo representa la pérdida del color azul-verdoso del radical en solución, en presencia de antioxidantes que es cuantificado como una disminución en la lectura de absorbancia, proporcional a la concentración de antioxidantes presentes. 


\subsection{MATERIALES Y MÉTODOS}

\subsubsection{Preparación de las muestras}

Para preparar el extracto etanólico, se cargó un termo con nitrógeno líquido y se pesaron aproximadamente $10 \mathrm{~g}$ de los laminados almacenados. Esta muestra se colocó en el colador o rejilla metálica para sumergirla en el nitrógeno líquido. Inmediatamente después de congelada, la muestra se trituró finamente en un molinillo Connoisserve Oster. Así, se evitó la descongelación de la muestra y se facilitó la extracción.

Se pesaron dos gramos de muestra congelada en tubos de centrífuga y se adicionaron cinco mililitros de etanol de $96^{\circ}$. Se homogeneizó la muestra y se conservó en lugar oscuro y refrigerado hasta ser centrifugada a $4^{\circ} \mathrm{C}$ y $14000-15000 \mathrm{rev} / \mathrm{min}$ durante 10 minutos. El sobrenadante obtenido se conservó en eppendorf de $1 \mathrm{ml}$ a $20^{\circ} \mathrm{C}$ hasta su uso.

\subsubsection{Ensayo de decoloración del radical $\mathrm{ABTS}^{*+}$}

El ensayo de decoloración del radical $\operatorname{ABTS}^{*+}$ (Re y col., 1999) es aplicable para estudiar los antioxidantes solubles en agua, en lípidos, compuestos puros y extractos de alimentos.

Al contactarse al catión preformado $\mathrm{ABTS}^{*+}$ con los antioxidantes de la muestra se produce una reacción de reducción del radical añadido para dar ABTS, cuyo grado de avance dependerá de la concentraron del antioxidantes. Para realizar la lectura de absorbancia se debe tener en cuenta que el radical tiene máximos de absorción a longitudes de onda de $645 \mathrm{~nm}, 734 \mathrm{~nm}$ y $815 \mathrm{~nm}$.

El radical $A B T S^{*+}$ fue preparado con reactivo ABTS $\left(\mathrm{C}_{18} \mathrm{H}_{24} \mathrm{~N}_{6} \mathrm{O}_{6} \mathrm{~S}_{4}\right)$ (Figura 6.1) solubilizado en agua a una concentración de $7 \mathrm{mM}$ y solución de persulfato de potasio $\left(\mathrm{K}_{2} \mathrm{~S}_{2} \mathrm{O}_{8}\right)$ 2,45 mM, en una relación estequiométrica 1:0,5, los que se dejaron reaccionar en la oscuridad a temperatura ambiente durante 12 a 16 horas. Para conservar el radical (Figura 6.2), se lo almacena en eppendorf de un $1 \mathrm{~mL}$ a $-18^{\circ} \mathrm{C}$ durante un máximo de 4 meses. 


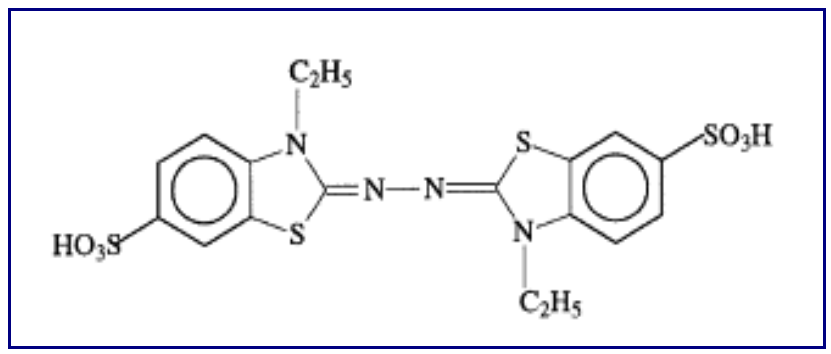

Figura 6.1 . Molécula de I ABTS que es incolora en solución.

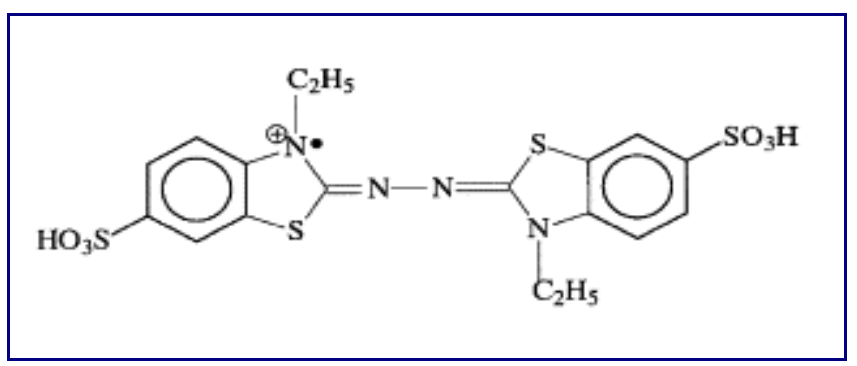

Figura 62 . Molécula del radical catión estable ABTS*+

Para su utilización, el radical $\mathrm{ABTS}^{*+}$ se descongeló en condiciones ambientes dentro del eppendorf y se sacaron alícuotas del mismo para diluir con etanol del $96^{\circ}$ hasta

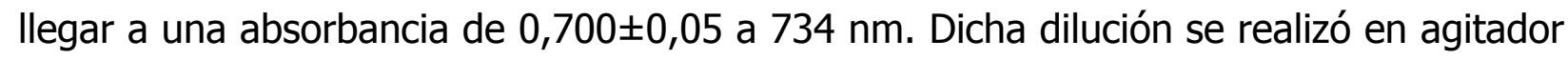
magnético, manteniéndose la agitación hasta estabilizar la lectura de absorbancia del reactivo, la que se dejó como base para el cálculo del porcentaje de reducción del ABTS $^{*+}$.

La reacción se llevó a cabo en tubos de ensayo colocando $10 \mu \mathrm{L}$ del extracto etanólico con $1 \mathrm{ml}$ del reactivo de $\mathrm{ABTS}^{*+}$. El sistema se agitó en un vortex y se esperaron 6 minutos para que evolucione la reacción. Luego se midió la absorbancia a 734 nm. El porcentaje de reducción de la absorbancia debe estar entre el 20 y 80 \% del valor base para que la medida sea válida.

Los resultados se expresan como porcentaje de reducción del $\mathrm{ABTS}^{*+}$ por gramo de materia seca, tomando como base la absorbancia del reactivo. 


\subsection{RESULTADOS}

Se realizaron los extractos etanólicos por duplicado a partir de las formulaciones $A$ (control) y B (adicionada con metabisulfito de potasio) mes a mes como se describe en 6.2.1. Todos los extractos se conservaron en un freezer a $-20^{\circ} \mathrm{C}$ hasta el final del almacenamiento, a efectos de ser analizados en una misma sesión de laboratorio.

Se realizó una curva de calibración con un patrón, que fue el ácido clorogénico por ser éste el compuesto fenólico mas abundante en las manzanas (Wu y col., 2007) para referir los resultados obtenidos del ensayo de decoloración como equivalentes de ácido clorogénico en micromoles por gramo de materia seca, el resultado se muestra en la Figura 6.3.

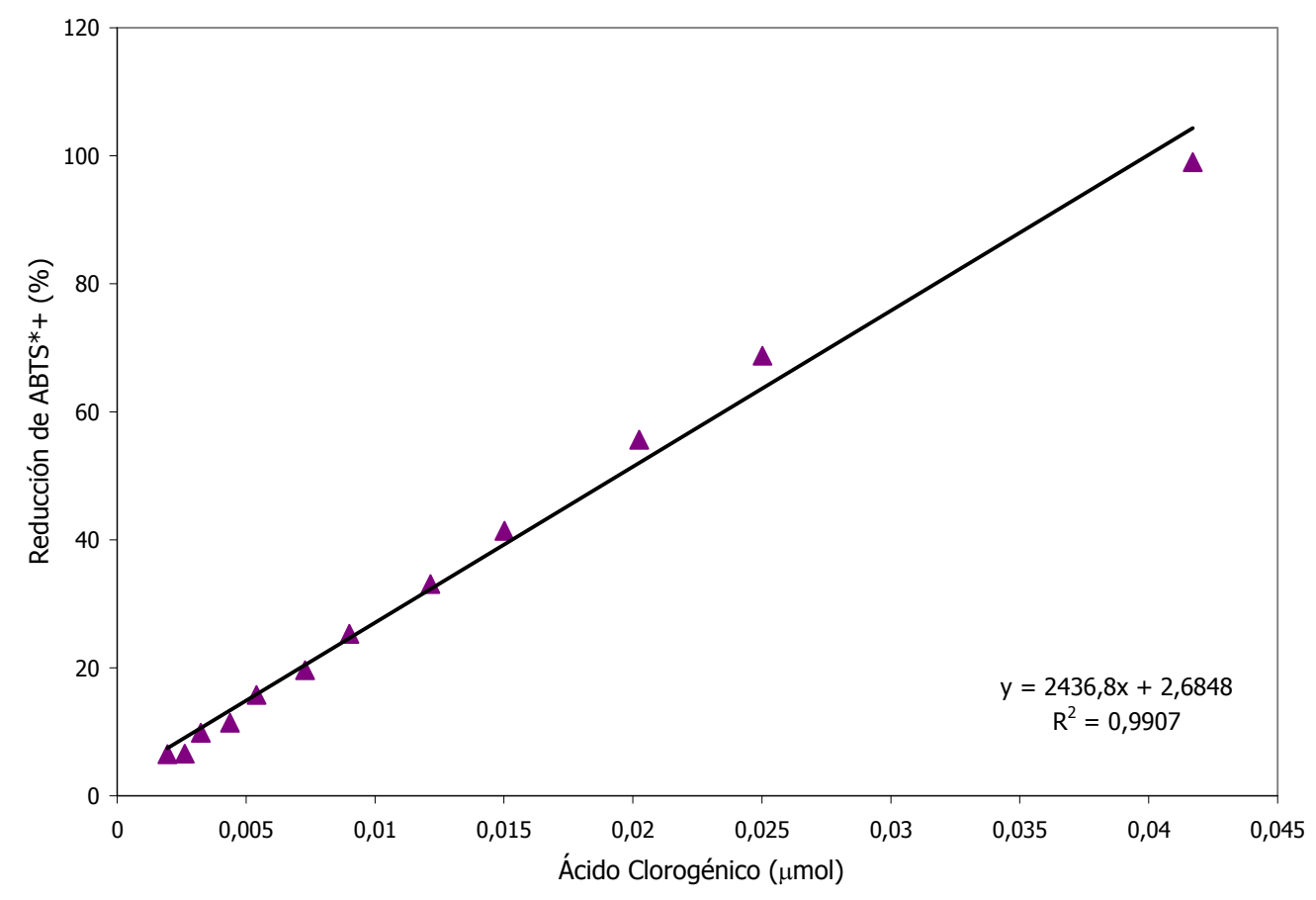

Figura 6 3. Curva de calibración con ácido clorogénico.

En todos los casos, la reducción del radical $\mathrm{ABTS}^{*+}$ se encontró entre el 20 y el $80 \%$, por lo que no fue necesario diluir o aumentar la concentración de los extractos. Tales porcentajes se transformaron en equivalentes de ácido clorogénico con la ecuación de ajuste obtenida de la curva de calibración. Ec. (6.1) 
Equivalente de ácido clorogénico $(\mu \mathrm{mol})=\frac{\text { \%Reducción } \mathrm{ABTS}^{*+}-2,685}{2436,767}$

Al analizar los resultados para la formulación B, la actividad antioxidante inicial fue de 0,0159 $\mu \mathrm{mol}$ ác. Clorogénico/g materia seca, la que disminuyó un 15,9 \% desde el inicio hasta el final del almacenamiento. Sin embargo, los resultados de ANOVA con $\mathrm{p}<$ 0,05 , indicaron que dicha variación no fue significativa. Para la formulación control $(A)$ sin embargo, la disminución de la capacidad antioxidante fue de un $47 \%$ durante el almacenamiento desde el valor inicial de 0,0162 $\mu \mathrm{mol}$ ác. Clorogénico/g materia seca, la cual fue significativa en este caso. Los resultados normalizados a la concentración inicial pueden verse en la Figura 6.4. Obsérvese que la adición de MBK (un reductor) en la formulación B, no implicó un aumento en la capacidad antioxidante inicial.

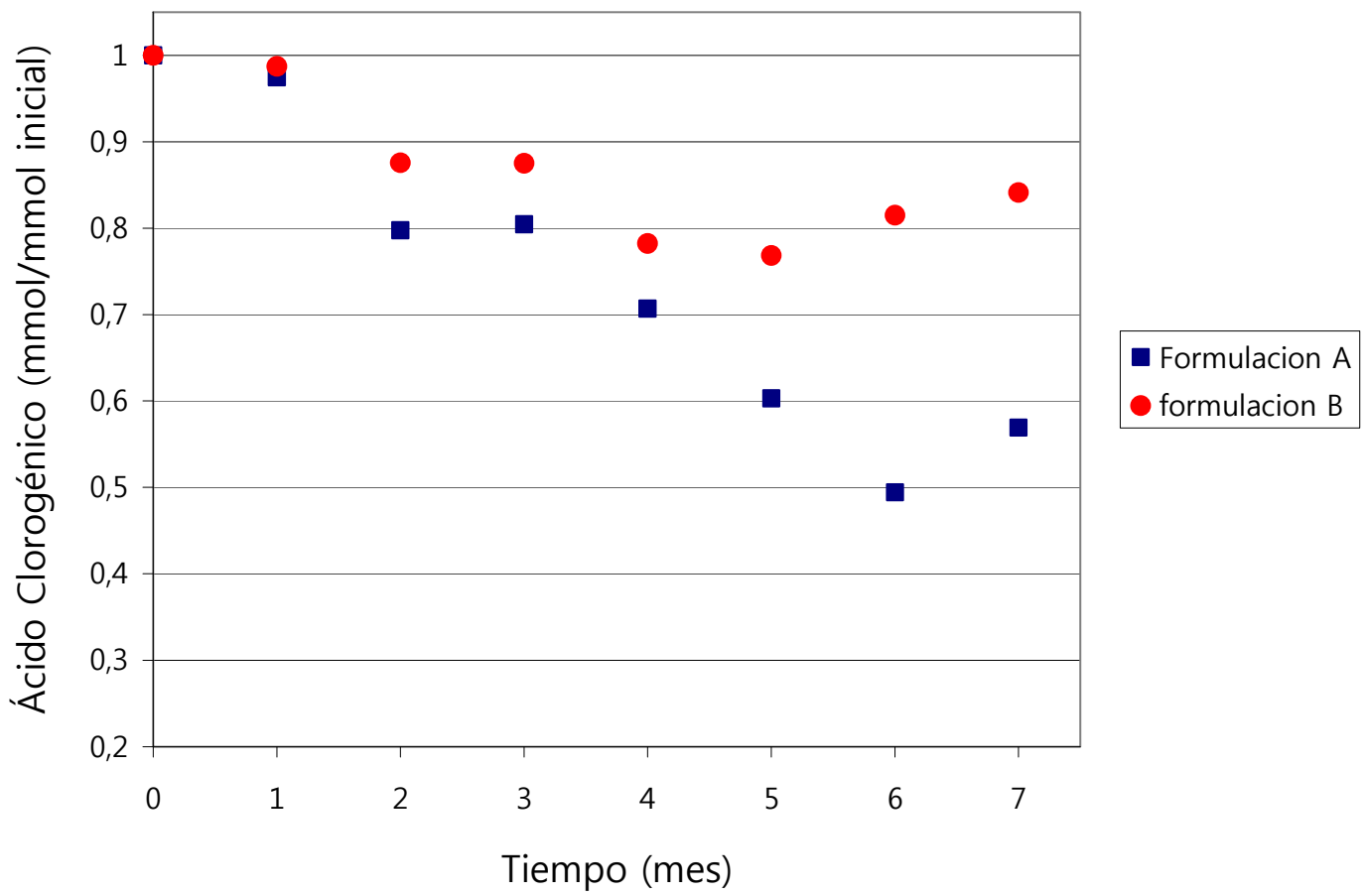

Figura 6.4. Resultados normalizados para el contenido de antioxidantes como equivalentes de ácido clorogénico durante el almacenamiento para la formulación $A(\square)$ y $B(\bullet)$.

La escasa variación de la capacidad antioxidante en la formulación B muestra que el uso de metabisulfito de potasio, es adecuado para preservar la retención de estos micronutrientes en los laminados, aún cuando su concentración representa la décima parte del máximo admisible en frutas deshidratas. 
No se encontraron datos publicados que permitieran hacer una comparación del cambio de la actividad antioxidante durante el almacenamiento en esta matriz de laminado deshidratado de manzana. Esto sucede porque la actividad antioxidante varía tanto por el tratamiento que se realiza sobre la muestra como por la variedad de manzana utilizada, como puede observarse en los resultados encontrados por Oszmianski y col. (2008). Estos autores trabajaron con dos variedades de manzana de piel roja, "Idared" y Champion, y estudiaron el almacenamiento de puré a partir de manzanas escaldadas por 4 min a $90^{\circ} \mathrm{C}$ (control, C), con manzanas tratadas en microondas durante 2 min a $80^{\circ} \mathrm{C}(\mathrm{M})$ y manzanas adicionadas con $500 \mathrm{ppm}$ de vitamina $\mathrm{C}$ y escaldadas como durante 4 min a $90^{\circ} \mathrm{C}(\mathrm{V})$. En la manzana Idared, la reducción de la actividad antioxidante (AA) determinada por el método del radical $\mathrm{ABTS}^{*+}$ para los tratamientos $C, M$ y $V$ fue de 63,30 y $23 \%$, respectivamente, mostrando que el tratamiento por microondas más corto, o bien el agregado de vitamina $C$ protegió la matriz. En la variedad Champion, los resultados mostraron pérdidas de AA de alrededor del $65 \%$, independientemente del tratamiento. Los resultados obtenidos en este trabajo para laminados adicionados con 100 ppm de MBK muestran menores pérdidas de AA que los del puré de manzana Idared, y muy inferior a los del puré de manzana Champion. 
CAPÍTULO VII

ANÁLISIS SENSORIAL 


\subsection{INTRODUCCIÓN}

Para los productos generados en cualquier nivel de la tecnología alimentaria (laboratorio, escala piloto o comercial) se hace necesaria su evaluación sensorial. Esta evaluación se conoce comúnmente como panel sensorial y los resultados obtenidos de él podrán ser utilizados para realizar cambios en la formulación, en el proceso, e incluso en los canales de comercialización, lo que a su vez impacta en la vida útil del producto.

Existen diversos tipos de pruebas de análisis sensorial: Paneles de expertos, paneles de laboratorio (jueces entrenados) y paneles de consumidores (utiliza un número grande de jueces no entrenados) (Dijksterhuis, 1997). Los dos primeros se utilizan en control de calidad durante el desarrollo de nuevos productos o para medir cambios en su composición. Los paneles de consumidores se utilizan más para sensar la opinión de consumidores genéricos.

Una evaluación sobre un producto similar (Leiva Díaz y col., 2009), realizada inmediatamente después del proceso de secado (podría considerarse correspondiente a tiempo $=0$ de almacenamiento) mostró que el laminado era aceptado, y que el producto se consumiría.

Teniendo en cuenta los parámetros de calidad anteriormente descriptos, el análisis sensorial se realizó sobre el laminado que contiene metabisulfito de potasio en su formulación, a lo largo del almacenamiento. 


\section{DISEÑO DE LA PRUEBA}

El objetivo es determinar la aceptabilidad sensorial y/o preferencia por parte del consumidor, por lo que la prueba guiaba a que cada panelista evaluara los siguientes atributos: color, sabor, textura y aceptabilidad general, sin comparar. Se les presentó un formato con una escala hedónica (Figura 7.1)

Nombre: Consumidor $\mathrm{N}^{\circ}$ :

MUESTRA No:

Utilizando la siguiente escala, por favor evalúe la aceptabilidad de cada atributo. Primero evalúe todos los atributos de la muestra de la derecha y luego los de la izquierda

\begin{tabular}{lllllllcc}
\multicolumn{1}{c}{$\begin{array}{c}\text { Disgusta } \\
\text { mucho }\end{array}$} & & & & & & Gusta \\
mucho
\end{tabular}

Figura 7 .1. Formato de escala hedónica utilizada para realizar la evaluación

Las muestras fueron cortadas en rectángulos de 40 × $20 \mathrm{~mm}$ y presentadas en recipientes descartables blancos, de poca profundidad, codificadas con números de tres dígitos elegidos al azar. Las muestras se acompañaron con agua fresca, y se sirvieron a temperatura ambiente $\left(20^{\circ} \mathrm{C}\right)$. Se recomendó a los panelistas beber agua entre muestras a efectos de eliminar el sabor residual (Figura 7.2). 


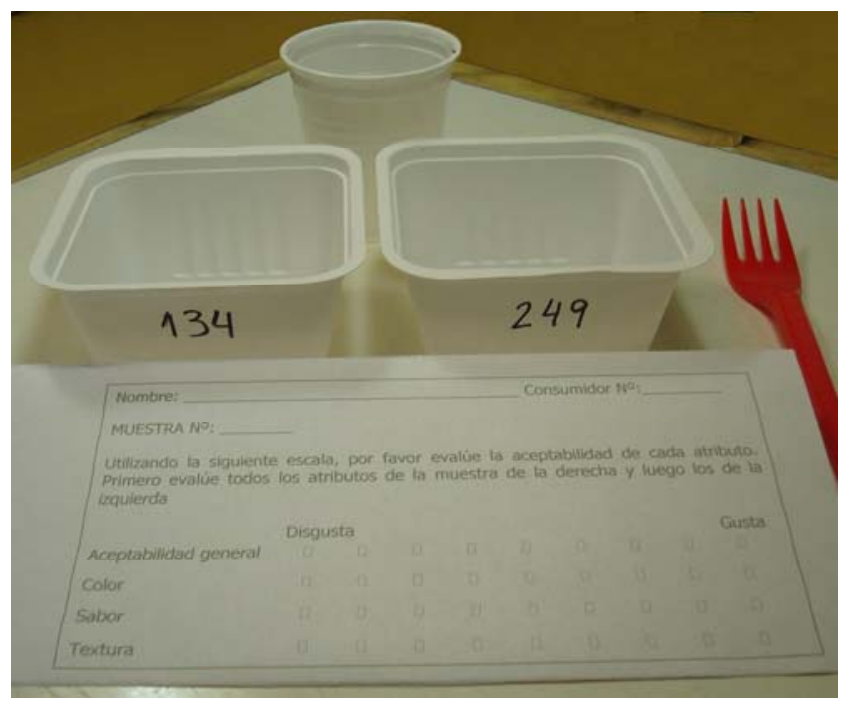

Figura 72 . Disposición de las muestras durante el panel.

Para analizar los resultados obtenidos del panel sensorial se transformó la escala hedónica en una escala numérica de 9 puntos. A efectos de comparar las medias de las distintas muestras evaluadas, se realizó un análisis de varianza (ANOVA) para cada uno de los atributos evaluados, definiendo como hipótesis nula $\left(\mathrm{H}_{0}\right)$ la inexistencia de diferencias sensoriales en el atributo evaluado a distintos tiempos de almacenamiento y como hipótesis alternativa $\left(\mathrm{H}_{1}\right)$, la existencia de al menos una diferencia sensorial.

Si el valor experimental del estadístico $\mathrm{F}$ calculado mediante el ANOVA es mayor o igual que los valores en la tabla de referencia, se debe rechazar la $\mathrm{H}_{0}$ y aceptar la hipótesis alternativa; de lo contrario se puede decir que no hay evidencia de diferencias significativas entre las muestras (Gacula, 1993).

Se realizaron dos paneles, cada uno de 30 personas, para evaluar los atributos definidos anteriormente. Se les suministró una muestra sin almacenar (mes 0) y tres almacenadas durante cuatro, cinco y seis meses. 


\subsection{RESULTADOS}

Los resultados obtenidos se muestran en las Figuras 7.3, 7.4, 7.5 y 7.6. Las medias de las puntuaciones obtenidas para cada atributo sensorial se muestran en la Tabla 7.1.

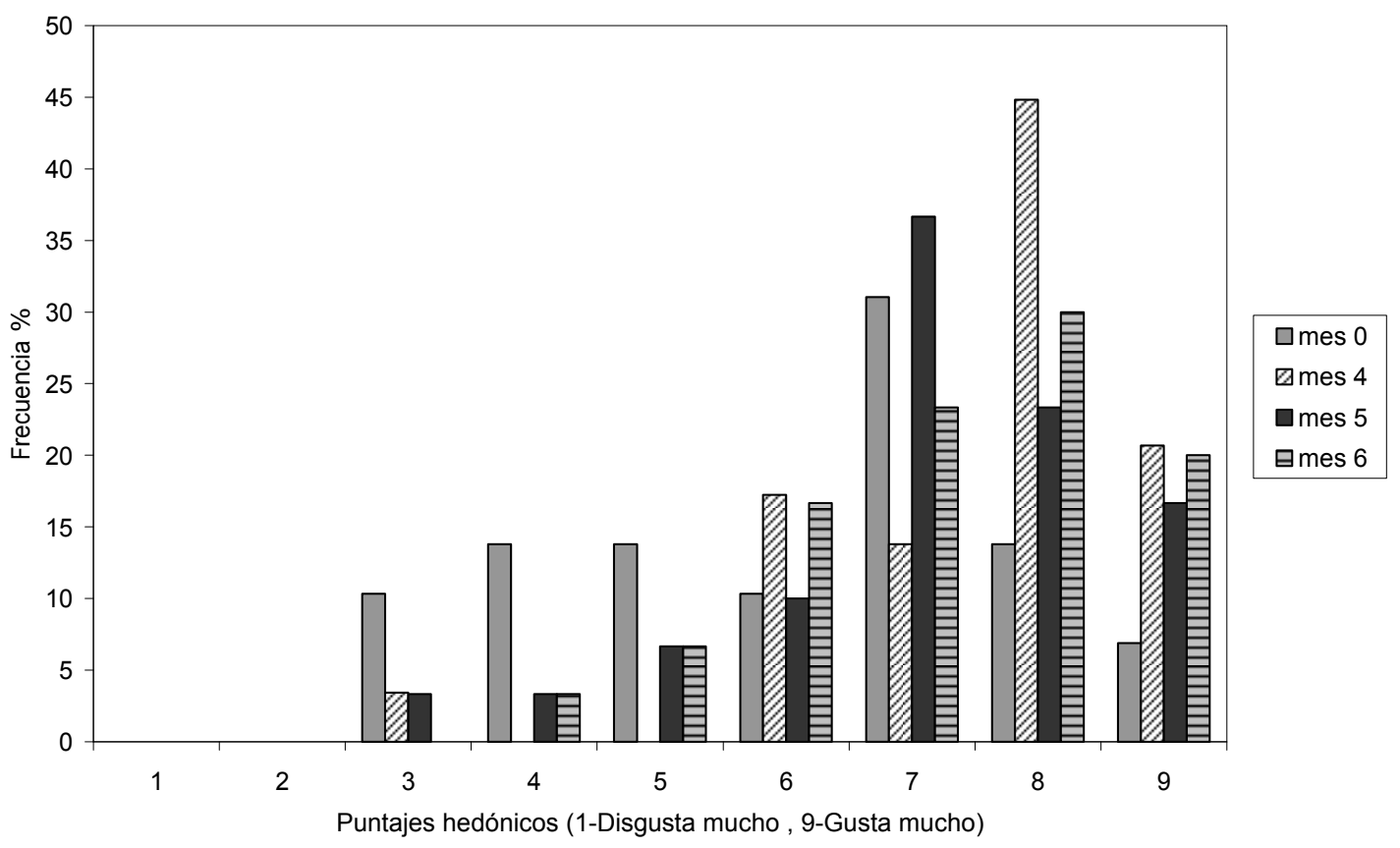

Figura 7 .3. Frecuencia de las respuestas obtenidas para el atributo Color

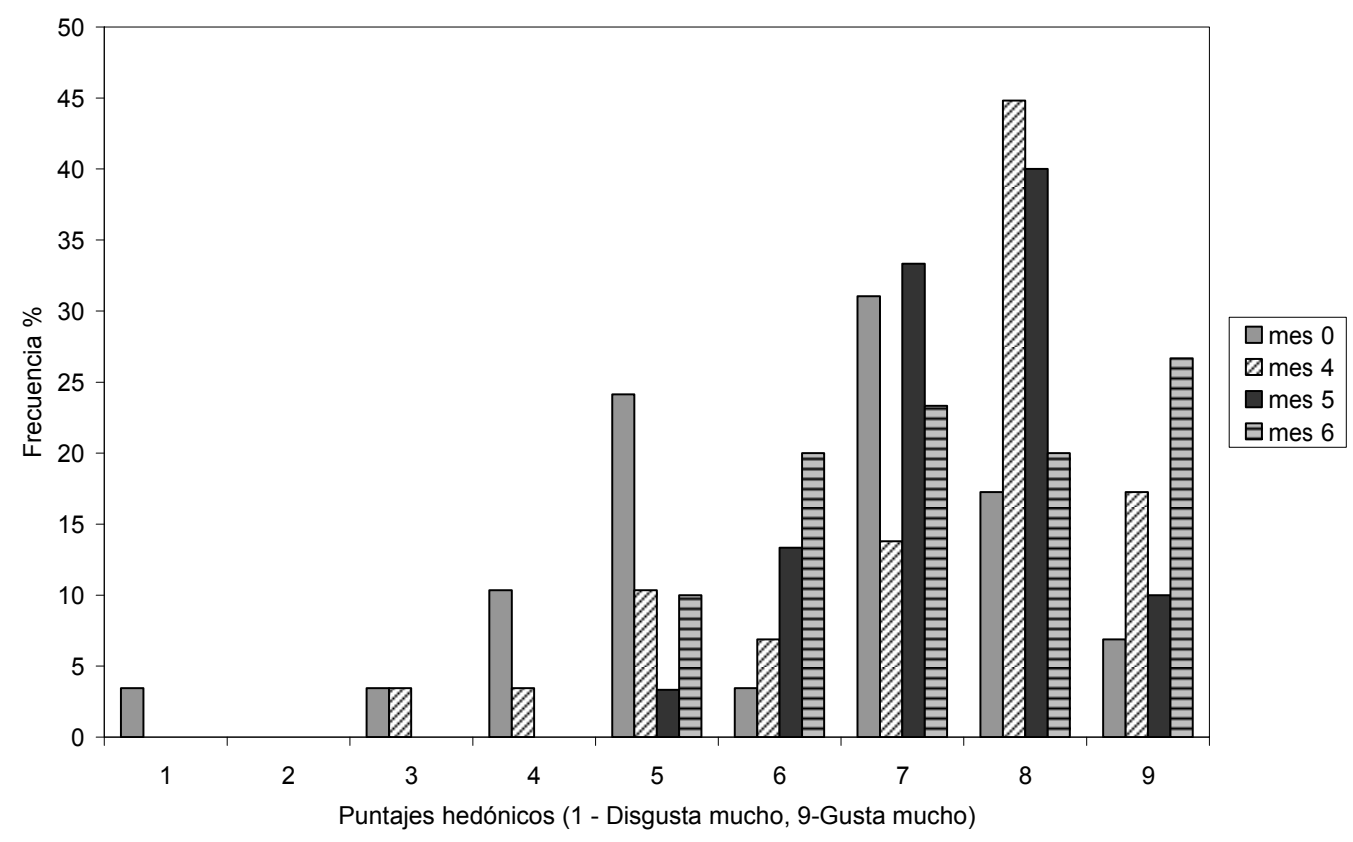

Figura 7 .4 Frecuencia de las respuestas obtenidas para el atributo Sabor 


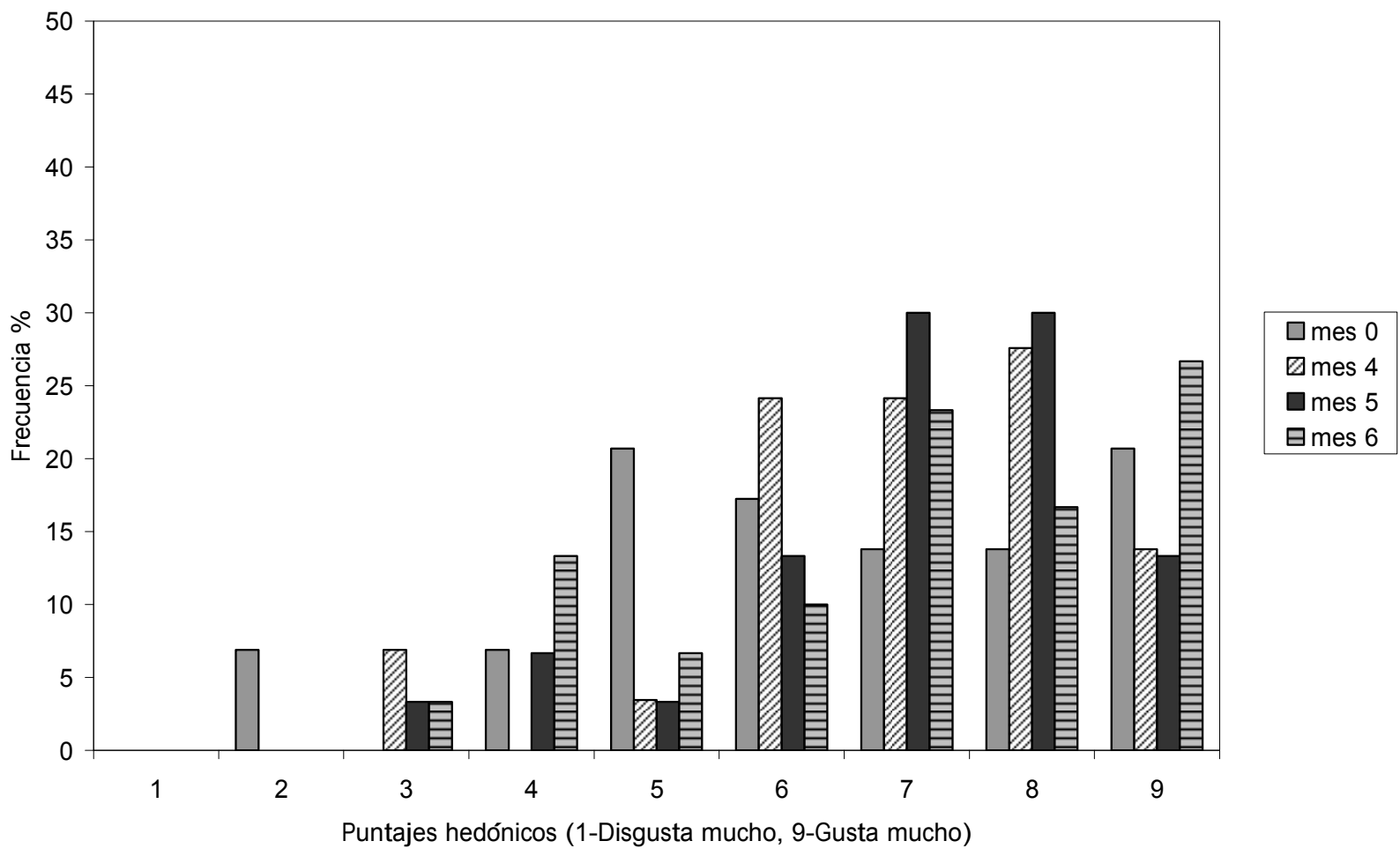

Figura 7.5 . Frecuencia de las respuestas obtenidas para el atributo Textura

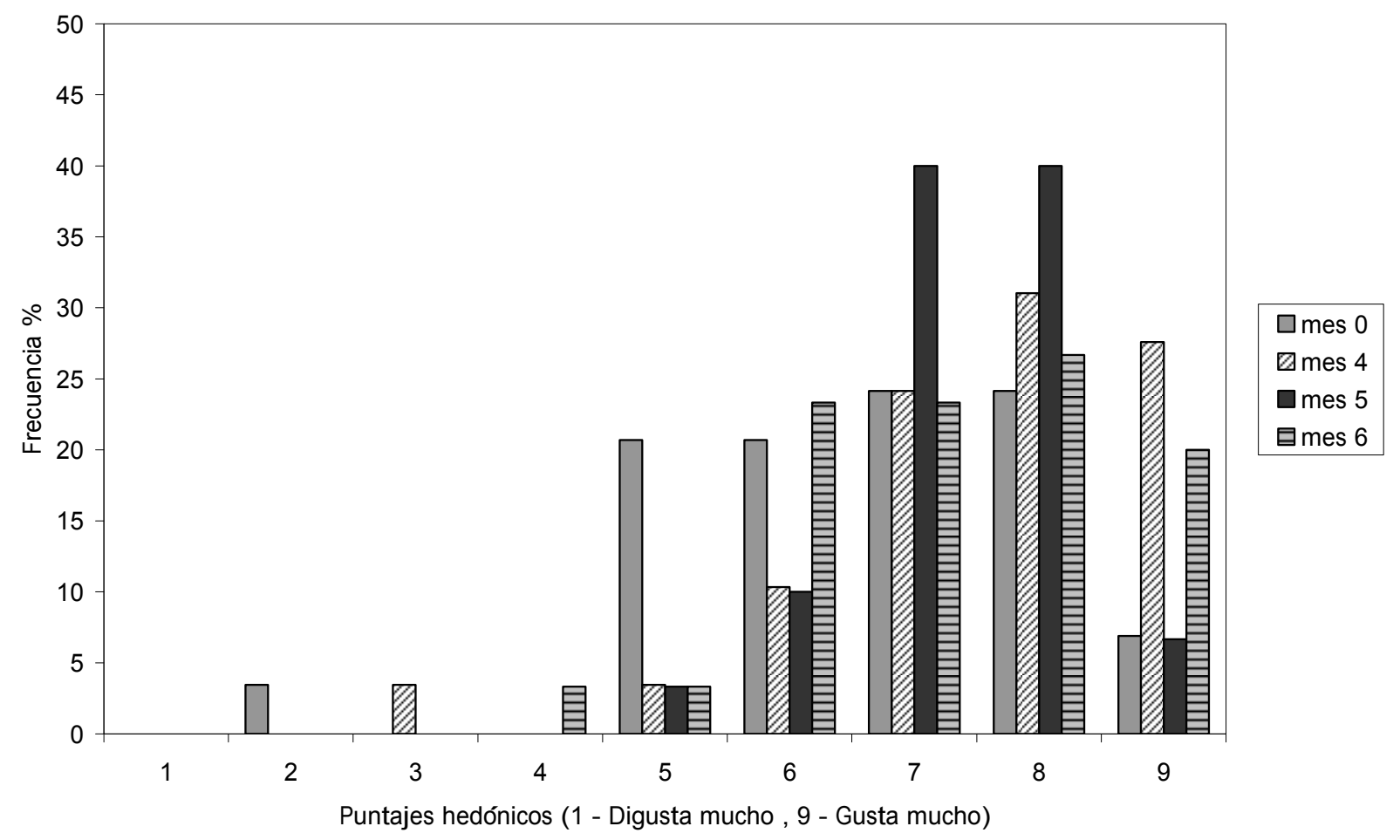

Figura 7 6. Frecuencia de las respuestas obtenidas para la Aceptabilidad General 
Tabla 7.1 . Medias de las puntuaciones obtenidas para cada atributo en las muestras evaluadas

\begin{tabular}{|c|c|c|c|c|}
\hline Atributo Tiempo & Mes $0^{\mathrm{A}}$ & Mes $4^{\mathrm{A}}$ & Mes $5^{\mathrm{A}}$ & Mes $6^{\mathrm{A}}$ \\
\hline Color & $6.06 \mathrm{a}$ & 7.55 & $7.10 \mathrm{a}$ & $7.3 \mathrm{a}$ \\
\hline Sabor & $6.13 \mathrm{a}$ & 7.27 & $7.40 \mathrm{a}$ & $7.33 \mathrm{a}$ \\
\hline Textura & $6.41 \mathrm{a}$ & $6.96 \mathrm{a}$ & $7.03 \mathrm{a}$ & $6.93 \mathrm{a}$ \\
\hline Aceptabilidad general & $6.58 \mathrm{a}$ & $7.55 \mathrm{~b}$ & $7.36 \mathrm{ab}$ & $7.26 \mathrm{ab}$ \\
\hline
\end{tabular}

${ }^{A}$ los datos corresponden a la media con $n=30$, para las filas letras iguales significa ausencia de diferecia significativa (Tukey, $p<0,05$ )

Al realizar el cálculo del ANOVA, no se observaron diferencias sensoriales significativas para el atributo textura, no obstante, las puntuaciones de textura son algo más bajas que las obtenidas para los otros atributos evaluados lo cual podría deberse a la falta de hábito del consumidor a texturas como las que posen los laminados. De todas maneras la puntuación resulto más que satisfactoria.

Para el atributo color se identificaron diferencias entre las muestras del mes cero y mes cuatro, no existiendo diferencias significativas entre ésta última y las muestras almacenadas por cinco y seis meses.

El sabor obtuvo resultados similares a los obtenidos para el color donde la muestra del mes cero presenta diferencias significativas con las demás, con menor puntuación, siendo igualmente mas que aceptable (valor > 5).

En resumen, se puede decir que el producto es promisorio para ingresar en la cadena de comercialización de laminados de fruta deshidratada, con una baja proporción de $\mathrm{SO}_{2}$ de 100 ppm, muy inferior a los 1000 ppm permitidos tanto por el del Código Alimentario Argentino y el Códex Alimentarius de la FAO/OMS (GSFA, 2009) para frutas deshidratadas. 


\section{CAPÍTULO VIII}

ALMACENAMIENTO ACELERADO 


\subsection{INTRODUCCIÓN}

Para determinar la vida útil de los productos de acuerdo a un parámetro de calidad definido (color, olor, sabor, pérdida de alguna característica textural o nutricional) teniendo en cuenta la influencia de la temperatura, se realiza un ensayo conocido como "almacenamiento acelerado". Este ensayo se caracteriza por el uso de temperaturas consideradas altas $\left(30-50^{\circ} \mathrm{C}\right)$ y cortos tiempos para el almacenamiento de alimentos, con la finalidad de obtener un factor conocido como $\mathrm{Q}_{10}$, que permite estimar el cambio en la calidad a menores temperaturas, donde los tiempos de experimentación resultarían mayores (Steele, 2004).

Es por esto que se evaluaron los cambios de color y actividad antioxidante que podrían darse en el laminado deshidratado de manzana preparado con la formulación $B$ (adicionada con metabisulfito de potasio) al almacenarlo a $30^{\circ} \mathrm{C}$ durante 35 días. Con los datos experimentales se ajustaron parámetros cinéticos, se determinaron los factores de influencia de temperatura $\mathrm{Q}_{10}$ tanto para el índice de pardeamiento como para la actividad antioxidante, los que se emplearon para estimar, en forma exploratoria, comportamientos a una temperatura menor sin que hubiera sido necesario un tiempo excesivamente largo de ensayos (Labuza y Riboh, 1982). 


\section{CONSIDERACIONES TEÓRICAS}

El factor $Q_{10}$, matemáticamente puede calcularse como el cociente de las constantes cinéticas para una temperatura $10^{\circ} \mathrm{C}$ mayor que la temperatura de referencia y la temperatura de referencia. Ec. (8.1).

$$
\mathrm{Q}_{10}=\frac{\mathrm{k}_{\mathrm{cT}+10}}{\mathrm{k}_{\mathrm{cT}}}
$$

El concepto de $Q_{10}$ está basado en constantes cinéticas pertenecientes a ecuaciones del tipo

$$
-\left(\frac{\mathrm{dC}}{\mathrm{dt}}\right)=\mathrm{k}_{\mathrm{c}} \mathrm{C}^{\mathrm{n}}
$$

Donde $\mathrm{n}$ es el orden de la reacción que puede tomar teóricamente cualquier valor $(0,1$, 2, etc), C es el índice de calidad medido y kc la constante cinética (Labuza y Schmidl, 1985).

En los alimentos, los datos experimentales de cinéticas de pérdida de calidad o de nutrientes, pueden interpretarse por ajuste de modelos cinéticos de orden cero o primer orden y de ellos se obtienen constantes cinéticas $\left(k_{c}\right)$ dependientes de la temperatura.

Es posible utilizar el valor de $Q_{10}$ para estimar la energía de activación de Arrhenius para los cambios en la calidad (Labuza y Schmidl, 1985).

$$
E_{a}=\frac{2,303 * \log _{10}\left(Q_{10}\right) R * T *(T+10)}{10} \text { con unidades } \mathrm{J} / \mathrm{mol}
$$




\subsection{METODOLOGÍA}

Se trabajo con laminados de la formulación B (Capítulo III) y se envasaron con el mismo tipo de material que aquellos evaluados a $20^{\circ} \mathrm{C}$. En estos ensayos de almacenamiento a $30^{\circ} \mathrm{C}$, los laminados se analizaron durante 35 días con una periodicidad de 5 días. Las experiencias se realizaron en una estufa de convección natural con control digital de temperatura marca San Jor.

Las determinaciones de cambio de color y actividad antioxidante se realizaron con las metodologías descriptas en Capítulos V y VI respectivamente.

\subsection{RESULTADOS}

8.4.1 Índice de pardeamiento (Browning Index, Bi)

El cambio de color determinado como índice de pardeamiento (BI), se muestra en la Figura 8.1

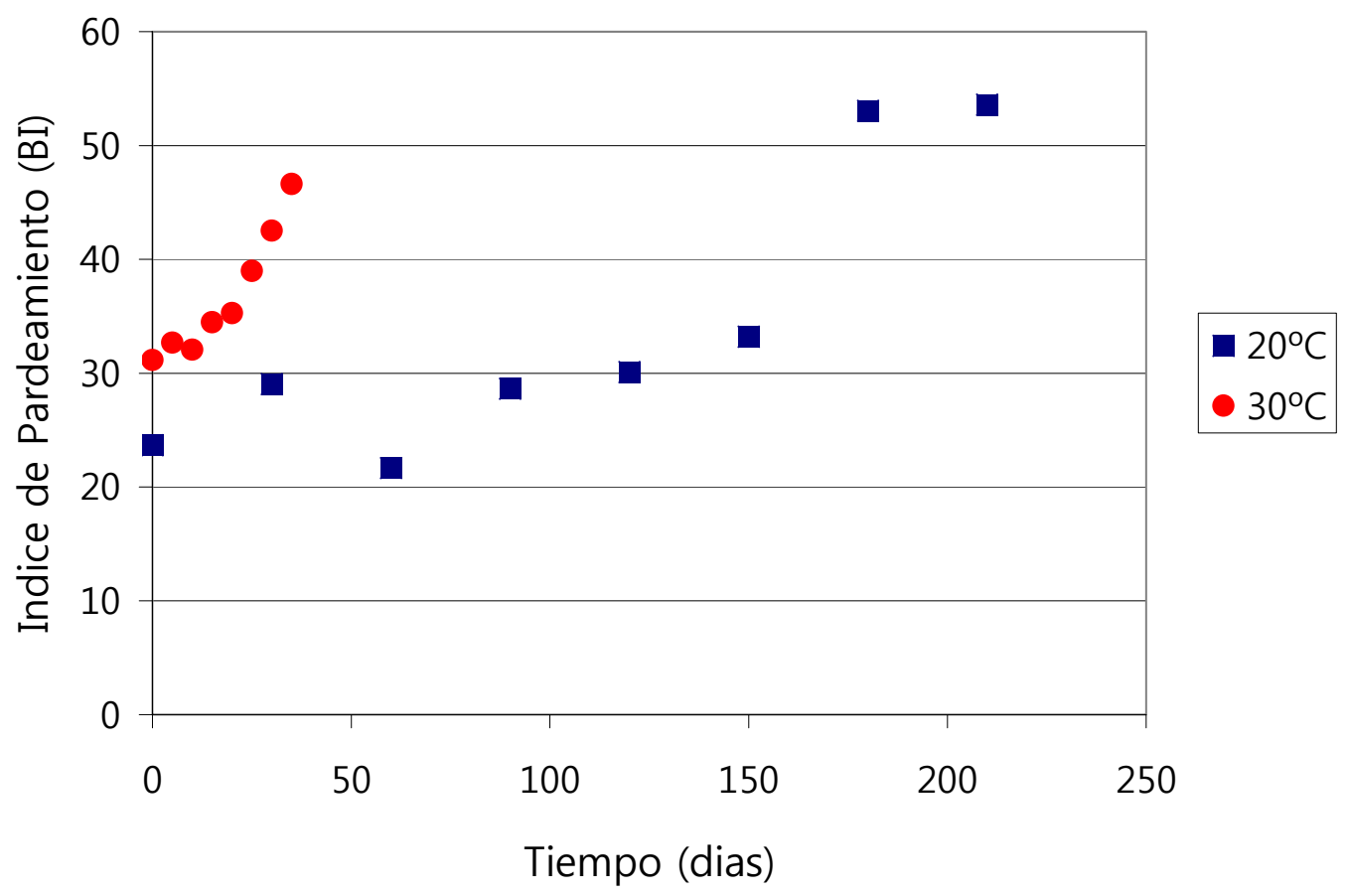

Figura 8.1. Cambio de color durante el almacenamiento expresado como índice de pardeamiento (BI) 
Al realizar el ajuste de los datos a tres modelos cinéticos (orden cero, primer orden y logístico) se obtuvo un mejor ajuste al utilizar el modelo logístico (Tabla 8.1), lo que está de acuerdo con los resultados obtenidos en el Capítulo V para almacenamiento a $20^{\circ} \mathrm{C}$.

Tabla 8.1 . Valor de los ajustes obtenidos para la formulación B almacenada a $30^{\circ} \mathrm{C}$

\begin{tabular}{|l|c|c|c|c|c|c|c|}
\hline \multirow{2}{*}{ Modelo } & \multirow{2}{*}{$\mathrm{r}^{2}$} & \multirow{2}{*}{$\mathrm{s}_{\mathrm{y}}$} & \multicolumn{5}{|c|}{ Parámetros de ajuste ( \pm desviación estándar) } \\
\cline { 5 - 8 } & & & $\mathrm{BI}_{\mathrm{i}}$ & $\mathrm{BI}_{\max }$ & $\mathrm{k}_{\mathrm{c}}$ & $\mathrm{t}_{\mathrm{m}}$ & $\mathrm{p}$ \\
\hline $\begin{array}{l}\text { orden } \\
\text { cero }\end{array}$ & 0,878 & 1,92 & $29,26 \pm 1,24$ & --- & $0,43 \pm 0,08$ & --- & --- \\
\hline $\begin{array}{l}\text { primer } \\
\text { orden }\end{array}$ & 0,915 & 1,60 & $29,46 \pm 0,94$ & ---- & $0,012 \pm 0,001$ & ---- & ---- \\
\hline logístico & 0,982 & 0,72 & $30,72 \pm 0,54$ & $46,67 \pm 1,66$ & ---- & $\begin{array}{c}26,51 \pm 0,1 \\
8\end{array}$ & $2,44 \pm 0,97$ \\
\hline
\end{tabular}

No obstante, dado que el concepto de coeficiente de temperaura está basado en modelos cinéticos de orden cero o uno, se eligió el segundo de éstos, por tener un mayor $r^{2}$ a ambas temperautras, a los efectos de calcular el $Q_{10}$ para el índice de pardeamiento. Los valores de las constantes cinéticas se muestran en la Tabla 8.2

Tabla 82 . Valor de los ajustes del modelo de primer orden obtenidos para la formulación B.

\begin{tabular}{|c|c|c|c|}
\hline $\begin{array}{c}\text { Temperatura de } \\
\text { almacenamiento }\end{array}$ & $\mathrm{r}^{2}$ & $\mathrm{~s}_{\mathrm{y}}$ & $\mathrm{k}_{\mathrm{c}}{ }^{\mathrm{a}}$ \\
\hline $20^{\circ} \mathrm{C}$ & 0,789 & 5,69 & $0,00473 \pm 9,27 \times 10^{-4}$ \\
\hline $30^{\circ} \mathrm{C}$ & 0,915 & 1,60 & $0,012 \pm 0,001$ \\
\hline \multicolumn{2}{|c|}{ a Los valores \pm la desviación estándar. }
\end{tabular}

Por medio de la Ec. (8.1) y los datos de la Tabla 8.2 el valor de $\mathrm{Q}_{10}$ calculado para el cambio de color fue de 2,55. Por su parte la Ec. (8.3) permitió estimar la energía de activación necesaria para que se formen los compuestos coloreados en los laminados deshidratados de manzana: $E_{a}=69 \mathrm{~kJ} / \mathrm{mol}$. Este valor, si bien provisional por basarse en dos temperaturas solamente, se encuentra dentro del rango de 68,6 - 80,8 kJ/mol para el cambio de color en jugo concentrado de manzana con un contenido de sólidos solubles similar al del laminado (Toribio y Lozano, 1984), y es cercano al valor de 75,0 kJ/mol determinado para cambios de color en puré de manzana por Ibarz y col. (2000). 


\subsubsection{Capacidad antioxidante}

La actividad antioxidante se calculó como equivalentes de ácido clorogénico obteniéndose un valor inicial de 0,0125 ( $\mu \mathrm{mol}$ Ác. Clorogénico/g materia seca) el que se redujo en un 53,5 \% durante los 35 días de análisis. El cambio de la actividad antioxidante se puede ver en la Figura 8.2.

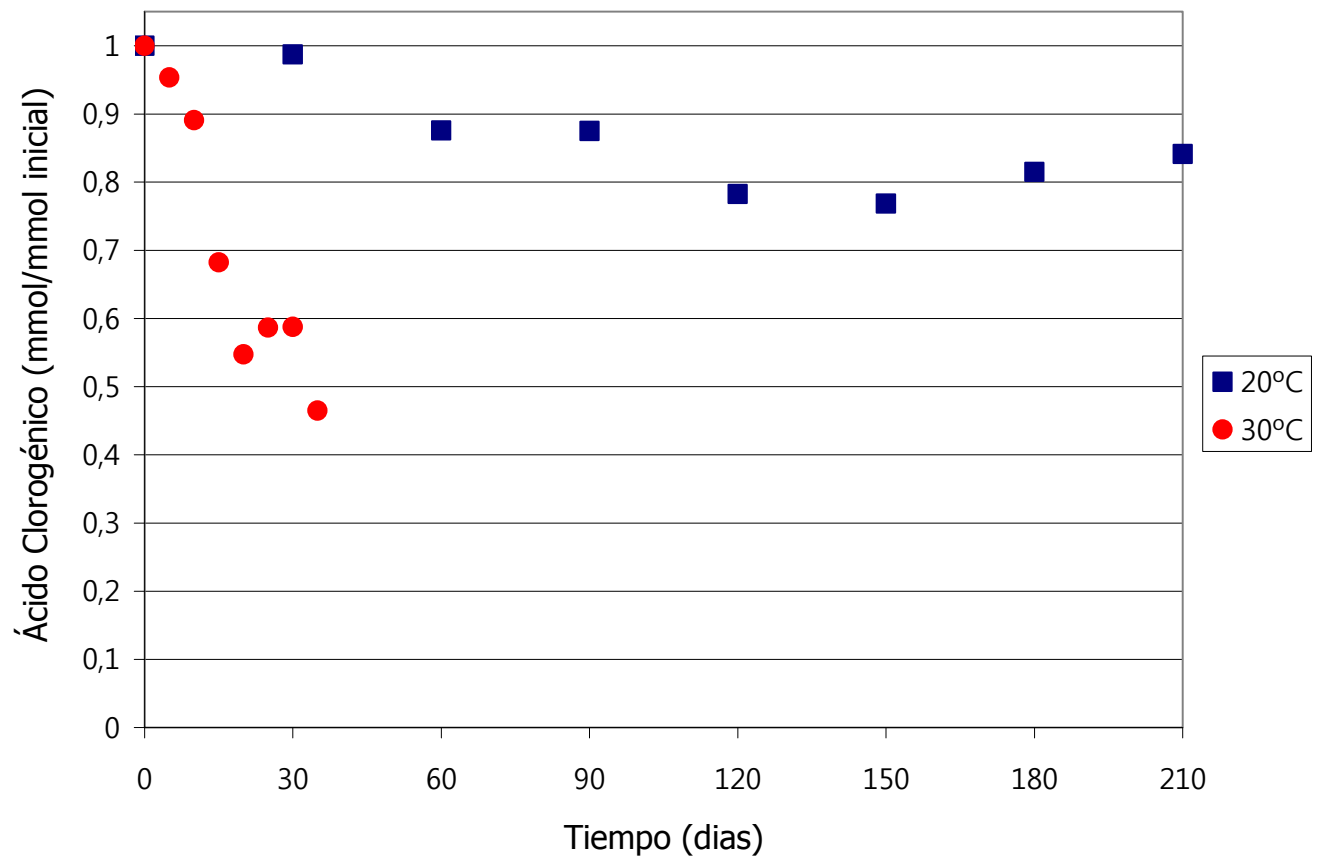

Figura 82 . Cambio normalizado de la actividad antioxidante en el laminado durante el almacenamiento.

Para evaluar el efecto del cambio de temperatura en la actividad antioxidante se ajustaron modelos de primer orden a los datos de la Figura 8.2, para la formulación B almacenada a $20^{\circ} \mathrm{C}$ y $30^{\circ} \mathrm{C}$. Los resultados se muestran en la Tabla 8.3.

Tabla 8 3. Valor de los ajustes del modelo de primer orden obtenidos para la formulación B.

\begin{tabular}{|c|c|c|c|}
\hline $\begin{array}{c}\text { Temperatura de } \\
\text { almacenamiento }\end{array}$ & $\mathrm{r}^{2}$ & $\mathrm{~s}_{\mathrm{y}}$ & $\mathrm{k}_{\mathrm{c}}{ }^{\mathrm{a}}$ \\
\hline $20^{\circ} \mathrm{C}$ & 0,617 & $8,53 \times 10^{-4}$ & $0,00114 \pm 3,19 \times 10^{-3}$ \\
\hline $30^{\circ} \mathrm{C}$ & 0,899 & $8,08 \times 10^{-4}$ & $0,02269 \pm 2,29 \times 10^{-2}$ \\
\hline \multicolumn{2}{|c|}{ a Los valores \pm la desviación estándar. }
\end{tabular}


El valor de $\mathrm{Q}_{10}$ estimado para la actividad antioxidante fue de 19,90. Por su parte la energía de activación para la perdida de actividad antioxidante tendría un valor de $\mathrm{Ea}=$ $221 \mathrm{~kJ} / \mathrm{mol}$.

8.4.3 Extrapolación de resultados a temperatura de almacenamiento menor a las usadas para las determinaciones

Labuza y Schmidl (1985) proponen que si dos reacciones con diferente valor de $\mathrm{Q}_{10}$ causan pérdidas de calidad en un alimento dado, aquella que posea un $\mathrm{Q}_{10}$ mayor, predominará a altas temperaturas, mientras que la que tenga un $\mathrm{Q}_{10}$ menor, predominará a bajas temperaturas

Con los resultados de $\mathrm{Q}_{10}$ para los dos factores de calidad se realizó una estimación exploratoria a la menor temperatura $\left(10^{\circ} \mathrm{C}\right)$. Aplicando los modelos de primer orden se estimaron las curvas teóricas para cada temperatura para duplicar el valor inicial del índice de pardeamiento, y una reducción del 20\% para la actividad antioxidante, valores para los cuales se considera que se iguala la calidad experimental obtenida luego del almacenamiento a $20^{\circ} \mathrm{C}$ Figuras 8.3 y 8.4 .

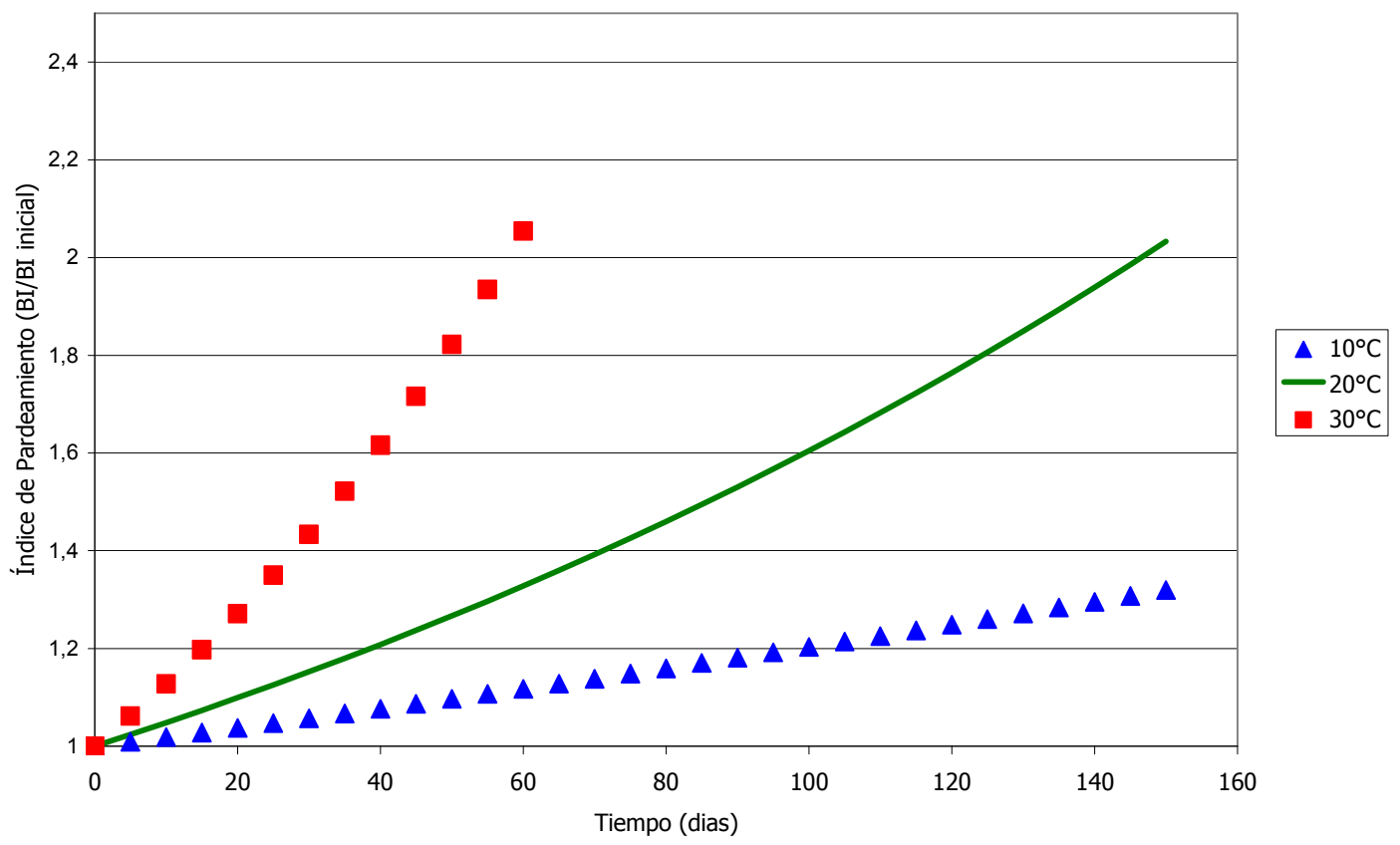

Figura 8 3. Cambio teórico en el Índice de pardeamiento durante el almacenamiento, a tres temperaturas. 


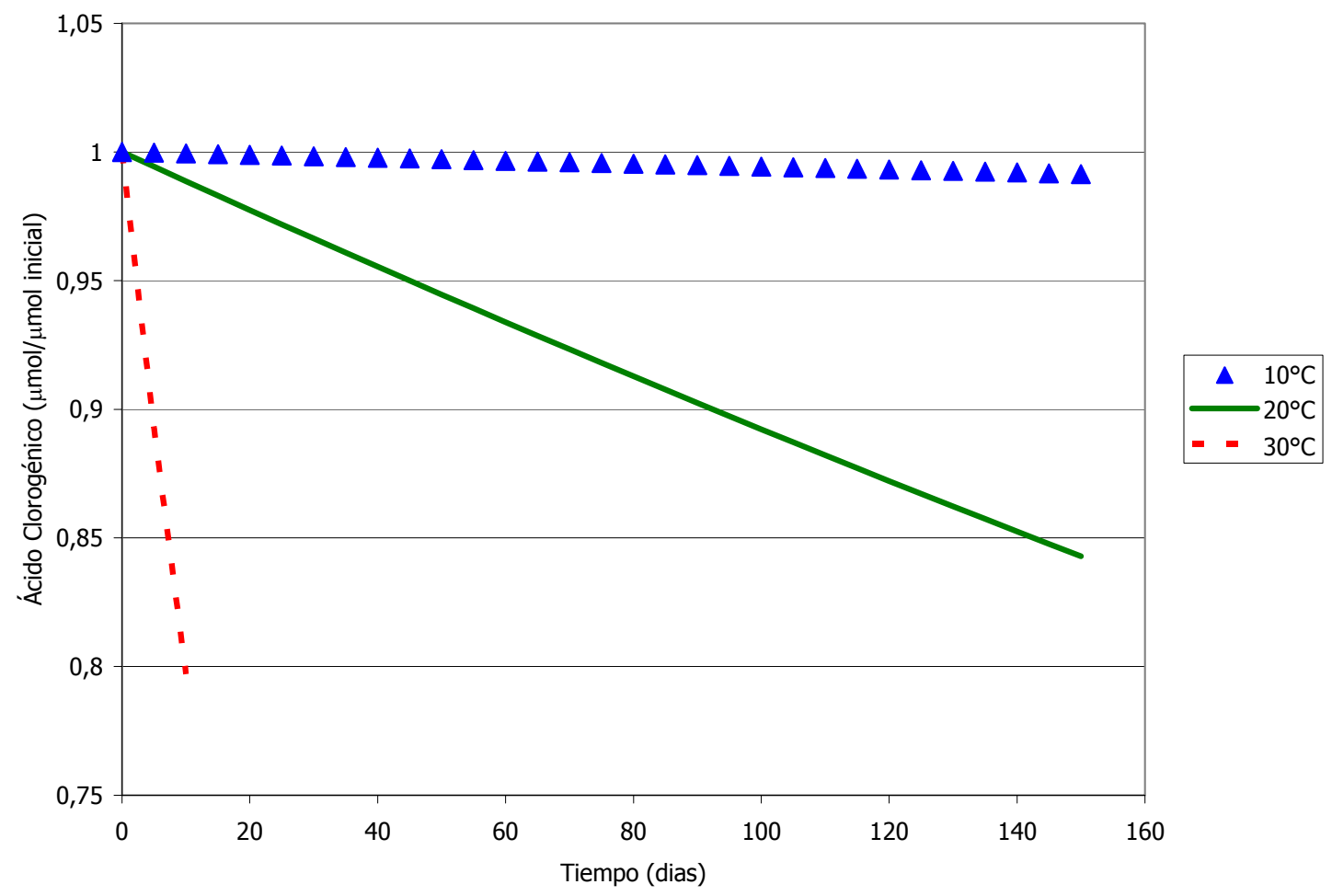

Figura 8 .4 . Cambio teórico en la actividad antioxidante durante el almacenamiento, a tres emperaturas.

Se han diseñado gráficos para visualizar rápidamente, en cada temperatura, el índice que definiría la vida útil del producto (Figuras $8.5,8.6$ y 8.7 ).

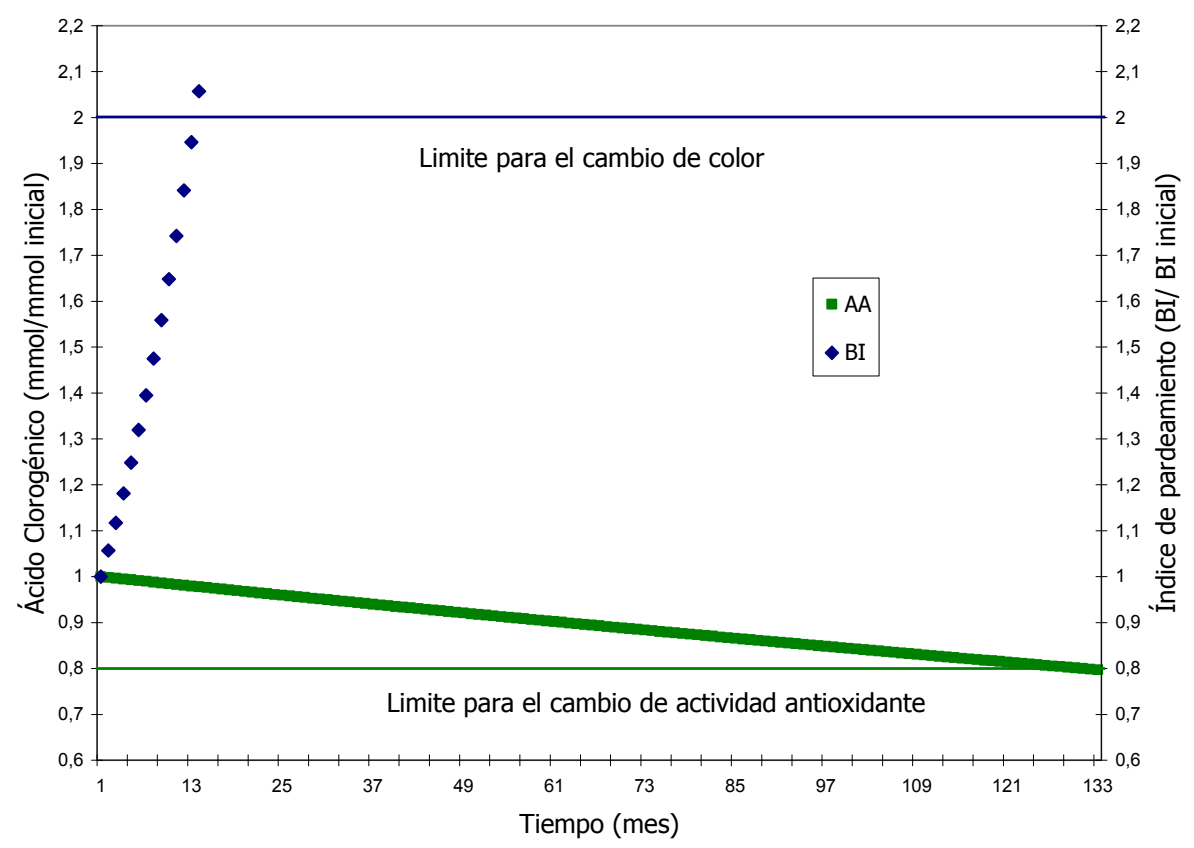

Figura 8 .5 . Cambio de los parámetros de calidad estimados a $10^{\circ} \mathrm{C}$. 


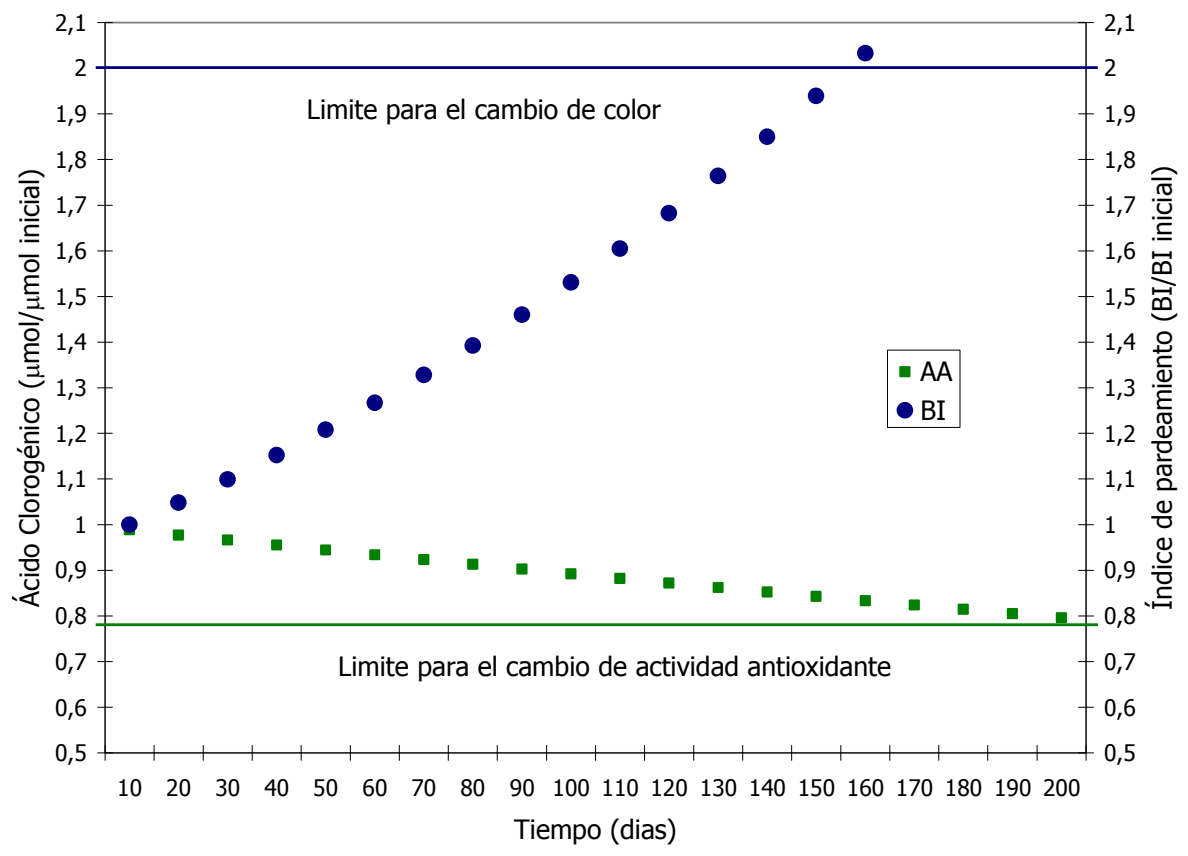

Figura 8.6. Cambio de los parámetros de calidad estimados a $20^{\circ} \mathrm{C}$.

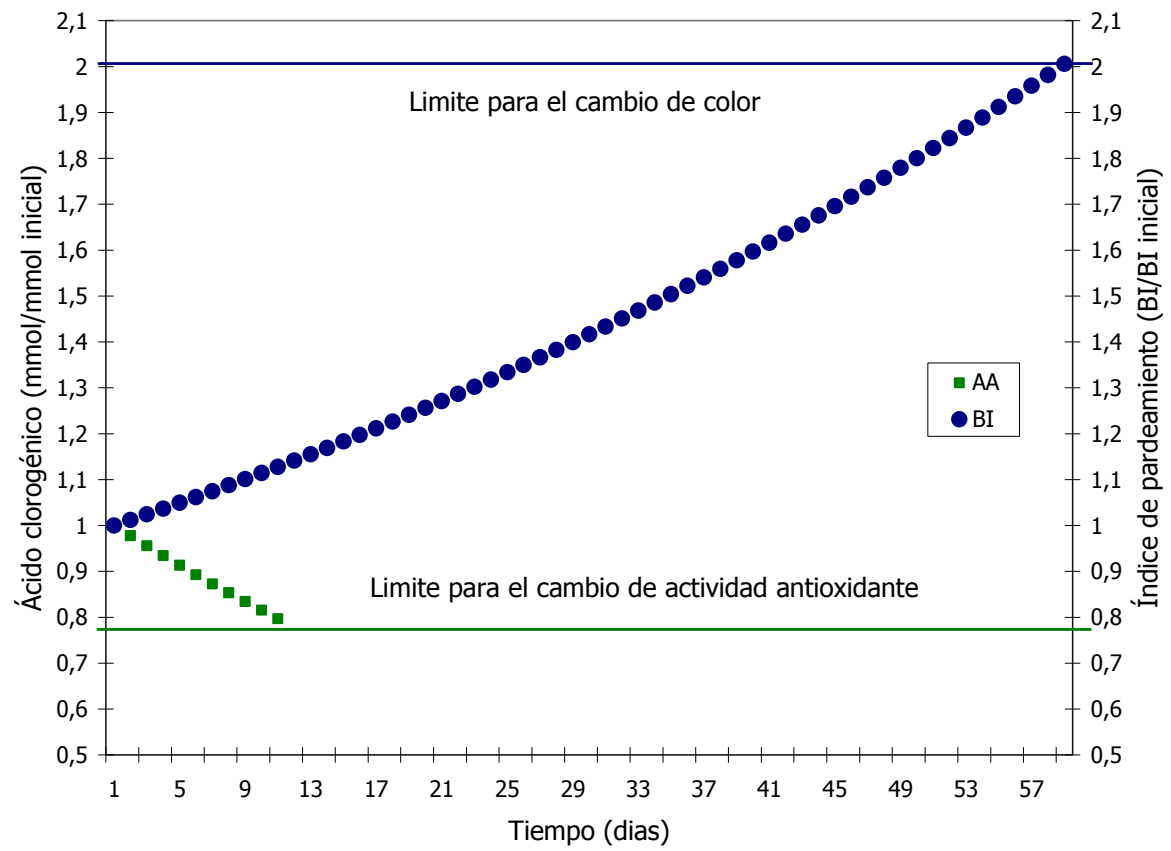

Figura 8 7. Cambio de los parámetros de calidad estimados a $30^{\circ} \mathrm{C}$.

Para las temperaturas de 10 y $20^{\circ} \mathrm{C}$ el cambio de color se da en un menor tiempo que en el caso de $30^{\circ} \mathrm{C}$, por tal motivo, se podría definir la actividad antioxidante como la base para determinar la calidad durante el almacenamiento a temperaturas mayores que la ambiente y el cambio de índice de pardeamiento a temperaturas de refrigeración. 
CONCLUSIONES 


\section{Ensayo delequipo de secado}

Dada la coincidencia práctica de velocidades de evaporación de agua en las tres posiciones en que pueden colocarse las bandejas en el secador de laboratorio, se comprobó que el equipo provee un tratamiento térmico uniforme, y por tanto puede ser empleado para procesar hasta tres muestras por experiencia.

Por su parte, el valor experimental del coeficiente de transferencia de calor para el equipo, de alrededor de $48 \mathrm{~W} / \mathrm{m}^{2} \mathrm{~K}$, obtenido mediante una técnica estacionaria, fue comparable al obtenido por autores previos mediante una técnica no estacionaria, siendo ambos considerablemente mayores a los predichos por las correlaciones para sistemas de flujo paralelo a platos, mostrando la necesidad de determinar los coeficientes de transferencia en forma experimental para cada equipo.

\section{Tratam iento térm ico previo}

Los cubos de manzana pelados fueron tratados térmicamente al vapor por 10 minutos. El tiempo de escaldado para inactivar peroxidasa fue de 3 minutos, siendo los 7 minutos adicionales empleados para proporcionar un atributo organoléptico deseable, el color dorado, previo al secado.

Se aplicó un modelo matemático de conducción no estacionaria en cubos resultante del balance local de energía. La ecuación diferencial parcial fue resuelta mediante una solución analítica en serie para la temperatura del centro del cubo, en función del tiempo, y del número de Biot. Mediante un procedimiento programado en Matlab, la solución se aplicó a la historia térmica experimental del cubo, determinándose un Biot de 0,60 , que denota control interno-externo a la transferencia de calor, con un coeficiente de transferencia de energíar de $58 \mathrm{~W} / \mathrm{m}^{2} \mathrm{~K}$. El comportamiento experimental se describió con muy poco error por parte del modelo, que en consecuencia puede emplearse para estimar tiempos de escaldado en cubos, si se fija una temperatura apropiada a alcanzar en su centro, para la cual se asegure la inactivación de la peroxidasa y por tanto de la polifenol oxidasa. 


\section{Obtención dellam inado m ediante deshidratación a $60^{\circ} \mathrm{C}$}

Se determinaron las curvas de secado con aire caliente durante la formación del laminado para condiciones del aire de $60^{\circ} \mathrm{C}$ y $2 \mathrm{~m} / \mathrm{s}$. Las cuatro formulaciones tuvieron curvas de secado (humedad media de la muestra en función del tiempo) similares. La predicción de las curvas se realizó con un modelo de difusión no estacionaria para $\mathrm{Bi}=$ 2 (control interno-externo) en "zona húmeda" o tiempos cortos, mientras que para la zona seca y tiempos largos, se utilizó una solución analítica para control interno estricto. Si bien el modelo había sido desarrollado previamente, nunca se lo había empleado para una formulación con una humedad inicial bastante mayor, a pesar de lo cual las curvas predichas fueron casi coincidentes con las experimentales. Asimismo, se graficó el modelo de evaporación de agua pura conjuntamente con los datos de secado, mostrando que el agua pura evapora a mayor velocidad, incluso desde el comienzo. Los modelos utilizados se pueden utilizar como base para el cálculo de los tiempos de secado y diseño básico de secadores.

\section{Ensayos de alm acenam ien to}

En las muestras realizadas, el tiempo de almacenamiento de muestras en las muestras envasadas en película de alta barrera a gases, vapor de agua y luz, no modificó considerablemente el contenido de humedad, $\mathrm{pH}$, contenido de sólidos solubles y actividad acuosa.

El panel sensorial realizado para la formulación B mostró una elevada aceptabilidad general, que en una escala de 1 a 9 obtuvo 7,6, 7,4 y 7,3 a los 4, 5 y 6 meses de almacenamiento, respectivamente. Esto subraya las posibilidades que tiene el producto para ingresar en el mercado dentro de la cadena de distribución de alimentos deshidratados.

La formulación que utilizó el aditivo metabisulfito de potasio en una concentración de 1/10 de la máxima permitida por la legislación para productos deshidratados de fruta fue la seleccionada, dado que mantuvo las características sensoriales sin desarrollo de microorganismos, en los geles pécticos de manzana por un periodo de 6 meses a temperatura ambiente. 
El Indice de pardeamiento (BI), determinado a partir del sistema triestímulo CIELAB, tendió a aumentar con el tiempo de almacenamiento a $20^{\circ} \mathrm{C}$, aunque la formulación con metabisulfito de potasio (MBK) lo hizo en menor medida que la muestra control. Las evoluciones fueron interpretadas con modelos cinéticos de orden cero, primer orden y logístico, siendo éste último el que presentó el mejor ajuste, posiblemente porque puede dar cuenta de la demora del BI en aumentar su valor.

Se cuantificó la actividad antioxidante como equivalentes de ácido clorogénico, mediante la técnica de decoloración del radical catión $\mathrm{ABTS}^{*+}$, obteniéndose para la formulación control un valor de 0,0162 $\mu$ mol Ác. Clorogénico/g materia seca a tiempo cero. Este valor disminuyó un $47 \%$ durante el almacenamiento de 7 meses a $20^{\circ} \mathrm{C}$. Con respecto a la formulación con MBK, su valor a tiempo cero fue de 0,0159 $\mu \mathrm{mol}$ Ác. Clorogénico/g materia seca, y sólo disminuyó 15,9\% durante el almacenamiento.

Se realizó un almacenamiento de la formulación con $\mathrm{MBK}$ a $30^{\circ} \mathrm{C}$, denominado "acelerado", a efectos de evaluar la influencia de la temperatura en el desarrollo de pardeamiento (BI) y la pérdida de actividad antioxidante (AA). La aplicación de un modelo de primer orden permitió evaluar las constantes cinéticas de ambos índices de calidad a 20 y $30^{\circ} \mathrm{C}$, con las cuales se calcularon los factores $Q_{10}$, que fueron de 2,55 para BI y 19,9 para AA.

Por medio de estimaciones extrapolatorias realizadas con los valores de $Q_{10}$ a $10^{\circ} \mathrm{C}$, y comparando curvas predichas a 10,20 y $30^{\circ} \mathrm{C}$, se observó que el índice de pardeamiento determinaría la vida útil a temperaturas bajas, mientras que la $A A$ lo haría en altas temperaturas. La causa es la diferencia notable en los valores de $\mathrm{Q}_{10}$ de ambos índices de calidad. 


\section{REFERENCIAS BIBLIOGRÁFICAS}

- AOAC (1998). Official Methods of Analysis. Gaithersburg, USA, AOAC International.

- Beuchat, L. R. (1981). "Microbial stability as affected by water activity." Cereal Foods World 26(7): 345-349.

- Buera, M. d. P., Lozano, R. D. y Petriella, C. (1985/1986). "Definition of Color in the Non-enzymatic Browning Process." Die Farbe 32/33: 316-326.

- Carlberg, D. M. (2005). Cleanroom Microbiology for the Non-microbiologist. Boca Raton, USA, CRC Press.

- Cheftel, J. C. y Cheftel, H. (1992). Introducción a la Bioquímica y Tecnológia de los Alimentos. Zaragoza, España, Editorial Acribia.

- Chirife, J. (2010). Novedades en la medición y aplicación práctica de la actividad de agua en la estabilidad microbiológica y desarrollo de alimentos. Curso de posgrado, Microanalitica Argentina S.R.L., Vicente Lopez, Provincia de Buenos Aires, Argentina. - Crank, J. (1975). The Mathematics of Diffusion. Londres, UK, Oxford University press.

- Calvo, C. y Durán, L. (2002). Propiedades físicas II. óptica y color. Cap 7 en Temas en Tecnología de Alimentos CYTED Vol 1, México D.F., Alfaomega Grupo editor.

- Damodaran, S., Parkin, K. L. y Fennema, O. R. (2010). FENNEMA Química de los Alimentos. Zaragoza, Acribia.

- Delgado Marroquin, M. T. y Martin Espítora, M. N. (2006). "Dieta en la hipertensión arterial." FMC - Formación Médica Continuada en Atención Primaria Dijksterhuis, G. B. (1997). Multivariate Data Analysis in Sensoru and Consumer Science. Trumbull, USA, Food and Nutrition Press, Inc.

- Eberhardt, M. V., Lee, C. Y. y Liu, R. H. (2000). "Nutrition: Antioxidant activity of fresh apples." Nature 405(6789): 903-904.

- Enachescu, M. (1995). Fruit and Vegetable Processing. Roma, Italia, FAO Agricultural Services Bulletin.

- Eskin, M. y Robinson, D. (2001). Shelf Life Stability: Chemical,Biochemical and Microbiological Changes. Boca raton, USA, CRC Press.

- FAO. (2002). "Latinfoods, Tabla de composición de Alimentos de América Latina." Accesado 18 de Mayo de 2010, http://www.rlc.fao.org/bases/alimento 
- Fiorentini, C., Diaz, E. L. y Giner, S. A. (2008). "A Mass-Transfer Model for the Drying of an Innovative Tomato Gel." Food Science and Technology International 14(1): $39-46$.

- Gacula, M. (1993). Design and Analysis of Sensory Optimization. Trumbull, USA, Food and Nutrition Press.

- Geankoplis, C. J. (1993). Procesos de Transporte y Operaciones Unitarias. Mexico, Compañia Editorial Continental.

- Genskow, L. R., Beimesch, W. E., Hecht, J. P., Kemp, I., Langrish, T., Schwartzbach, C. y Smith, F. L. (2007). Perry's Chemical Engineers' Handbook Section 12. USA, Mc Graw Hill.

- Gely, M. C. y Giner, S. A. (2000). "Water - Corn Equilibrium: Temperature Dependency of the G.A.B. model parameters andcalculation of the heat of sorption." Drying Technology: An International Journal 18(7): 1449 - 1464.

- Giner, S. A. (1999). Diseño de secadoras continuas de trigo. Simulación de la transferencia de calor y materia y de pérdidas de calidad. Ingeniría Química. La Plata, Argentina, Universidad Nacional de La Plata. Doctor en Ingenierí.

- Giner, S. A. (2009). "Influence of Internal and External Resistances to Mass Transfer on the constant drying rate period in high-moisture foods." Biosystems Engineering 102(1): 90-94.

- Giner, S. A. y Gely, M. C. (2005). "Sorptional Parameters of Sunflower Seeds of Use in Drying and Storage Stability Studies." Biosystems Engineering 92(2): 217-227.

- Giner, S. A. y Mascheroni, R. H. (2001). "PH--Postharvest Technology: Diffusive Drying Kinetics in Wheat, Part 1: Potential for a Simplified Analytical Solution." Journal of Agricultural Engineering Research 80(4): 351-364.

- Gonzales, A. P., Burin, L. y Buera, M. d. P. (1999). "Color changes during storage of honeys in relation to their composition and initial color." Food Research International 32(3): 185-191.

- Greensmith, M. (1998). Practical dehydration. Cambridge, UK, Woodhead Publising Limited.

- GSFA (2009). Norma General para Aditivos Alimentarios. Frutas desecadas 04.1.2.2, FAO/OMS 
- Holdsworth, D. y Simpson, R. (2007). Thermal Processing of Packaged Food. Pullman, USA, Springer.

- Huang, X. y Hsieh, F.-H. (2005). "Physical Properties, Sensory Attributes, and Consumer Preference of Pear Fruit Leather." Journal of Food Science 70(3): E177E186.

- Ibarz, A., Pagán, J. y Garza, S. (2000). "Kinetic models of non-enzymatic browning in apple puree." Journal of the Science of Food and Agriculture 80(8): 1162-1168.

- JECFA (1998). Compendium of Food Additive Specification. FAO Food and Nutrition Paper (FNP) 52, FAO/WHO Expert Committee on Food Additives. Add. 6.

- JECFA (1999). Compendium of Food Additives Specification. FAO Food and Nutrition Paper (FNP) 52, FAO/WHO Expert Committee on Food Additives. Add. 7.

- Kang, H. R. (2006). Computational Color Technology, SPIE, .

- Krotchta, J. (2007). Food Packaging, Chapter 13 en Handbook of Food Engineering. D. Heldman and D. Lund. Boca Raton, USA, CRC Press.

- Labuza, L. P. y Riboh, D. (1982). "Theory and Application of Arrhenius Kinetics to the Prediction of Nutrient Losses in Foods." Food Technology 36(10): 66-74.

- Labuza, L. P. y Schmidl, M. P. (1985). "Accelerated Shelf-life Testing of Foods." Food Technology 39(9): 57-64.

- Leistner, L. y Gould, G. W. (2002). Hurdle Technologies: Combination Treatment for Food Stability, Safety and Quality. New York, USA, Springer.

- Leiva Día, E., Giannuzzi, L. y Giner, S. (2009). "Apple Pectic Gel Produced by Dehydration." Food and Bioprocess Technology 2(2): 194-207.

- MacDougall, D. B. (2002). Colour in food. Boca Raton, USA, CRC Press.

- Martinez, M. V. y Whitaker, J. R. (1995). "The biochemistry and control of enzymatic browning." Trends in Food Science \& Technology 6(6): 195-200.

- Origin (2009). OriginPro 8.1. Northampton,USA, Originlab Corporation.

- Ortolani, C. y Pastorello, E. A. (2006). "Food allergies and food intolerances." Best Practice \& Research Clinical Gastroenterology 20(3): 467-483.

- Oszmianski, J., Wolniak, M., Wojdylo, A. y Wawer, I. (2008). "Influence of apple purée preparation and storage on polyphenol contents and antioxidant activity." Food Chemistry 107(4): 1473-1484. 
- Perez-Gago, M. B., Serra, M. y Río, M. A. d. (2006). "Color change of fresh-cut apples coated with whey protein concentrate-based edible coatings." Postharvest Biology and Technology 39(1): 84-92.

- Petriella, C., Resnik, S. L., Lozano, R. D. y Chirife, J. (1985). "Kinetics of Deteriorative Reactions in Model Food Systems of High Water Activity: Color Changes Due to Nonenzymatic Browning." Journal of Food Science 50(3): 622-626.

- Picouet, P. A., Landl, A., Abadias, M., Castellari, M. y Viñas, I. (2009). "Minimal processing of a Granny Smith apple purée by microwave heating." Innovative Food Science \& Emerging Technologies 10(4): 545-550.

- Raab, C. y Oehler, N. (1976). Making Dried Fruit Leather, Oregon State University. Extension Service.

- Rahman, M. S. (2009). Food Properties Handbook. Boca Raton, EUA, CRC press.

- Ratti, C. y Crapiste, G. H. (1995). "Determiantion of Heat Transfer Coefficients Duiring Drying of Foodstuffs." Journal of Food Process Engineering 18(1): 41-53.

- Re, R., Pellegrini, N., Proteggente, A., Pannala, A., Yang, M. y Rice-Evans, C. (1999). "Antioxidant activity applying an improved ABTS radical cation decolorization assay." Free Radical Biology and Medicine 26(9-10): 1231-1237.

- Schmidt Hebbel, H. y Pennacchiotti Monti, I. (2001). Enzimas en los Alimentos, su importancia en la química y tecnología de los alimentos, Biblioteca Digital Universidad Nacional de Chile http://mazinger.sisib.uchile.cl/repositorio/lb/ciencias_quimicas_y_farmaceuticas/sch midth02/.

- Sikorski, Z. E. (2007). Chemical and Functional Properties of Food Components. Londres, UK, CRC Press.

- Singh, P. y Heldman, D. (2009). Introduccion a la Ingeniería de Alimentos, Acribia Editorial.

- Steele, R. (2004). Understanding and Measuring the Shelf-Life of Food. Cambridge, UK, Woodhead Publishing Limited.

- Toribio, J. L. y Lozano, J. E. (1984). "Nonenzymatic Browning in Apple Juice Concentrate during Storage." Journal of Food Science 49(3): 889-892. 
- Vaikousi, H., Koutsoumanis, K. y Biliaderis, C. G. (2008). "Kinetic modelling of nonenzymatic browning of apple juice concentrates differing in water activity under isothermal and dynamic heating conditions." Food Chemistry 107(2): 785-796.

- Valentas, K., Rotstein, E. y Singh, P. (1997). Handbook of Food Engineering Practice. Boca raton, USA, CRC press.

-Vega, P. V. y Florentino, B. (2000). Toxicologia de Alimentos. Mexico D.F, México, Centro Nacional de Salud Ambiental.

- Velázquez, O. (2009). Técnicas Para el Análisis Microbiológico de Alimentos. México D.F, México, Facultad de Química, UNAM.

- Visser, J. y Voragen, A. (1995). Pectins and Pectinases. Amsterdan, Holanda., Elsevier Science B.V.

-Wu, J., Gao, H., Zhao, L., Liao, X., Chen, F., Wang, Z. y Hu, X. (2007). "Chemical compositional characterization of some apple cultivars." Food Chemistry 103(1): 8893.

- Zulueta, A., Esteve, M. J. y Frígola, A. (2009). "ORAC and TEAC assays comparison to measure the antioxidant capacity of food products." Food Chemistry 114(1): 310316. 


\section{ANEXO 1}

\section{NOMENCLATURA}
A Área $\left(\mathrm{m}^{2}\right)$
$a^{*} \quad$ Coordenada cromática en el eje del verde - rojo en el espacio de color CIELAB
$a_{w} \quad$ Actividad acuosa a $25^{\circ} \mathrm{C}$
$b^{*} \quad$ Coordenada cromática en el eje amarillo - azul en el espacio de color CIELAB
Bi Número de Biot
BI índice de pardeamiento
$\mathrm{BI}_{\mathrm{i}} \quad$ Parámetro de ajuste relacionado con el índice de pardeamiento
$B_{\text {imax }}$ Valor máximo que puede alcanzar el índice de pardeamiento
$\mathrm{C}_{\text {apf }} \quad$ Concentración de aditivo en el producto final (ppm)
$\mathrm{C}_{\text {MBKpf }}$ Concentración del aditivo MBK en el producto final (ppm)
$\mathrm{c}_{\mathrm{p}} \quad$ Calor específico $(\mathrm{J} / \mathrm{kg} \mathrm{K})$
$\mathrm{C}_{\mathrm{SKpf}}$ Concentración de aditivo SK en el producto final ( $\mathrm{ppm}$ )
$D_{0 h m} \quad$ Coeficiente de difusión inicial a altas humedades $\left(\mathrm{m}^{2} / \mathrm{s}\right.$.)
$D_{0 l m} \quad$ Coeficiente de difusión inicial a bajas humedades $\left(\mathrm{m}^{2} / \mathrm{s}\right.$.)
$D_{h m} \quad$ Coeficiente de difusión a altas humedades $\left(\mathrm{m}^{2} / \mathrm{s}\right.$.)
$D_{\operatorname{lm}} \quad$ Coeficiente de difusión a bajas humedades $\left(\mathrm{m}^{2} / \mathrm{s}\right.$.)
$\mathrm{E}_{\mathrm{a}} \quad$ Energía de activación $(\mathrm{J} / \mathrm{mol})$
$E_{\text {ahm }}$ Energía de activación en la zona de alto contenido de humedad $(\mathrm{J} / \mathrm{mol})$
Ealm Energía de activación en la zona de bajo contenido de humedad $(\mathrm{J} / \mathrm{mol})$
$e_{m h m}$ Espesor medio en la zona de alto contenido de humedad $(\mathrm{m})$
$\mathrm{e}_{\mathrm{mlm}}$ Espesor medio en la zona de alto contenido de humedad $(\mathrm{m})$
G Flujo másico de aire $\left(\mathrm{kg} / \mathrm{m}^{2} \mathrm{~s}\right)$
$\mathrm{G}_{\mathrm{h}} \quad$ Flujo másico de aire $\left(\mathrm{kg} / \mathrm{m}^{2} \mathrm{~h}\right)$
$\mathrm{H}_{0} \quad$ Hipótesis nula
$\mathrm{H}_{1} \quad$ Hipótesis alternativa
HRE Humedad relativa en equilibrio (\%)
$\mathrm{h}_{\mathrm{T}} \quad$ Coeficiente de transferencia de calor $\left(\mathrm{J} / \mathrm{sm}^{2}{ }^{\circ} \mathrm{C}\right)$
$h_{T v m}$ Coeficiente de transferencia de calor en el sistema vapor-cubo $\left(\mathrm{J} / \mathrm{s} \mathrm{m}^{2}{ }^{\circ} \mathrm{C}\right)$
$\mathrm{k} \quad$ Conductividad térmica $\left(\mathrm{W} / \mathrm{m}^{\circ} \mathrm{C}\right)$
$\mathrm{k}_{\mathrm{c}} \quad$ Constante cinética 
$\mathrm{k}_{\mathrm{c}} \quad$ Constante cinética a la temperatura de referencia

$\mathrm{k}_{\mathrm{CT}+10}$ Constante cinética a la temperatura de referencia mas $10^{\circ} \mathrm{C}$

$k_{p} \quad$ Coeficiente efectivo de transferencia de materia $\left(\mathrm{kg} / \mathrm{m}^{2} \mathrm{sPa}\right)$

$\mathrm{k}_{\mathrm{Ta}} \quad$ Conductividad térmica a la temperatura $\mathrm{T}_{\mathrm{a}}\left(\mathrm{W} / \mathrm{m}^{\circ} \mathrm{C}\right)$

L Longitud (m)

$L^{*} \quad$ Luminosidad entre el blanco y el negro para el espacio de color CIELAB

$\mathrm{L}_{\mathrm{c}} \quad$ Longitud característica $(\mathrm{m})$

$\mathrm{L}_{\text {wbh }} \quad$ Calor de vaporización del agua a la temperatura de bulbo húmedo $(\mathrm{J} / \mathrm{kg})$

$\mathrm{m}_{\mathrm{A}} \quad$ Masa de aditivo $(\mathrm{kg})$

$\mathrm{m}_{\mathrm{ac}} \quad$ Masa de solución de ácido cítrico $(\mathrm{kg})$

$\mathrm{m}_{\mathrm{az}} \quad$ Masa de azúcar $(\mathrm{kg})$

MBK Metabisulfito de Potasio

$\mathrm{m}_{\mathrm{pf}} \quad$ Masa final del producto, masa de laminado deshidratado $(\mathrm{kg})$

$\mathrm{m}_{\mathrm{fo}} \quad$ Masa de formulación sin secar $(\mathrm{kg})$

$m_{n} \quad$ Coeficiente entre la masa de agua y la masa de agua inicial

$\mathrm{m}_{\mathrm{p}} \quad$ Masa de puré $(\mathrm{kg})$

$M_{v} \quad$ Masa molecular del agua $(\mathrm{mol} / \mathrm{g})$

$\mathrm{m}_{\mathrm{w}} \quad$ Masa de agua $(\mathrm{kg})$

$\mathrm{m}_{\text {wa }} \quad$ Masa de agua adicionada $(\mathrm{kg})$

$\dot{\mathrm{m}}_{\text {wev }}$ Velocidad de evaporación de agua $(\mathrm{kg} / \mathrm{s})$

$\mathrm{m}_{\text {wo }} \quad$ Masa inicial de agua $(\mathrm{kg})$

Nu Número de Nusselt

$\mathrm{p} \quad$ Presión atmosférica $(\mathrm{Pa})$

$\mathrm{pH} \quad$ Logaritmo negativo de la concentración de iones hidrógeno

$\mathrm{p}_{\mathrm{s}} \quad$ Presión de saturación de vapor de agua $(\mathrm{Pa})$

$\mathrm{p}_{\mathrm{sbh}} \quad$ Presión de saturación de vapor de agua a la temperatura de bulbo húmedo ( $\mathrm{Pa}$ )

$\mathrm{p}_{\mathrm{v}} \quad$ Presión de vapor del agua en una solución o alimento $(\mathrm{Pa})$

$\mathrm{p}_{\mathrm{va}} \quad$ Presión parcial de vapor del aire $(\mathrm{Pa})$

$\mathrm{Q}_{10} \quad$ Cociente de constantes cinéticas evaluadas a $\mathrm{T}+10$ y $\mathrm{T}$

$\mathrm{R}$ Constante universal de los gases $(\mathrm{J} / \mathrm{molK})$

Re Número de Reynolds

SK Sorbato de potasio

Sy Desvío típico de la predicción 
$\mathrm{t} \quad$ Tiempo (s)

$\mathrm{T}$ Temperatura $\left({ }^{\circ} \mathrm{C}\right)$

$\mathrm{T}^{*}{ }_{\mathrm{c}}$ Temperatura adimensional en el centro de un cubo

$\mathrm{T}_{\mathrm{a}} \quad$ Temperatura ambiente $\left({ }^{\circ} \mathrm{C}\right)$

$\mathrm{T}_{\mathrm{bh}} \quad$ Temperatura de bulbo húmedo $\left({ }^{\circ} \mathrm{C}\right)$

$\mathrm{T}_{\mathrm{C}} \quad$ Temperatura en el centro de un cubo $\left({ }^{\circ} \mathrm{C}\right)$

$\mathrm{T}_{\mathrm{i}} \quad$ Temperatura inicial del cubo $\left({ }^{\circ} \mathrm{C}\right)$

$\mathrm{t}_{\mathrm{m}}$ Tiempo para que BI alcance $\left(\mathrm{BI}_{\mathrm{i}}+\mathrm{BI}_{\max }\right) / 2$ (mes)

$\mathrm{T}_{\mathrm{v}} \quad$ Ttemperatura de vapor $\left({ }^{\circ} \mathrm{C}\right)$

UFC Unidad formadora de Colonia

W Humedad (kg agua/ kg masa seca)

$\mathrm{W}_{\mathrm{a}} \quad$ Humedad absoluta del aire de secado ( $\mathrm{kg}$ vapor/ $\mathrm{kg}$ de aire seco)

$W_{\text {ad }}$ Humedad adimensional

$\mathrm{W}_{\mathrm{e}} \quad$ Humedad en el equilibrio ( $\mathrm{kg}$ agua/ $\mathrm{kg}$ de masa seca)

$\mathrm{W}_{\mathrm{pf}} \quad$ Humedad en el laminado ( $\mathrm{kg}$ agua/ $\mathrm{kg}$ de masa seca)

$\mathrm{W}_{\mathrm{fo}} \quad$ Humedad inicial de la formulación ( $\mathrm{kg}$ agua/ $\mathrm{kg}$ de masa seca)

$\mathrm{W}_{\mathrm{r}} \quad$ Humedad relativa del aire de secado ( $\mathrm{kg}$ agua/ $\mathrm{kg}$ de aire seco)

$\mathrm{X}$ Parámetro de color (rojo)

$X_{n} \quad$ Parámetro de referencia para el blanco

$X_{\text {wac }} \quad$ Fracción de agua en la solución de acido cítrico

$\mathrm{x}_{\text {waz }} \quad$ Fracción de agua en el azúcar

$\mathrm{x}_{\text {wfo }} \quad$ Fracción de agua en la formulación a secar

$\mathrm{X}_{\mathrm{wp}} \quad$ Fracción de agua en el puré

Y Parámetro de color (verde)

$\mathrm{Y}_{\mathrm{n}} \quad$ Parámetro de referencia para el blanco

Z Parámetro de color (azul)

$Z_{\mathrm{n}} \quad$ Parámetro de referencia para el blanco

LETRAS GRIEGAS

a Difusividad térmica $\left(\mathrm{m}^{2} / \mathrm{s}\right)$

$\beta_{n} \quad$ Raíces positivas de la ecuación $\beta_{n} \tan \beta_{n}=B i$

$\rho \quad$ Densidad $\left(\mathrm{kg} / \mathrm{m}^{3}\right)$ 


\section{ANEXO 2}

Programa en Matlab 7.0 desarrollado para la determinación del coeficiente de tranferencia de calor $\mathrm{h}$ del vapor generado en la vaporera Moulinex -Aroma difusión.

- Función para calcular las raíces $\beta$ de Biot function beta $=$ raizbeta $(\mathrm{Bi})$

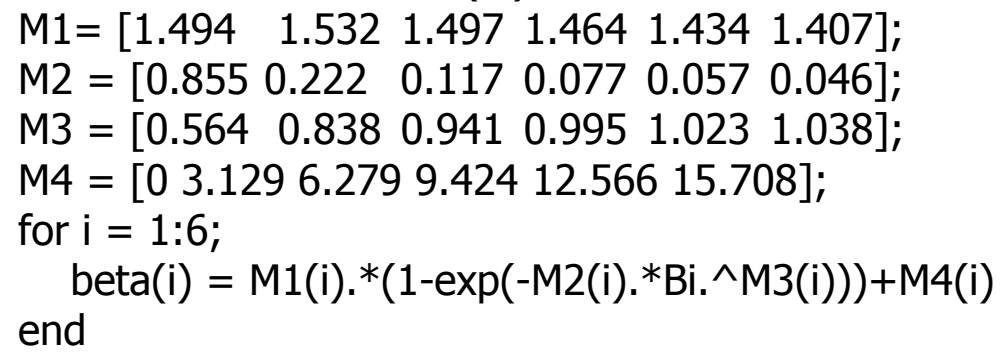

- Programa para calcular el h óptimo para el vapor generado

clear all, clc

texp =0:30:600;

ntexp = length(texp);

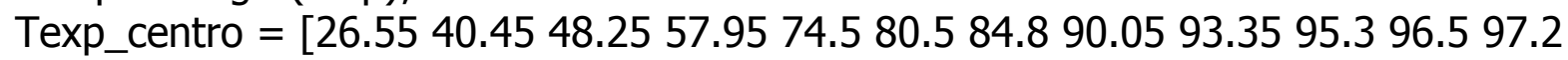

$97.7597 .998 .1598 .9599 .599 .4599 .5599 .5599 .55]$

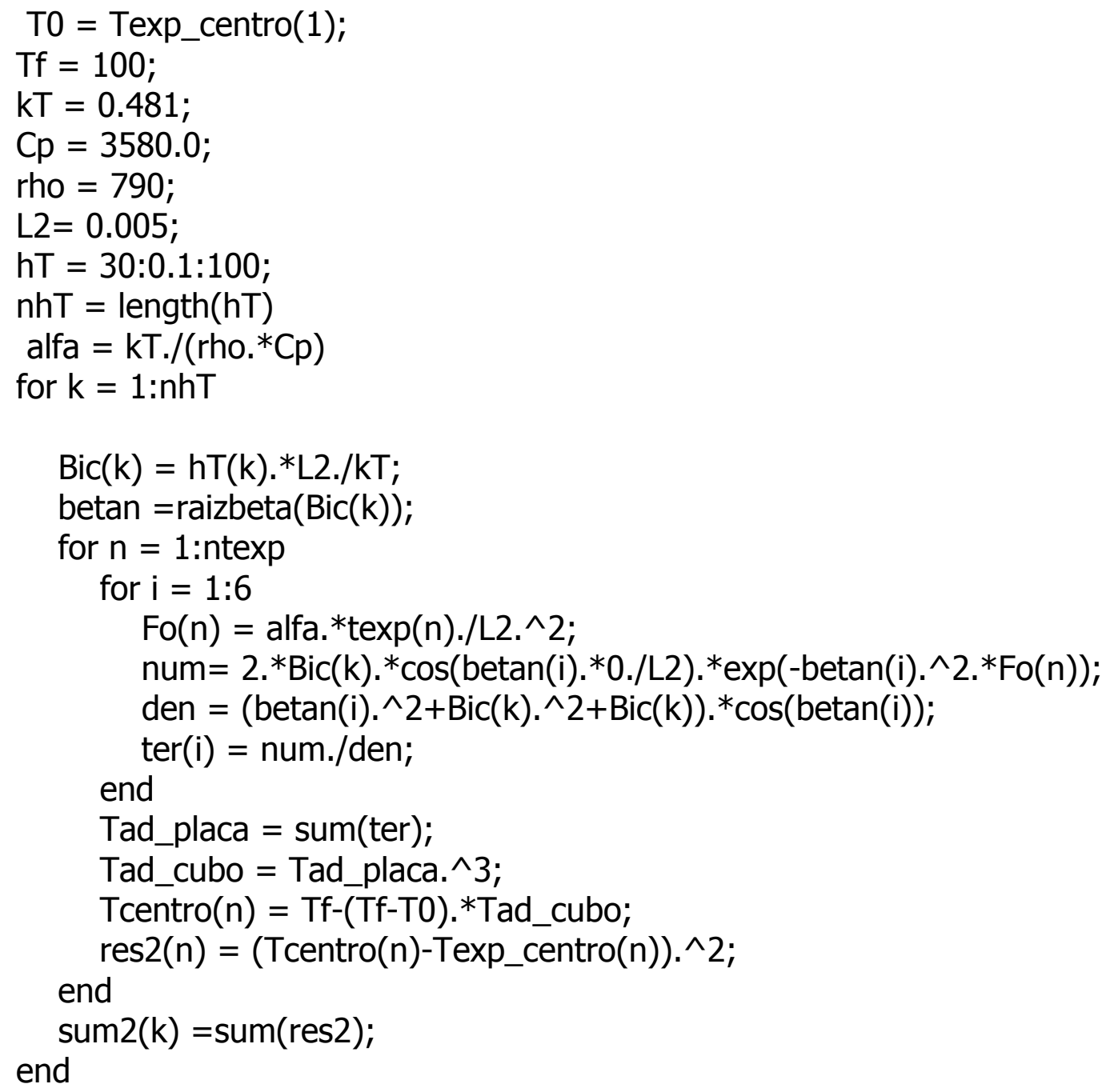


[sum2_min,pos]=min(sum2);

$\%$ hT_opt $=$ hT(pos)

$\%$ Biot_opt $=$ Bic(pos)

plot(hT, sum2,'LineWidth',2)

xlabel ('Coeficiente de transferencia de calor, $\mathrm{W} / \mathrm{m}^{\circ}{ }^{\circ} \mathrm{C}^{\prime}$ )

ylabel ('Suma de cuadrados de diferencia de temperatura')

Title ('Coeficiente de transferencia para escaldado a vapor')

$\mathrm{c}=$ polyfit(hT, sum2,6)

sum2_pred=polyval $(\mathrm{c}, \mathrm{hT})$;

[sum2_min, pos] =min(sum2_pred)

hT_opt $=$ hT(pos)

Bic_opt $=$ Bic(pos)

- Programa para calcular la temperatura en el centro de un cubo de manzana de un centímetro de lado con el h optimo y su comparación con los datos experimentales

clear all, clc

texp =0:30:600;

ntexp = length(texp);

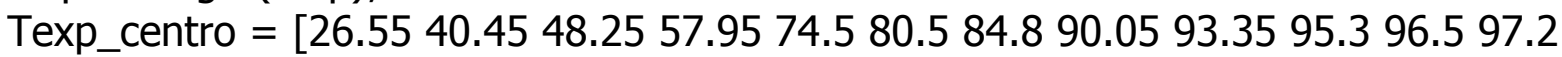

97.75 97.9 98.15 98.9599.5 99.45 99.55 99.55 99.55];

T0 = Texp_centro(1);

$\mathrm{Tf}=100$;

$\mathrm{kT}=0.481 ;$

$\mathrm{Cp}=3580.0$;

rho $=790 ;$

$\mathrm{L} 2=0.005$;

$\mathrm{hT}=58$;

alfa $=\mathrm{kT} . /($ rho. $* \mathrm{Cp})$

$\mathrm{Bic}=\mathrm{hT} . * \mathrm{~L} 2 . / \mathrm{kT}$;

betan =raizbeta(Bic);

for $\mathrm{n}=1$ :ntexp

for $i=1: 6$

$\mathrm{Fo}(\mathrm{n})=\mathrm{alfa} \cdot * \operatorname{texp}(\mathrm{n}) \cdot / \mathrm{L} 2 .^{\wedge} 2 ;$

num $=2 .{ }^{*}$ Bic. ${ }^{*} \cos \left(\right.$ betan $\left.(\mathrm{i}) \cdot{ }^{*} 0 . / \mathrm{L} 2\right) . * \exp \left(-\operatorname{betan}(\mathrm{i}) . \wedge 2 .{ }^{*} \mathrm{Fo}(\mathrm{n})\right)$;

den $=\left(\right.$ betan $(\mathrm{i}) \cdot{ }^{\wedge} 2+$ Bic. ${ }^{\wedge} 2+$ Bic $) \cdot{ }^{*} \cos (\operatorname{betan}(\mathrm{i}))$;

$\operatorname{ter}(\mathrm{i})=$ num./den;

end

Tad_placa = sum(ter);

Tad_cubo $=$ Tad_placa.^3;

Tcentro(n) $=$ Tf- $(\mathrm{Tf}-\mathrm{TO}){ }^{*}{ }^{*}$ Tad_cubo;

end

plot(texp, Tcentro,'b', texp, Texp_centro,'or','MarkerFaceColor','r','lineWidth',2)

xlabel ('Tiempo, s','Fontsize',14)

ylabel ('Temperatura, ${ }^{\circ} \mathrm{C}$ ')

title ('Escaldado cubo manzana de $1 \mathrm{~cm}$ ')

legend ('Predicho', 'Experimental') 
- Programa para calcular la curva de secado para el laminado con los modelos de altos y bajos contenidos de humedad y su comparación con los datos experimentales

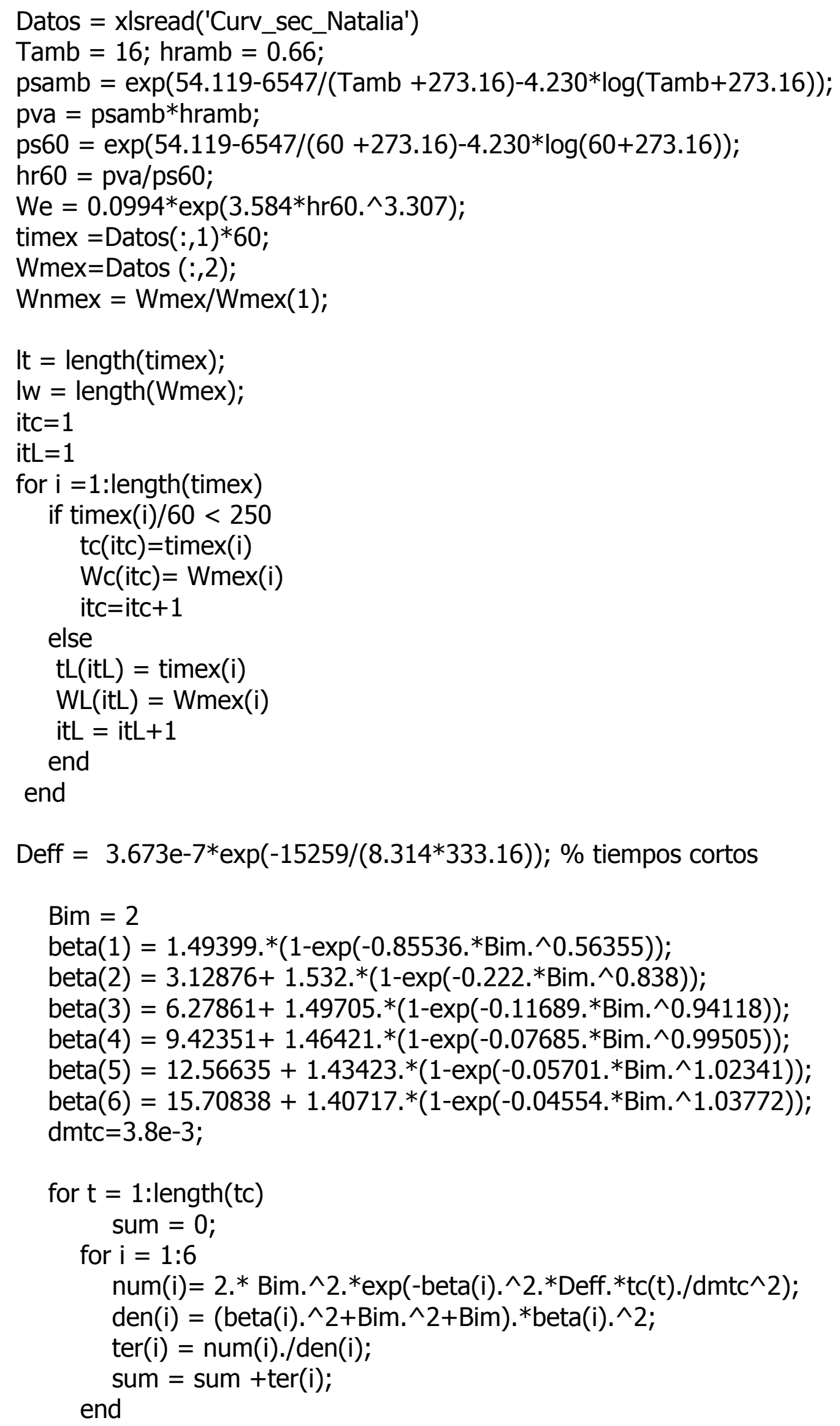


wad $(\mathrm{t})=$ sum;

Wnctc $(\mathrm{t})=(\mathrm{Wmex}(1)-\mathrm{We}) * \operatorname{wad}(\mathrm{t}) / \mathrm{Wmex}(1)+\mathrm{We} / \mathrm{Wmex}(1)$

$\operatorname{Wmctc}(\mathrm{t})=(\operatorname{Wmex}(1)-\mathrm{We}) * \operatorname{wad}(\mathrm{t})+\mathrm{We}$;

end

$\mathrm{dmtL}=1.8 \mathrm{e}-3$;

Deff $=6.970 \mathrm{e}-8 * \exp (-16800 /(8.314 * 333.16)) ; \%$ tiempos largos

for $\mathrm{t}=1$ :length $(\mathrm{tL})$

wad $(\mathrm{t})=8 /$ pi.^2*exp(-pi.^2/4*Deff*tL(t)/dmtL.^2);

WmctL $(\mathrm{t})=(\mathrm{Wmex}(1)-\mathrm{We}) * \operatorname{wad}(\mathrm{t})+\mathrm{We}$;

$\mathrm{WnctL}(\mathrm{t})=(\mathrm{Wmex}(1)-\mathrm{We}) * \operatorname{wad}(\mathrm{t}) / \mathrm{Wmex}(1)+\mathrm{We} / \mathrm{Wmex}(1)$

end

$\mathrm{tw}=0: 10: 7200$;

$\mathrm{mwn}=1-1.1215 \mathrm{e}-4 . * \mathrm{tw}$;

plot ( timex/60, Wmex,'o', tc/60, Wmctc,'--',tL/60,WmctL, 'Linewidth', 2)

xlabel('tiempo, min', 'Fontsize', 14)

ylabel('Humedad, kg agua/kg ms', 'Fontsize', 14)

legend ('Datos experimentales', 'Modelo tiempos cortos', 'Modelo tiempos largos')

figure (2)

plot ( timex/60, Wnmex,'o', tw/60, mwn, 'Linewidth', 2)

Legend ('Datos Laminado de manzana', 'Evaporación agua pura', 'Fontsize', 14)

xlabel('tiempo, min', 'Fontsize', 14)

ylabel('kg agua/kg agua inicial', 'Fontsize', 14) 


\section{ANEXO 3}

\section{ÁCIDO CÍTRICO}

Preparado en la reunión 53 de la JECFA (1999), publicado en FNP 52 Add. 7 (1999), reemplazando las especificaciones preparadas en la reunión 51 de JECFA (1998) publicada en FNP 52 Add. 6 (1998).

Grupo IDA no limitado para ácido citrico y sus sales de calcio, potasio, sodio y amonio, establecido en la reunión 17 de JECFA en 1973

SINONIMOS

DEFINICIÓN

Nombres químicos

Número C.A.S.

Formula química

Peso molecular

Ensayo

DESCRIPCIÓN

USOS FUNCIONALES

CARACTERÍSTICAS

IDENTIFICACIÓN

Solubilidad (Vol.4)
INS No. 330

El ácido cítrico puede ser producido o recuperado de fuentes como el limón, el jugo de piña o la fermentación de soluciones de carbohidratos u otro medio utilizando Candida spp o una cepa no toxica de Aspergillus niger.

acido 2-hidroxi-1,2,3-propanotricarboxilico

77-92-9 (anhídrido)

5949-29-1 (monohidratado)

$\mathrm{C}_{6} \mathrm{H}_{8} \mathrm{O}_{7}$ (anhídrido)

$\mathrm{C}_{6} \mathrm{H}_{8} \mathrm{O}_{7}-\mathrm{H}_{2} \mathrm{O}$ (monohidratado)

192.13 (anhídrido)

210.14 (monohidratado)

no menos de $99.5 \%$ y no mas de $100.5 \%$ en base seca.

Sólido cristalino incoloro o blanco, sin olor.

Acidulante, secuestrante, antioxidante, agente saborizador. 
Test para citrato (Vol. 4) Pasa el test

PUREZA

Agua (Vol. 4) anhídrido: no mas de $0.5 \%$ (método Karl Fischer)

Monohidratado: no menos de $7.5 \%$ y no mas de $8.8 \%$ (método Karl Fischer)

Ceniza Sulfatada (Vol. 4) No mas de 0.05\%

Oxalato (Vol. 4)

No mas de $100 \mathrm{mg} / \mathrm{kg}$

Probar $1.0 \mathrm{~g}$ de la muestra por el test de limite de oxalato. Medir la absorbancia a $520 \mathrm{~nm}$ en una celda de $10 \mathrm{~mm}$. La solución debe tener menos de 0,023 unidades de absorbancia.

Sulfatos (Vol. 4)

No mas de $150 \mathrm{mg} / \mathrm{kg}$

Probar $20 \mathrm{~g}$ de la muestra por el test de limite de sulfatos usando $6,0 \mathrm{ml}$ de ácido sulfúrico $0,01 \mathrm{~N}$ en el patrón

Sustancias carbonizables

Calentar $1,0 \mathrm{~g}$ de muestra con $10 \mathrm{ml}$ de acido sulfúrico $98 \%$ en un baño de agua a $90 \pm 1^{\circ} \mathrm{C}$ por 60 min. Ningún color mas oscuro que el MatchingFluid $K\left(25^{\circ} \mathrm{C}\right)$ debe producirse. (No más de 0,5 unidades de absorbancia a $470 \mathrm{~nm}$ en una celda de $10 \mathrm{~mm}$ )

Plomo (Vol. 4)

No mas de $0.5 \mathrm{mg} / \mathrm{kg}$

Determinar utilizando una técnica de absorción atómica apropiada para determinar el nivel la selección del tamaño de la muestra y su método de preparación debe estar basado en los principios del método descrito en el libro "instrumental Methods" Volumen 4.

\section{METODOS DE ENSAYO}

Pesar lo más aproximado a $2,5 \mathrm{~g}$ de muestra y colocarlo en un matraz, disolver en $40 \mathrm{ml}$ de agua y titular con hidróxido de sodio $1 \mathrm{~N}$, usando fenolftaleína como indicador.

Cada $\mathrm{ml}$ de hidróxido de sodio es equivalente a $64,04 \mathrm{mg}$ de $\mathrm{C}_{6} \mathrm{H}_{8} \mathrm{O}_{7}$. 
Preparado en la reunión 53 de la JECFA (1999) y publicada en el FNP 52 Add. 7 (1999), reemplazando las especificaciones preparadas en la reunión 51 de la JECFA (1998) publicada en FNP 52 Add. 6 (1998).

Grupo IDA 0- 0,7 mg/kg de peso corporal. Como $\mathrm{SO}_{2}$ para sulfito establecido en la reunión 51 de JECFA de 1998

SINÓNIMOS INS No. 224

\section{DEFINICIÓN}

Nombres Químicos: $\quad$ Disulfito de potasio

Número C.A.S.: $\quad$ 16731-55-8

Fórmula química: $\quad \mathrm{K} 2 \mathrm{~S} 2 \mathrm{O} 5$

Peso molecular: $\quad 222.33$

DESCRIPCIÓN Cristales, polvo cristalino o gránulos, usualmente con olor a dióxido de azufre.

USOS FUNCIONALES Agente anti-pardeante, antioxidante, conservante.

\section{CARACTERÍSTICAS}

IDENTIFICACIÓN

Solubilidad (Vol. 4) Soluble en agua, insoluble en etanol.

Test de potasio (Vol. 4) Pasa el test

Test para sulfitos (Vol. 4) Pasa el test

PUREZA

Insolubles en agua

Disolver $20 \mathrm{~g}$ de la muestra en $200 \mathrm{ml}$ de agua, la solución debe ser clara con solo un poco de materia suspendida. 
Tiosulfato

Hierro (Vol. 4)

Plomo (Vol. 4)

Selenio

TESTS

TEST DE PUREZA

Selenio
No mas de $0,1 \%$

Un $10 \%$ de la muestra en solución de permanecer clara al ser acidificada con acido sulfúrico o acido hidroclorhídrico.

No más de $10 \mathrm{mg} / \mathrm{kg}$

Determinar como se indica en el Test utilizando $0,5 \mathrm{ml}$ de solución patrón de hierro $(5 \mu \mathrm{ge})$ en el control

No más de $2 \mathrm{mg} / \mathrm{kg}$

Determinar utilizando una técnica de absorción atómica apropiada para determinar el nivel la selección del tamaño de la muestra y su método de preparación debe estar basado en los principios del método descrito en el libro "instrumental Methods" Volumen 4.

No más de $5 \mathrm{mg} / \mathrm{kg}$

Ver la descripción en la sección TESTS

Reactivos: Acido hidroclorhídrico, sulfato de hidracina, solución patrón de selenio $(100 \mu \mathrm{g} \mathrm{se} / \mathrm{ml})$

Procedimiento: Pesar 2,0 $\pm 0,1 \mathrm{~g}$ de muestra y transferirla a un vaso de precipitado de $50 \mathrm{ml}$, adicionar $10 \mathrm{ml}$ de agua, $5 \mathrm{ml}$ de acido hidroclorhídrico y hervir para remover el $\mathrm{SO}_{2}$, en un segundo vaso de precipitado, pesar $1,0 \pm 0,1 \mathrm{~g}$ de muestra y adicionar 0,05 $\mathrm{ml}$ de solución patrón de selenio y proceder de igual forma que con el vaso anterior.

A cada vaso adicionar $2 \mathrm{~g}$ de sulfato de hidracina y calentar para disolver, deje actuar por 5 minutos, diluya el contenido de cada vaso hasta $50 \mathrm{ml}$ dentro de un tubo de Nessler y compare el color 
de las dos soluciones. La muestra debe ser menos rosada que aquella que tiene el patrón.

\section{MÉTODO DE ENSAYO}

Pesar $250 \mathrm{mg}$ de muestra, adicionar $50,0 \mathrm{ml}$ de iodo $0,1 \mathrm{~N}$ en un matraz con tapa. Deje reaccionar $5 \mathrm{~min}$. y añada $1 \mathrm{ml}$ de acido hidroclorhídrico diluido y titule el exceso de iodo con tiosulfato de sodio $0,1 \mathrm{~N}$ utilizando almidón como indicador.

Cada $\mathrm{ml}$ de iodo $0,1 \mathrm{~N}$ es equivalente a $5,558 \mathrm{mg}$ de $\mathrm{K}_{2} \mathrm{~S}_{2} \mathrm{O}_{5}$. 


\section{SORBATO DE POTASIO}

Preparado en la reunión 51 de la JECFA (1998), publicado en FNP 52 Add. 6 (1998), reemplazando las especificaciones preparadas en la reunión 17 de JECFA (1973) publicada en FNP 4 (1978) y republicado en FNP 52 (1992).

Grupo IDA 0-25 mg/kg pc para ácido sórbico y sus sales de calcio, potasio y sodio expresadas con ácido sórbico, establecido en la reunión 17 de JECFA en 1973

SINÓNIMOS INS No. 202

\section{DEFINICIÓN}

Nombres químicos $\quad$ Sorbato de potasio, sal de potasio del acido trans, trans-2,4hexadienico

Numero C.A.S. $\quad 24634-61-5$

Formula química $\quad \mathrm{C}_{6} \mathrm{H}_{7} \mathrm{KO}_{2}$

Peso molecular $\quad 150.22$

Ensayos

no menos de $98 \%$ y no mas de $102 \%$ en base seca

DESCRIPCIÓN Cristales blancos u amarillos claros o polvo cristalino o gránulos

USOS FUNCIONALES Conservador

\section{CARACTERÍSTICAS}

IDENTIFICACIÓN

Solubilidad (Vol. 4) Soluble libremente en agua, soluble en etanol

Test de potasio (Vol.4) pasa el test

Test de instauración $\quad$ A $2 \mathrm{ml}$ de una solución 1 en 10 de la muestra. Adicionar unas gotas de bromina. El color de la bromina debe desaparecer.

Punto de fusión del ácido sórbico derivado de la muestra $132-135^{\circ} \mathrm{C}$

Acidificar una solución de la muestra con ácido hidroclorhídrico diluido. Recolectar el acido sórbico precipitado en papel de filtro, lavar con agua y secar bajo vacío sobre acido sulfúrico. 


\section{PUREZA}

Perdida en el secado (Vol.4) No mas de $1 \%\left(105^{\circ} \mathrm{C}, 3 \mathrm{~h}\right)$

Acidez o alcalinidad

No más de $1 \%$ (como ácido sórbico o carbonato de potasio).

Disolver $1,1 \mathrm{~g}$ de la muestra en $20 \mathrm{ml}$ de agua, añadir 3 gotas de fenolftaleína si la solución es incolora, titular con hidróxido de sodio $0,1 \mathrm{~N}$ hasta alcanzar un color rosado durante $15 \mathrm{seg}$. No más de 1,1 $\mathrm{ml}$ deben ser necesarios. si la solución es rosa titular con acido hidroclorhídrico $0,1 \mathrm{~N}$, no mas de $0,8 \mathrm{ml}$ de acido serán necesarios para eliminar el color.

Aldehídos

No más de $0,1 \%$ como formaldehído

Preparar una solución al $0,3 \%$ de la muestra, ajustar el pH a 4 con $\mathrm{HCl} 1 \mathrm{~N}$ y filtrar. a $5 \mathrm{ml}$ del filtrado adicionar $2,5 \mathrm{ml}$ del reactivo de Schiff y dejar reaccionar 10.15 min. Comparar el color con el producido por $5 \mathrm{ml}$ de una solución de control conteniendo $15 \mu \mathrm{g}$ de formaldehído en lugar de la muestra. El color de la solución a evaluar no debe ser mas intenso que el de la solución control.

Plomo (Vol.4)

No mas de $2 \mathrm{mg} / \mathrm{kg}$

Determinar utilizando una técnica de absorción atómica apropiada para determinar el nivel la selección del tamaño de la muestra y su método de preparación debe estar basado en los principios del método descrito en el libro "instrumental Methods" Volumen 4.

\section{MÉTODOS DE ENSAYO}

Pesar lo más exactamente $0,25 \mathrm{~g}$ de muestra, previamente secada a $105^{\circ} \mathrm{C}$ durante 3 horas, disolver en $36 \mathrm{ml}$ de ácido acético glacial y $4 \mathrm{ml}$ de anhídrido acético en un matraz con tapón de $250 \mathrm{ml}$, calentar para realizar la solución.

Enfriar a temperatura ambiente y adicionar 2 gotas de cristal violeta y titular con acido perclórico en acido acético glacial $0,1 \mathrm{~N}$ hasta un color verde azul que persista durante 30 seg. Realizar una determinación blanco y realizar cualquier corrección.

Cada $\mathrm{ml}$ de acido perclórico $0,1 \mathrm{~N}$ es equivalente a $15,02 \mathrm{mg}$ de $\mathrm{C}_{6} \mathrm{H}_{7} \mathrm{KO}_{2}$. 


\section{ANEXO 4}

Características del Agar YGC. (En ingles Yeast extrac, Glucose, Chloramphenicol) (Merck, 2000)

Agar genérico selectivo para aislar y cuantificar los hongos y levaduras, que cumple con las normas de la organización internacional de estandarización (ISO)

Modo de acción

El medio de cultivo contiene cloranfenicol para inhibir la flora bacteriana acompañante. A diferencia de otros medios de cultivo similares como el YGO (oxitetraciclina, glucosa y levadura) puede ponerse en la autoclave. Una vez preparado es estable hasta 4 meses.

Com posición ( $g /$ litro)

Extracto de levadura 5,0

$\mathrm{D}(+)$ glucosa $\quad 20,0$

cloramfenicol $\quad 0,1$

agar-agar $\quad 14,9$.

Preparación

Disolver $40 \mathrm{~g} /$ litro y autoclavar durante $15 \mathrm{~min}$. a $121^{\circ} \mathrm{C}$.

$\mathrm{pH}: 6.6 \pm 0.2$ a $25^{\circ} \mathrm{C}$.

Las cajas son amarillentas y traslucidas.

\section{Aplicación y evaluación}

El medio es inoculado usualmente usando el método de inmersión y es incubado por 5 días a $25^{\circ} \mathrm{C}$ en medio aeróbico. 
Controlde calidad

\begin{tabular}{|l|c|}
\hline \multicolumn{1}{|c|}{ Cepas de ensayo } & Crecimiento \\
\hline Geotrichum candidum DSM 1240 & Bueno /muy bueno \\
\hline Penicillium spp. & Bueno /muy bueno \\
\hline Aspergillus niger & Bueno /muy bueno \\
\hline
\end{tabular}

Controlde calidad (siem bra en plato en espiral)

\begin{tabular}{|l|c|c|}
\hline Cepas de ensayo & Inoculo (UFC/ml) & Tasa de recuperación\% \\
\hline Candida albicans ATCC 10231 & $103-105$ & $\geq 70$ \\
\hline Saccharomyces cerevisiae ATCC 9763 & $103-105$ & $\geq 70$ \\
\hline Saccharomyces cerevisiae ATCC 9080 & $103-105$ & $\geq 70$ \\
\hline Escherichia coli ATCC 25922 & $>105$ & $\leq 0,01$ \\
\hline Bacillus cereus ATCC 11778 & $>105$ & $\leq 0,01$ \\
\hline Staphylococcus aureus ATCC 25923 & $>105$ & $\leq 0,01$ \\
\hline
\end{tabular}

